\section{JOHN C. ROBERTS}

SECRETARY
COMMONWEALTH OF KENTUCKY

DEPARTMENT OF TRANSPORTATION

BUREAU OF HIGHWAYS

JOHN C. ROBERTS

COMMISSIONER

Division of Research

533 South Limestone

Lexington, $\mathrm{KY} 40508$
JULIAN M. CARROLL

GOVERNOR

H.2.74

May 31, 1976

MEMORANDUM TO: G. F. Kemper

State Highway Engineer

Chairman, Research Committee

SUBJECT:

Research Report No. 448; "Constant-Rate-of-Strain and Controlled-Gradient Consolidation Testing;" HPR.PL1(11), Part II; KYHPR-75-74.

One of the factors deterring more extensive analyses of settlement and consolidation rates in the design of embankments and foundations has been the long, consuming time usually needed to perform consolidation tests. It is now possible to complete a test in less than 48 hours. The enabling, basic theory and some of the equipment were developed by others. The report submitted herewith presents an evaluation of two, newer methods with respect to or in comparison with the more conventional, standard method. Apparatus for the controlled-rate-of-strain test needs to be refined, and automatic processing of analog outputs is being developed. Although these features would be desirable now, the CRS test could be adopted and used effectively in the meantime.

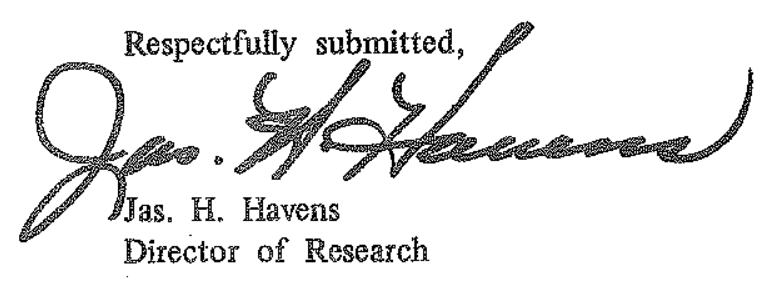

JHH:gd

Enc.

cc's: Research Committee

Soils Section, Division of Materials 
Technical Keport Documentation Page

\begin{tabular}{|c|c|c|}
\hline I. Report No. & 2. Government Accession No. & 3. Recipient's Catalog No. \\
\hline \multirow{2}{*}{\multicolumn{2}{|c|}{$\begin{array}{l}\text { 4. Title and Subtitle } \\
\text { Constant-Rate-of-Strain and Controlled-Gradient Consolidation Testing }\end{array}$}} & $\begin{array}{l}\text { 5. Report Date } \\
\text { May } 1976\end{array}$ \\
\hline & & 6. Performing Organization Code \\
\hline \multirow{2}{*}{\multicolumn{2}{|c|}{$\begin{array}{l}\text { 9. Performing Organization Name and Address } \\
\text { Division of Research } \\
\text { Kentucky Bureau of Highways } \\
533 \text { South Limestone Street } \\
\text { Lexington, Kentucky } 40508\end{array}$}} & 10. Work Unit No. (TRAIS) \\
\hline & & $\begin{array}{l}\text { 11. Contract or Grant No. } \\
\text { KYHPR-75.74 }\end{array}$ \\
\hline \multicolumn{2}{|l|}{ 12. Sponsoring Agency Name and Address } & 14. Sponsoring Agency Code \\
\hline
\end{tabular}

15. Supplementary Notes

Prepared in cooperation with the US Department of Transportation, Federal Highway Administration

Study Title: Controlled Rate of Strain and Controlled Gradient Consolidation Testing

16. Abstraet

Controlled-gradient (CG), constant-rate-of-strain (CRS), and conventional incremental-loading (STD) consolidation testing are compared and evaluated. Undisturbed samples representing three soils common to Kentucky were used in the testing program. Settlements estimated by each testing technique were compared with settlement records from one of the sites. Results of $15 \mathrm{CG}, 14$ CRS, and 32 STD consolidation tests are shown. No significant differences were noted in values obtained from the three types of consolidation tests. Feasibility of the new test methods for routine testing is briefly discussed and recommendations were made for refinements in testing procedures.

\begin{tabular}{|l|l|l|l|l|}
\hline $\begin{array}{l}\text { 17. Key Words } \\
\text { Consolidation }\end{array}$ & \multicolumn{1}{|c|}{ 18. Distribution Statement } \\
Laboratory Tests & \multicolumn{1}{|c|}{$\begin{array}{l}\text { Constant-Rate-of-Strain } \\
\text { Controlled-Gradient }\end{array}$} \\
$\begin{array}{l}\text { Strain Rate } \\
\text { Settlement Records }\end{array}$ & 20. Security Classif. (of this poge) & 21. No. of Pages & 22. Price \\
\hline 19. Security Classif. (of this report) & & & \\
\end{tabular}


Research Report

\title{
CONSTANT-RATE-OF-STRAIN AND CONTROLLED-GRADIENT CONSOLIDATION TESTING
}

\author{
Interim Report \\ by \\ C. Thomas Gorman \\ Research Engineer
}

KYHPR-75-74; HPR-PL-1(11), Part II

\author{
Division of Research \\ Bureau of Highways \\ DEPARTMENT OF TRANSPORTATION \\ Commonwealth of Kentucky
}

in cooperation with

Federal Highway Administration

U. S. DEPARTMENT OF TRANSPORTATION

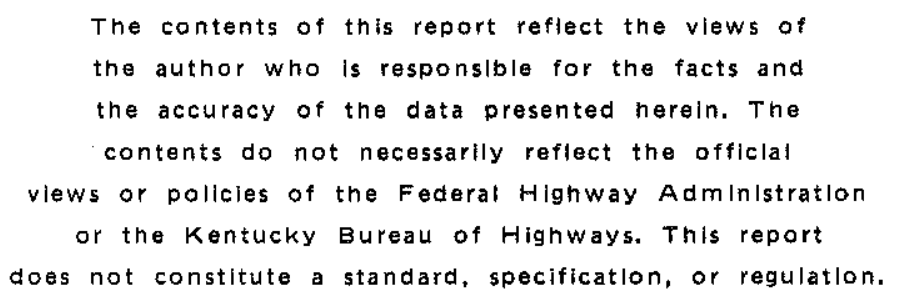

May 1976 


\section{INTRODUCTION}

Proper foundation design for engineered structures requires a fairly accurate estimate of the magnitude and rate of settlement of the foundation soil. Buildings and bridges must be designed to withstand differential and total settlement. Highway embankments must be designed to eliminate settlements which can produce an uneven roadway surface and pavement distress. Design information needed to estimate magnitude and rate of settlement is obtained by laboratory testing of soil samples taken at the proposed site. For the past 40 years, samples have been subjected to increasingly large increments of load, and the resulting measured deformations have been used to estimate settlements. This test requires approximately 2 weeks to complete and yields information which requires a good deal of interpretation. Refinements eventually led to the development of controlled-gradient (CG) and constant-rate of-strain (CRS) tests.

Soil is not a homogeneous material having easily defined engineering properties. Different methods of testing may yield different values of soil properties. The objectives of this research are (1) to compare test data obtained from CG and CRS tests with that obtained from conventional incremental-loading (STD) tests, (2) to compare CG and CRS test results with field measurements, and (3) to determine the feasibility of using CG and(or) CRS testing in routine investigations.

Undisturbed (Shelby tube) soil samples were taken from three sites. CG, CRS, and STD tests were performed; the data formed the basis for the comparisons among the test methods. Settlements were monitored at one of the sites where a highway embankment had been constructed; comparisons of predicted and observed settlements were used to determine how well each test would have predicted settlement. Finally, economic factors such as equipment cost and time to complete the tests were considered. 


\section{BACKGROUND}

The CRS test was introduced in 1959 by Hamilton and Crawford (1) as a rapid means of determining the preconsolidation pressure, $\mathrm{P}_{\mathrm{c}}$. In the $\mathrm{CRS}$ test, boundary conditions imposed on the soil were much the same as in the STD test with one-way drainage. The specimen was confined laterally by the same type of ring used in the conventional test apparatus (oedometer), and drainage of pore water was permitted at the top only. In the CRS test, however, the specimen was loaded at a constant rate of strain instead of incrementally. The strain rate was chosen such that "significant" pore pressures did not develop in the specimen; thus, effective stress was assumed equal to the applied stress. Continuous stress-strain pairs provided a well defined, stress-strain curve; this is not possible in the STD test. Higher strain rates gave higher "indicated" preconsolidation pressures. However, the two lowest strain rates gave the same value of $\mathrm{P}_{\mathrm{c}}$; it was concluded that the CRS test showed promise as a rapid means of determining $\mathrm{P}_{\mathrm{c}}$.

One of the problems Hamilton and Crawford pointed out in the STD test was that gas bubbles in test specimens accounted for most of the initial compression observed at loads below $\mathrm{P}_{\mathrm{C}}$. Lowe et al. (2) agreed with their findings and proposed a solution in 1964 involving the use of back pressure to saturate specimens. A constant pressure was applied to the pore water at both the top and bottom of the specimen; this produced a constant water pressure within the specimen. Lowe et al. stated that sampling caused a relaxation of stress and emergence of gas bubbles from solution. Since the permeability of a soil is less when gas bubbles are present, the rate of consolidation and determination of the coefficient of consolidation, $\mathrm{C}_{\mathrm{V}}$, is affected. Results of STD tests with and without back pressure indicated that back pressure has little effect on the compressibility of the soil but does affect the rate of consolidation.

Crawford (3) later showed the difference in stress-strain curves, and hence $\mathrm{P}_{\mathrm{c}}$, produced by various methods of STD consolidation testing. The three stress-strain curves in Figure 1 yield three different values of $\mathrm{P}_{\mathrm{c}}$; these values depend on the duration of the load increment. CRS tests were also performed on the same soil, using the same procedure as in 1959. The pore pressure generated at the base of the specimen was measured and subtracted from the total applied stress. The difference in stress-strain curves obtained in this manner and the total stress-strain curves was negligible if pore pressures were not allowed to exceed 5 percent of the total applied stress. Crawford concluded that $P_{c}$ was a function of loading procedure and recommended that "... the laboratory consolidation test be conducted at a steady rate of comprcssion, sufficiently slow to prevent the development of significant pore pressures."

The CRS test, at this point, had two significant drawbacks. Theory had not been developed to take excess pore pressure into account or to determine $\mathrm{C}_{\mathrm{v}}$. This theory was developed and published in 1969 by Smith and Wahls (4) and independently by Wissa et al. (5) in 1971. Both works extended Terzaghi's theory to the boundary conditions imposed by the CRS test. Smith and Wahls assumed that 


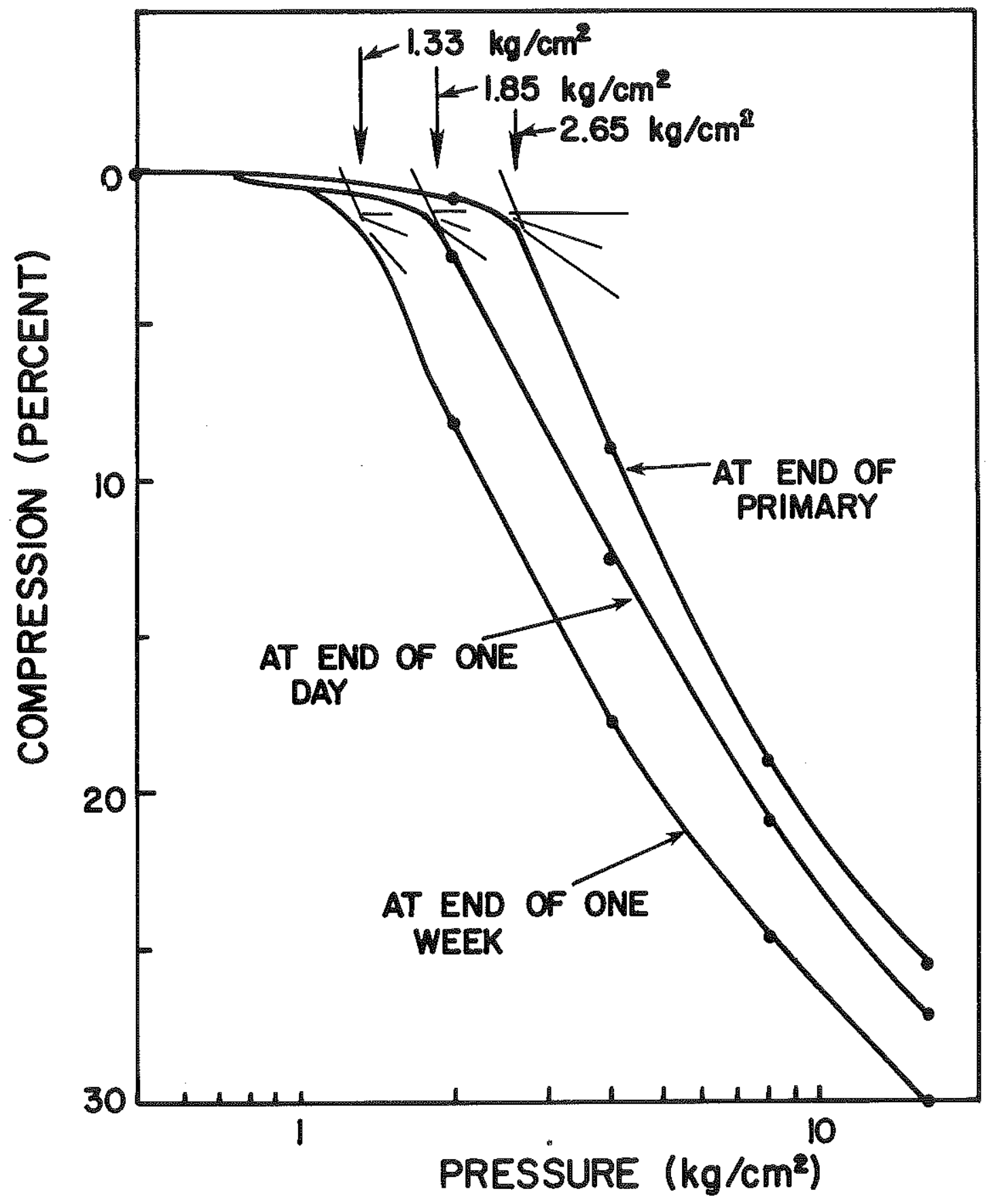

Figure 1. STD Consolidation Test Results (after Crawford). 
the coefficient of volume change, $\mathrm{m}_{\mathrm{v}}$, remained constant and that void ratio, and hence effective stress, was a linear function of vertical distance, $z$, from the drainage face and time, $t$. Using these assumptions, along with those made by Terzaghi, to solve the differential equation of consolidation yielded the following formulas for $\mathrm{C}_{\mathrm{V}}$ and average vertical effective stress, $\sigma_{\mathrm{V}}{ }^{\prime}$, in the specimen:

$$
\mathrm{C}_{\mathrm{v}}=\partial \sigma_{\mathrm{v}} / \partial \mathrm{t}\left[\mathrm{H}^{2}(1 / 2-\mathrm{b} / 12 \mathrm{r}) / \mathrm{u}_{\mathrm{b}}\right.
$$

where $\partial \sigma_{\mathrm{v}} / \partial \mathrm{t}=$ the partial derivative of applied stress with respect to time,

$\mathrm{H}=$ drainage path length in the specimen,

$\mathrm{u}_{\mathrm{b}} \quad=$ excess pore pressure measured at the base of the specimen,

b $=a$ constant relating void-ratio change with depth,

$\mathrm{r}=$ rate of change of average void ratio (the quantity $b / r$ is a dimensionless ratio and is termed the void-change ratio);

and $\quad \sigma_{\mathrm{v}}^{\prime}=\sigma_{\mathrm{v}}-a \mathrm{u}_{\mathrm{b}}$

where $a=a$ constant defined as the ratio of average pore pressure in the specimen, $u_{\text {avg' }}$ to $u_{b}$ and is dependent on the value of $b / r$.

It was also shown that for practical purposes $\mathrm{b} / \mathrm{r}$ could be assumed equal to zero and that $\partial \sigma_{\mathrm{v}} / \partial \mathrm{t}$ could be evaluated as stress increments, $\Delta \sigma_{\mathrm{v}}$. Over small time increments, $\Delta t$, Equations (1) and (2) can be simplified to

$$
\mathrm{C}_{\mathrm{v}} \quad=\mathrm{H}^{2} \Delta \sigma_{\mathrm{v}} / 2 \Delta \mathrm{t} \mathrm{u}_{\mathrm{b}}
$$

and

$$
\sigma_{\mathrm{v}}^{\prime}=\sigma_{\mathrm{v}} \cdot 2 \mathrm{u}_{\mathrm{b}} / 3
$$

CRS tests by Smith and Wahls using this theory showed excellent agreement with STD tests for remolded samples, as shown in Figure 2. Smith and Wahls recommended that excess pore pressures measured at the base of the specimen not be allowed to exceed 50 percent of the applied stress at any given time.

Wissa et al. arrived at the same equations for $\mathrm{C}_{\mathrm{v}}$ and $\sigma_{\mathrm{v}}{ }^{\prime}$ by assuming that strain was a. parabolic function of $z$. The theory was also extended to the case where $m_{v}$ was not assumed constant but was assumed to vary linearly with the logarithm of $\sigma_{\mathrm{v}}{ }^{\prime}$. Theory using this more reasonable assumption was compared to the simpler linear theory; and it was shown that, for $\mathrm{u}_{\mathrm{b}} / \sigma_{\mathrm{v}}$ less than about 5 percent, the linear and nonlinear theories yield approximately the same result. CRS and STD test results by Wissa et al. on remolded Boston blue clay are shown in Figure 3.

The CG consolidation test was introduced to more closely duplicate field conditions in the laboratory consolidation test. It was noted that, in STD consolidation tests, rates of compression were often several orders of magnitude greater than field rates and that nonuniform stress conditions existed in the specimen during loading. The CG test proposed by Lowe et al. (6) was similar to the CRS test except the specimen 
Figure 2. Comparison of STD and CRS Test Results, Remolded Samples (after Smith and Wahls (4)).

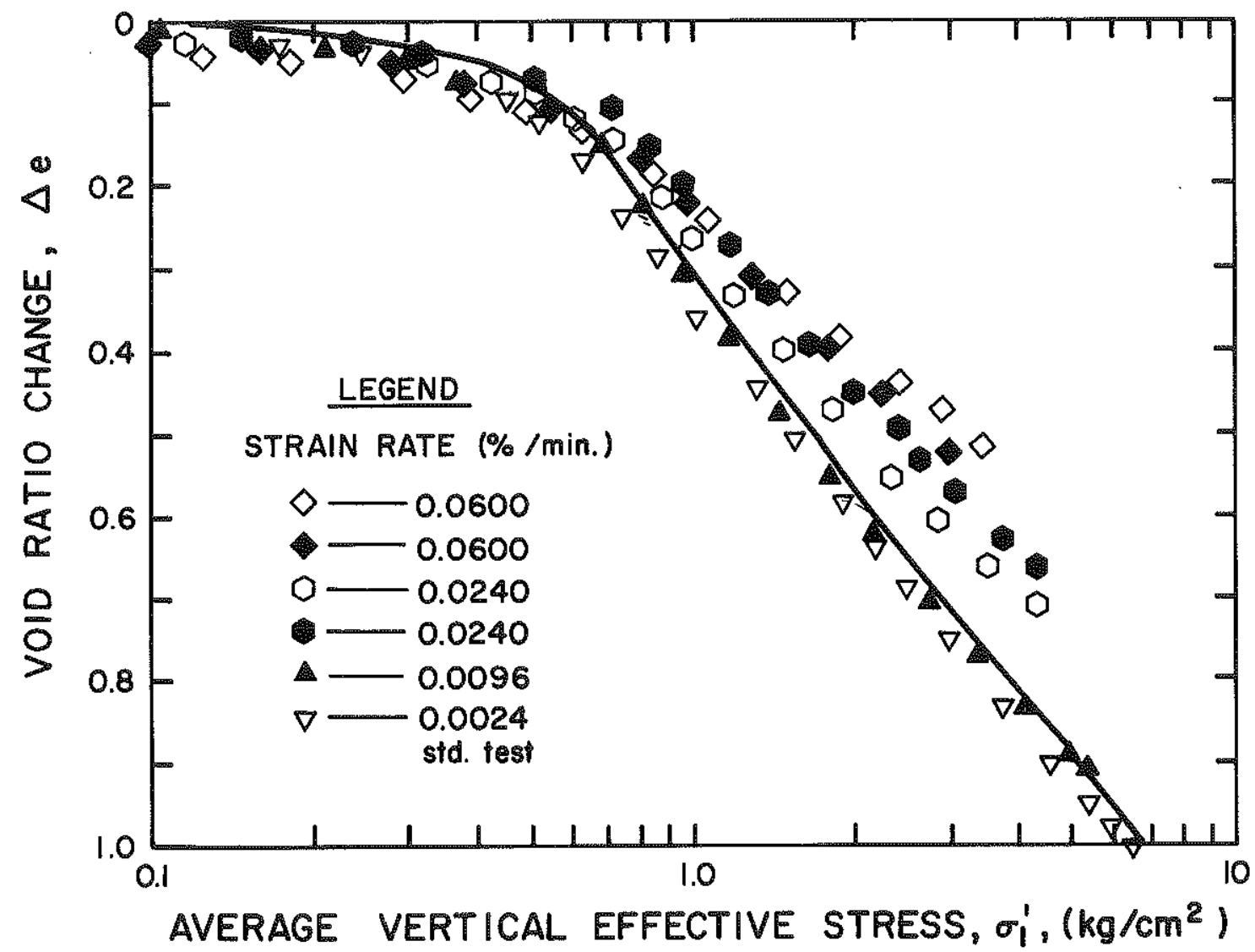


Figure 3. Comparison of STD and CRS Test Results, Remolded Samples (after Wissa et al. (5/).
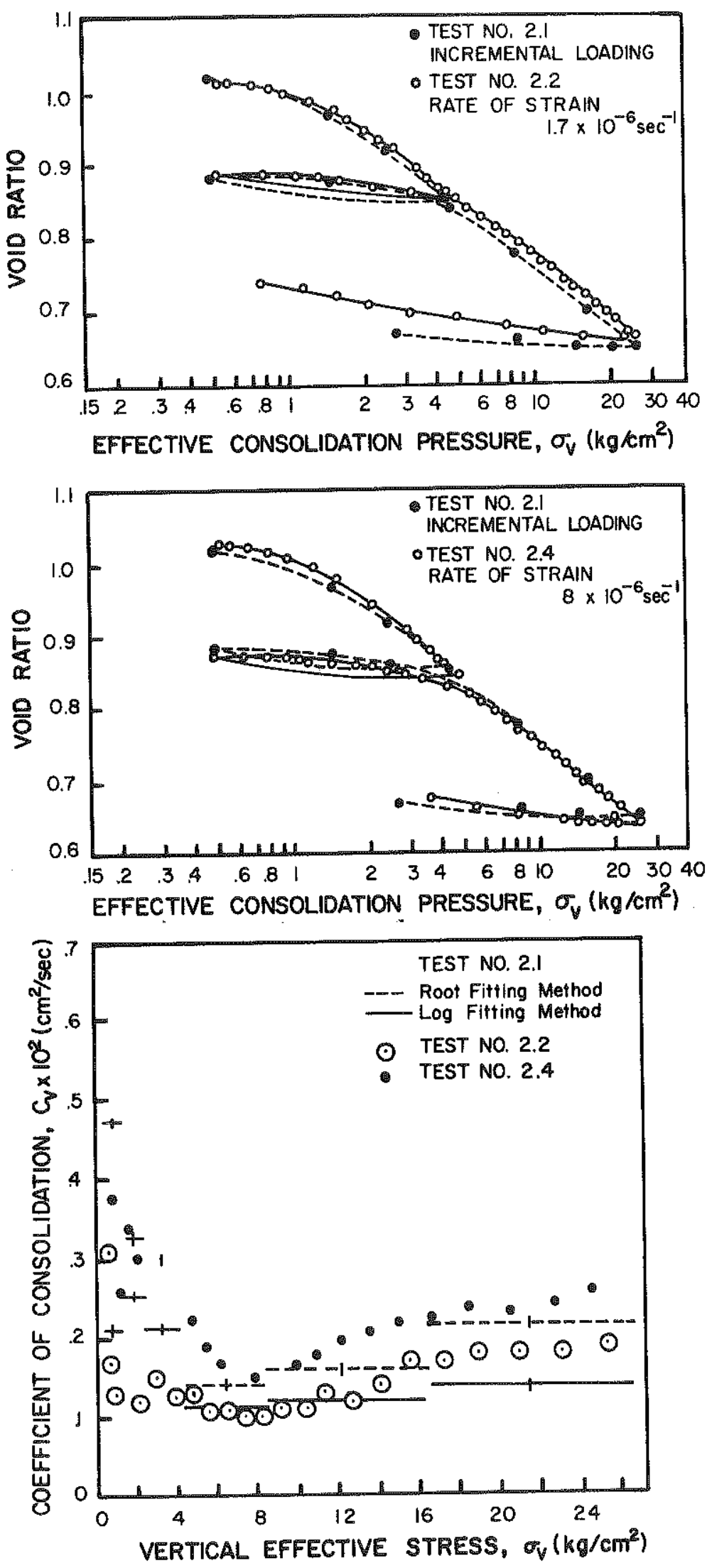
was loaded at a rate such that the excess pore pressure generated at the base (undrained end) of the specimen remained constant. Thus a constant hydrualic gradient was established across the consolidating specimen. Again, Terzaghi's theory was used to derive equations for $\mathrm{C}_{\mathrm{v}}$ and $\sigma_{\mathrm{v}}{ }^{\prime}$. An assumption of a parabolic distribution of pore pressure across the specimen yielded equations for $\mathrm{C}_{\mathrm{v}}$ and $\sigma_{\mathrm{v}}{ }^{\prime}$ identical to those derived for the CRS tests. Comparison of CG and STD tests by Lowe et al. are shown in Figure 4. Lowe et al. also proposed an alternate method of determining $P_{c}$ using $C G$ tests results. In this method, applied stress, $\sigma_{\mathrm{v}}$, is plotted versus time, $t$, and the point at which the slope of this curve decreases indicates $\mathbf{P}_{\mathrm{C}}$. As pore pressure tends to increase, the loading rate must decrease to keep the pore pressure constant. Thus, the point at which the loading rate decreases marks the vertical stress at which the pore pressure tends to increase, and this has been associated with $\mathbf{P}_{c}$ as follows.

Sallfors (7) proposed a mechanism for the increase in pore pressure at $P_{c}$ and showed CRS test results to confirm the phenomenon. The increase in pore pressure at $P_{c}$ was attributed to a breakdown in soil structure, induced by the maximum past stress, $P_{c}$, and the associated increase in compressibility. The breakdown in structure was shown by measuring lateral stresses generated in the CRS test and plotting the stress path followed by the specimen during the test. In these tests, a critical or maximum shear stress was reached at the same point that $P_{c}$ and an increase in pore pressure were noted. Critical shear stress was also found to decrease with decreasing rate of strain as the preconsolidation pressure decreased with decreasing rate of strain (7).

The CRS and CG tests offer several improvements in laboratory consolidation testing:

1. the rate of compression in these tests more nearly duplicates field conditions,

2. $\mathrm{C}_{\mathrm{V}}$ may be determined directly without the use of curve-fitting schemes necessary in the STD consolidation test,

3. the stress-strain curve is well defined, and

4. the tests can be easily auromated.

As a result, the CG and CRS tests are becoming more popular for routine laboratory investigations. This research evaluates the feasibility of CG and CRS testing for several soils commonly encountered in Kentucky. 
Figure 4. Comparison of STD and CG Test Results, Undisturbed Marine Clay (after Lowe et al. (6)).
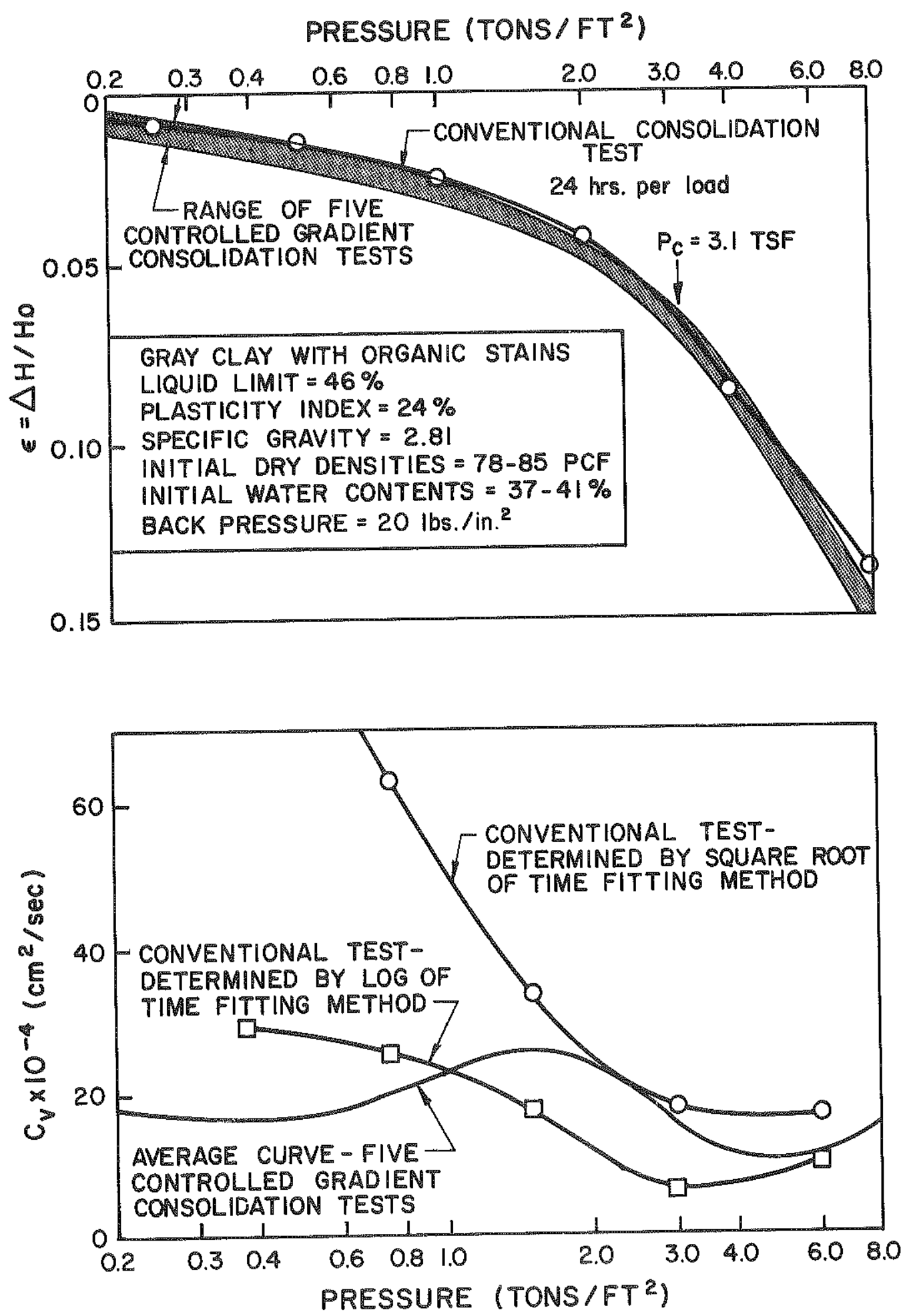


\section{CONSOLIDATION THEORY}

When a soil deposit of low permeability is subjected to an increased vertical stress, pore-water pressure within the soil will increase, and water will drain from the soil at a "drainage face", a region of high permeability. This drainage will continue until the excess water pressure created by the load has dissipated. This process is shown schematically in Figure 5. As a soil consolidates, water is squeezed out of the soil with a subsequent volume decrease. This is shown for a thin, horizontal soil layer of thickness $\mathrm{dz}$ in Figure 6.

Extrapolating this volume decrease and rate, as measured in the laboratory, to predictions of the magnitude and rate of field settlement is the object of consolidation testing and theory. Volume decrease is a function of the effective stress or intergranular stress within the soil mass. Change in volumetric strain is related to change in effective stress by $\mathrm{m}_{\mathrm{v}}$, which may be evaluated in the laboratory, and is expressed for one-dimensional consolidation as

$$
\text { where } \begin{aligned}
\mathrm{m}_{\mathrm{v}} & =\Delta \epsilon / \Delta \sigma_{\mathrm{v}}{ }^{\prime} \\
\Delta \epsilon & =\text { change in one-dimensional strain and } \\
\Delta \sigma_{\mathrm{v}}{ }^{\prime} & =\text { change in one-dimensional (vertical) effective stress. }
\end{aligned}
$$

Since pore pressure will dissipate more rapidly near the drainage face, it follows that, at any time during consolidation, the pore pressure will increase with increasing distance from the drainage face. Thus, the pore pressure difference on the faces of the thin, horizontal layer in Figure 6 may be expressed as a difference in pressure head,

$$
\mathrm{dh}=\mathrm{h}_{1}-\mathrm{h}_{2} \text {, }
$$

where $h_{1}>h_{2}$. The hydraulic gradient, $i$, across the consolidating layer may now be expressed as

$$
i \quad=. \partial \mathrm{h} / \partial \mathrm{z} \text {. }
$$

Since

$$
\mathrm{h} \quad=\quad \mathrm{u} / \gamma_{\mathrm{w}},
$$

where $u=$ pore-water pressure and $\gamma_{\mathrm{W}}=$ unit weight of water, Equation 7 may be rewritten as

$$
i=-\left(1 / \gamma_{\mathrm{W}}\right) \partial \mathrm{u} / \partial \mathrm{z} \text {. }
$$

Thus, water is forced from the consolidating layer under gradient $i$ at a velocity $\mathrm{v}$ in the $\mathrm{z}$ direction.

The rate of this volume decrease may be expressed by differentiating Equation 5 with respect to time, yielding

$$
\partial \epsilon / \partial \mathrm{t}=\mathrm{m}_{\mathrm{v}}\left(\partial \sigma_{\mathrm{v}}{ }^{\prime} / \partial \mathrm{t}\right)
$$

The effective-stress principle for soils may be written as

$$
\partial \sigma_{\mathrm{v}} / \partial \mathrm{t}=\partial \sigma_{\mathrm{v}} / \partial \mathrm{t} \cdot \partial \mathrm{u} / \partial \mathrm{t}
$$

where $\sigma_{\mathrm{v}}=$ total applied vertical stress. Substituting Equation 11 into Equation 10 yields 
Figure 5. Schematic of the Consolidation Process.

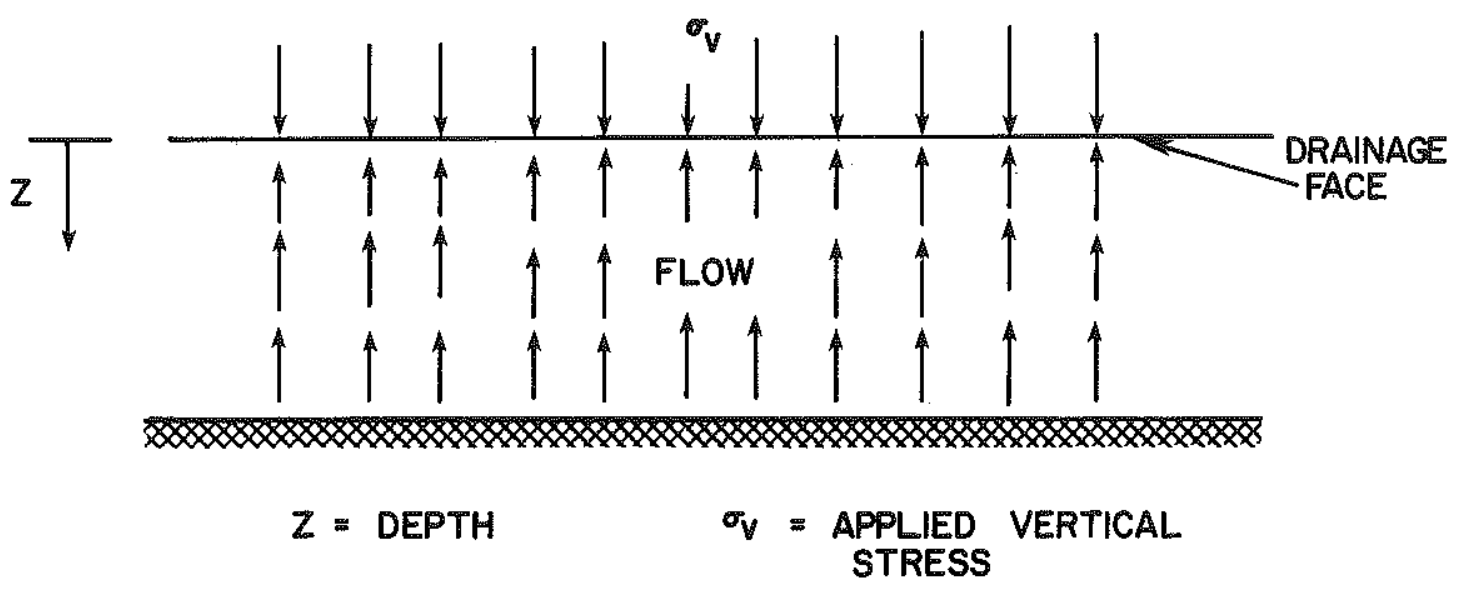


Figure 6. One-Dimensional Consolidation of a Thin Element.

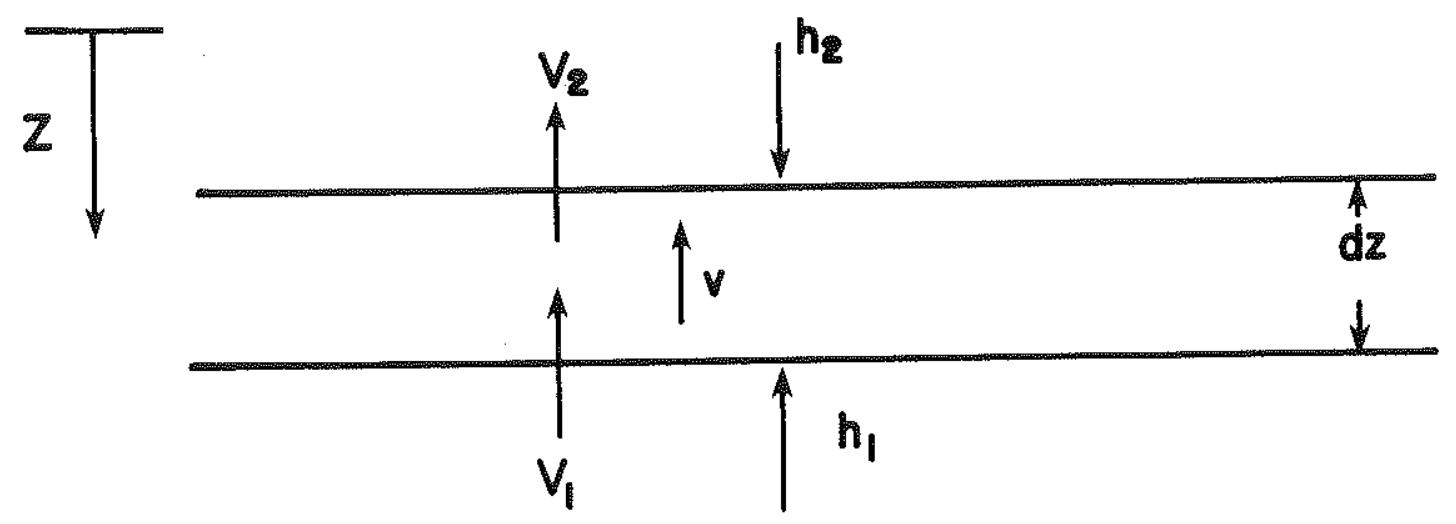

$$
\begin{aligned}
h_{1}, h_{2} & =\text { PRESSURE HEAD } \\
v_{1}, v_{2} & =\text { VOLUME OF FLOW } \\
v & =\text { VELOCITY OF FLOW } \\
d z & =\text { LAYER THICKNESS }
\end{aligned}
$$




$$
\partial \epsilon / \partial \mathrm{t}=\mathrm{m}_{\mathrm{v}}\left(\partial \sigma_{\mathrm{v}} / \partial \mathrm{t} \cdot \partial \mathrm{u} / \partial \mathrm{t}\right)
$$

However, this rate of volume decrease may be expressed in terms of the velocity of flow, v:

$$
\partial \epsilon / \partial \mathrm{t}=\partial \mathrm{v} / \partial \mathrm{z} \text {. }
$$

Equating Equation 12 and Equation 13,

$$
\partial \mathrm{v} / \partial \mathrm{z}=\mathrm{m}_{\mathrm{v}}\left(\partial \sigma_{\mathrm{v}} / \partial \mathrm{t}-\partial \mathrm{u} / \partial \mathrm{t}\right)
$$

Darcy's Law for flow through porous media states that

$$
\begin{array}{lll}
\mathrm{v}=\mathrm{k} i, & 15
\end{array}
$$

where $\mathrm{k}=$ coefficient of permeability. Substituting for $i$ from Equation 9 in Equation 15 yields

$$
\mathrm{v} \quad=-\mathrm{k}(\partial \mathrm{u} / \partial \mathrm{z}) / \gamma_{\mathrm{w}} .
$$

Taking the partial derivative of both sides with respect to $\mathrm{z}$ yields

$$
\partial \mathrm{v} / \partial \mathrm{z}=-\mathrm{k}\left(\partial^{2} \mathrm{u} / \partial \mathrm{z}^{2}\right) / \gamma_{\mathrm{w}}
$$

Substituting for $\partial v / \partial z$ from Equation 17 into Equation 14 yields

$$
-k\left(\partial^{2} u / \partial z^{2}\right) / \gamma_{w}=m_{v}\left(\partial \sigma_{v} / \partial t-\partial u / \partial t\right) \text {. }
$$

Rearranging,

$$
\partial \sigma_{\mathrm{v}} / \partial \mathrm{t}-\partial \mathrm{u} / \partial \mathrm{t}=\mathrm{k}\left(\partial^{2} \mathrm{u} / \partial \mathrm{z}^{2}\right) / \mathrm{m}_{\mathrm{v}} \gamma_{\mathrm{w}}
$$

Defining $\mathrm{C}_{\mathrm{v}}$ as $\mathrm{k} / \mathrm{m}_{\mathrm{v}} \gamma_{\mathrm{W}}$ and rewriting Equation 19 yields

$$
\partial \sigma_{\mathrm{v}} / \partial \mathrm{t}-\partial \mathrm{u} / \partial \mathrm{t}=\mathrm{C}_{\mathrm{v}}\left(\partial^{2} \mathrm{u} / \partial \mathrm{z}^{2}\right)
$$

which is the controlling differential equation of consolidation. This equation may be solved for a given set of boundary conditions.

In the preceding derivation, the following assumptions have been made:

1. $\mathrm{k}$ and $\mathrm{m}_{\mathrm{v}}$ are constant at every point in the sample at all times,

2. flow of pore water occurs only in the vertical direction,

3. secondary consolidation effects are neglected,

4. Darcy's Law for flow through porous media applies,

5. the soil is homogeneous,

6. the soil is saturated, and

7. the compressibilities of soil grains and water are negligible.

\section{Conventional Theory}

In the STD test, a soil specimen is compressed under vertical stress while allowing no lateral deformation. Drainage of pore water from the soil is allowed at both top and bottom of the specimen. This situation closely approximates assumptions used in the derivation of the consolidation theory. As can be seen from the consolidation theory, some finite time will be required for the pore water to 


$$
\partial \epsilon / \partial \mathrm{t}=\mathrm{m}_{\mathrm{v}}\left(\partial \sigma_{\mathrm{v}} / \partial \mathrm{t} \cdot \partial \mathrm{u} / \partial \mathrm{t}\right)
$$

However, this rate of volume decrease may be expressed in terms of the velocity of flow, $v$ :

$$
\partial e / \partial \mathrm{t}=\partial \mathrm{v} / \partial \mathrm{z}
$$

Equating Equation 12 and Equation 13,

$$
\partial \mathrm{v} / \partial \mathrm{z}=\mathrm{m}_{\mathrm{v}}\left(\partial \sigma_{\mathrm{v}} / \partial \mathrm{t} \cdot \partial \mathrm{u} / \partial \mathrm{t}\right) \text {. }
$$

Darcy's Law for flow through porous media states that

$$
\mathrm{v}=\mathrm{k} i,
$$

where $\mathrm{k}=$ coefficient of permeability. Substituting for $i$ from Equation 9 in Equation 15

yields

$$
\mathrm{v}=\mathrm{k}(\partial \mathrm{u} / \partial \mathrm{z}) / \gamma_{\mathrm{w}}
$$

Taking the partial derivative of both sides with respect to $\mathrm{z}$ yields

$$
\partial v / \partial z=-k\left(\partial^{2} u / \partial z^{2}\right) / \gamma_{w}
$$

Substituting for $\partial \mathrm{v} / \partial \mathrm{z}$ from Equation 17 into Equation 14 yields

$$
-k\left(\partial^{2} u / \partial z^{2}\right) / \gamma_{w}=m_{v}\left(\partial \sigma_{v} / \partial t-\partial u / \partial t\right)
$$

Rearranging,

$$
\partial \sigma_{\mathrm{v}} / \partial \mathrm{t}-\partial \mathrm{u} / \partial \mathrm{t}=\mathrm{k}\left(\partial^{2} \mathrm{u} / \partial \mathrm{z}^{2}\right) / \mathrm{m}_{\mathrm{v}} \gamma_{\mathrm{w}}
$$

Defining $\mathrm{C}_{\mathrm{v}}$ as $\mathrm{k} / \mathrm{m}_{\mathrm{v}} \gamma_{\mathrm{W}}$ and rewriting Equation 19 yields

$$
\partial \sigma_{\mathrm{v}} / \partial \mathrm{t} \cdot \partial \mathrm{u} / \partial \mathrm{t}=\mathrm{C}_{\mathrm{v}}\left(\partial^{2} \mathrm{u} / \partial \mathrm{z}^{2}\right)
$$

which is the controlling differential equation of consolidation. This equation may be solved for a given set of boundary conditions.

In the preceding derivation, the following assumptions have been made:

1. $\mathrm{k}$ and $\mathrm{m}_{\mathrm{v}}$ are constant at every point in the sample at all times,

2. flow of pore water occurs only in the vertical direction,

3. secondary consolidation effects are neglected,

4. Darcy's Law for flow through porous media applies,

5. the soil is homogeneous,

6. the soil is saturated, and

7. the compressibilities of soil grains and water are negligible.

\section{Conventional Theory}

In the STD test, a soil specimen is compressed under vertical stress while allowing no lateral deformation. Drainage of pore water from the soil is allowed at both top and bottom of the specimen. This situation closely approximates assumptions used in the derivation of the consolidation theory. As can be seen from the consolidation theory, some finite time will be required for the pore water to 
drain from the soil and for $\sigma_{\mathrm{v}}{ }^{\prime}$ to become equal to $\sigma_{\mathrm{v}}$. Primary consolidation is defined as the change in axial strain, $\Delta \epsilon$ (or void ratio, $\Delta \mathrm{e}$ ), which occurs from the moment of application of a change in vertical stress, $\Delta \sigma_{\mathrm{v}}$, until the applied stress is carried entirely by the soil grains. Thus, at the end of primary consolidation, the change in effective stress, $\Delta \sigma_{\mathrm{v}}{ }^{\prime}$, equals the change in applied stress, $\Delta \sigma_{\mathrm{v}}$.

To determine the magnitude of primary consolidation strain due to a change in applied stress, the instant when $\Delta \sigma_{\mathrm{v}}{ }^{\prime}$ becomes equal to $\Delta \sigma_{\mathrm{v}}$ must be known. Therefore, a knowledge of the relationship between primary consolidation and time is necessary.

Solution of Equation 20 for the boundary conditions of the STD consolidation test $\left(\partial \sigma_{\mathrm{v}} / \partial \mathrm{t}=0\right.$ and two-way drainage) yields a solution for degree of primary consolidation, $U$, in terms of a time factor, $\mathrm{T}$, where $\mathrm{T}=\mathrm{C}_{\mathrm{v}} \mathrm{t} / \mathrm{H}^{2}(\mathrm{t}=$ elapsed time and $\mathrm{H}=$ drainage path length in the consolidating layer). This solution is shown graphically in Figure 7. Figure 7 shows that no further consolidation strain occurs past $\mathrm{U}=100$ percent. Experimental results do not, however, bear this out; compression of the sample beyond this point is termed "secondary compression".

Distribution of excess pore pressure on a vertical section of a specimen during consolidation in the conventional test is shown in Figure 8 . Excess pore pressure and hence effective stress are shown at various times (or time factors, $\mathrm{T}$ ) during consolidation of the specimen under a constant load increment, $\Delta \sigma_{\mathrm{v}}$. For the case of two-way drainage, the constant pressure lines at any time are symmetrical about the midplane of the sample; therefore, only one-half of the specimen is shown.

In the STD test, a specimen is loaded incrementally and deflection-time data recorded for each increment of load. Various graphical constructions have been developed $(8,9)$ to determine the time required for different degrees of consolidation. The time required for a specified degree of consolidation and the theoretical relationship between $U$ and $T$ provide sufficient information to determine deformation (and hence strain) at the end of primary consolidation, $\mathrm{D}_{100}$, and $\mathrm{C}_{\mathrm{V}}$ for a given increment of load. Field magnitude and rate of settlement can then be estimated from the laboratory effective stress-strain relationship, the value of $\mathrm{C}_{\mathrm{v}}$, the differential equation of consolidation, and the appropriate field boundary conditions.

\section{Controlled-Gradient Theory}

Since pore pressures are not measured in the conventional test, the only means of determining effective stress is to allow complete dissipation of excess pore pressure under a constant load increment. If average pore pressure were determined during the consolidation test, then there would be no need to allow complete drainage under each load increment; in fact, incremental loading would not be necessary. Loading conditions in the $C G$ test and extension of the differential equation of consolidation to the boundary conditions imposed in the $C G$ test will ultimately lead to effective stress-strain and $C_{V}$ 


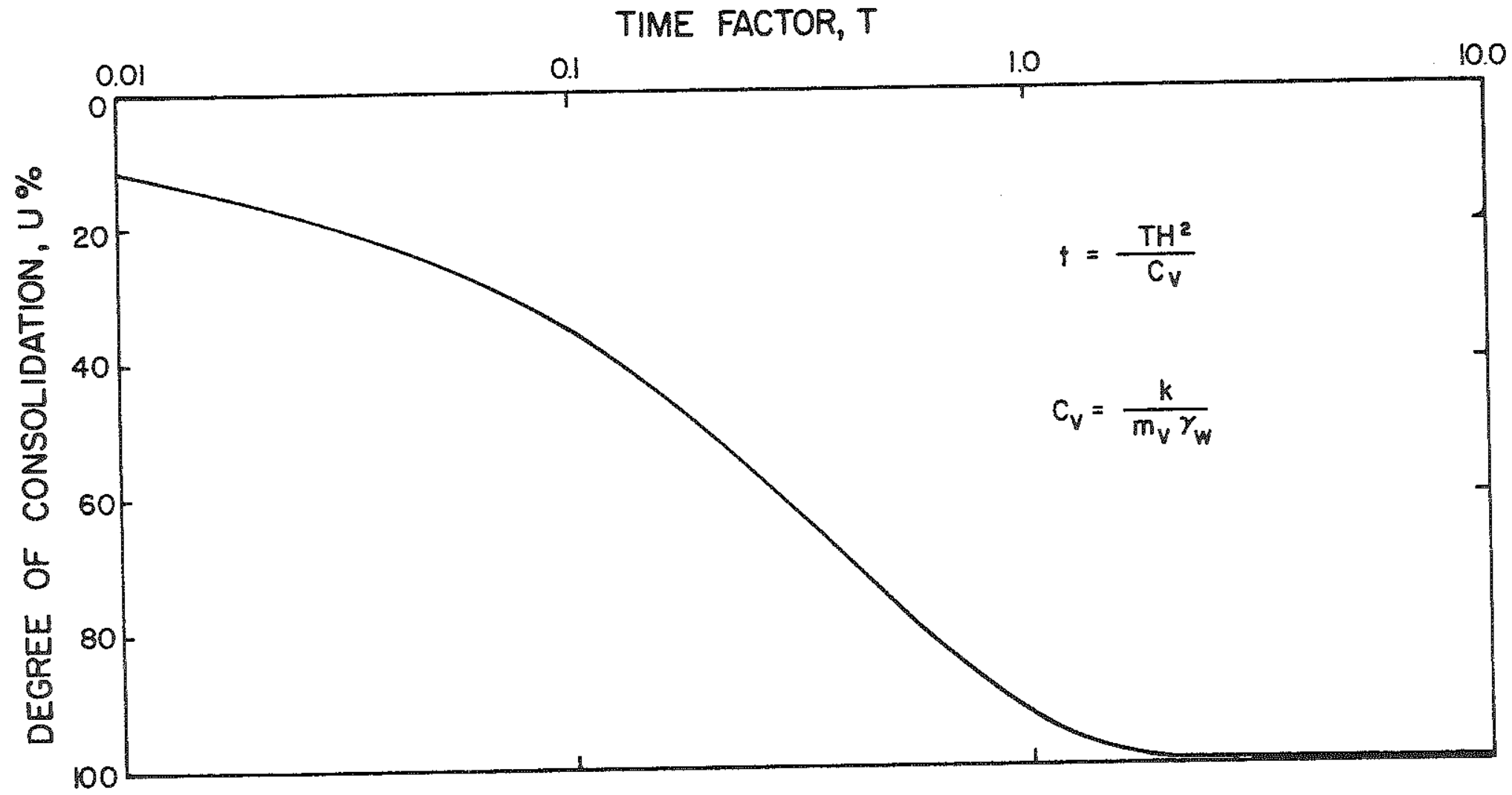

Figure 7. Solution of the Equation of Consolidation for Boundary Conditions of the STD Test. 

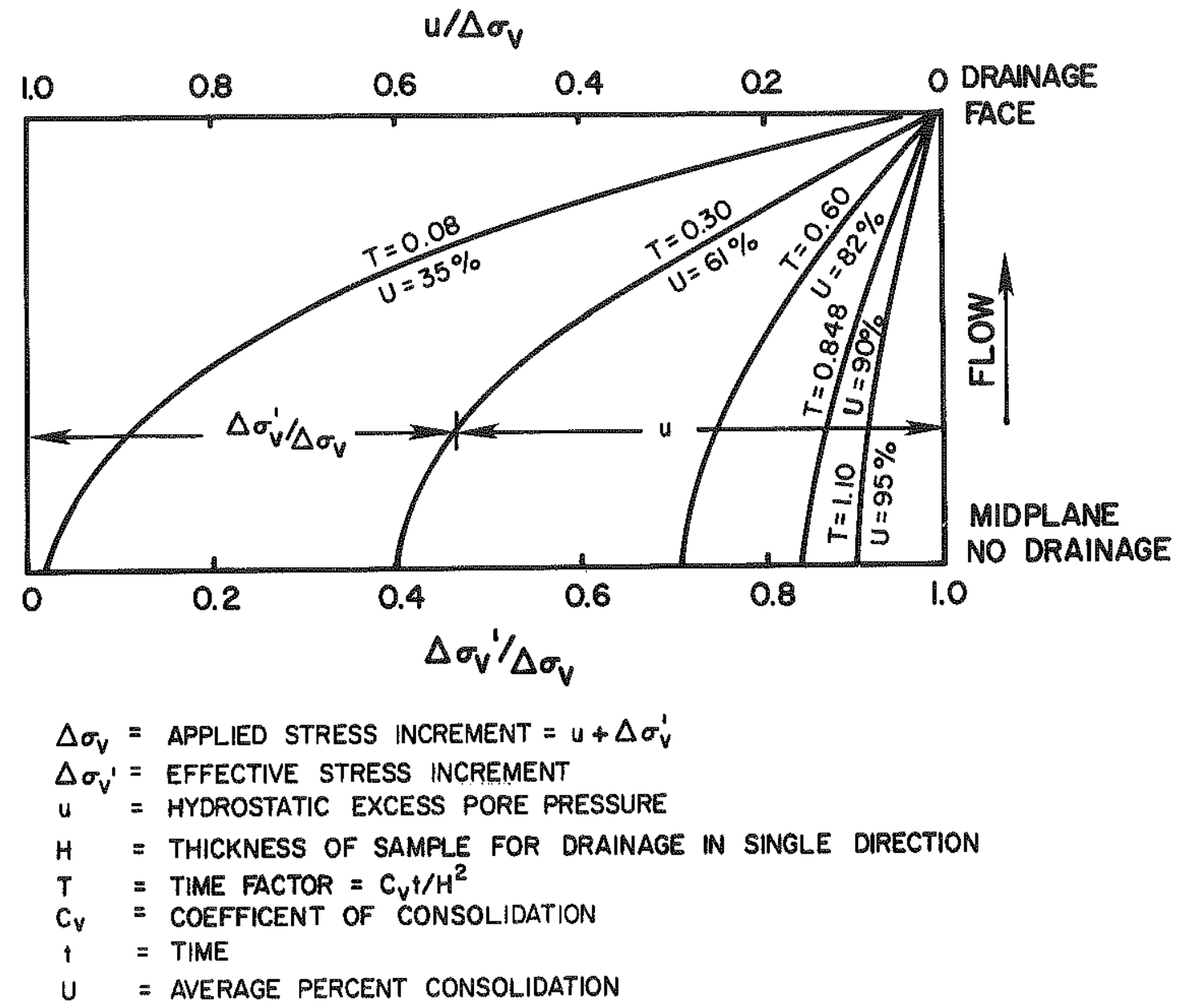

Figure 8. Pore-Pressure Distribution during the STD Test (after Lowe et al. $(6 /$ ). 
relationships.

Boundary conditions imposed on the specimen in the CG test are shown schematically in Figure 9. Drainage is allowed only at the top of the specimen, and the specimen is loaded in a manner such that a constant pore pressure, $u_{b}$, is maintained at the base (undrained end) of the specimen. A value of $u_{b}$ is chosen which will cause the pore pressure distribution with depth to assume a constant parabolic shape. Examination of Figure 8 reveals that the pore pressure distribution with depth may be assumed parabolic for values of $\mathrm{u} / \Delta \sigma_{\mathrm{v}}<0.3$. Previous work (6) has established that a range of $\mathrm{u}_{\mathrm{b}}$ from 0.8 to $4.0 \mathrm{psi}(5$ to $28 \mathrm{kPa}$ ) yields a parabolic pore-pressure distribution.

Solution of the differential equation of consolidation for boundary conditions of the CG test yields a solution for pore pressure, $\mathfrak{u}$, in terms of $z$ :

$$
\mathrm{u}=\mathrm{u}_{\mathrm{b}}\left(1-\mathrm{z}^{2} / \mathrm{H}^{2}\right) .
$$

Knowledge of the pore-pressure distribution (Equation 21) allows the calculation of $u_{a v g}$. By definition,

$$
\mathrm{u}_{\mathrm{avg}}={ }_{0} \int^{\mathrm{H}}(\mathrm{u} / \mathrm{H}) \mathrm{dz} \text {. }
$$

Substituting for $u$ from Equation 21 in Equation 22 yields

$$
u_{\text {avg }}=\int_{0}^{H}\left[u_{b}\left(1-z^{2} / H^{2}\right) / H\right] d z
$$

Solution of Equation 23 gives

$$
u_{\text {avg }}=2 u_{b} / 3 \text {. }
$$

Subtracting $u_{a v g}$ from the total applied stress at any time during the test, $\sigma_{v}{ }^{\prime}$ may be obtained. This is expressed mathmatically as

$$
\sigma_{\mathrm{v}}{ }^{\prime}=\sigma_{\mathrm{v}} \cdot \mathrm{u}_{\mathrm{avg}} \text {. }
$$

Solving for $\partial^{2} \mathrm{u} / \partial \mathrm{z}^{2}$ using Equation 21 and substituting the result into the differential equation for the $\mathrm{CG}$ test, a solution for $\mathrm{C}_{\mathrm{v}}$ may be obtained. The differential equation for the $\mathrm{CG}$ test is Equation 20 , where $\partial u / \partial t=0$, since the pore pressure is maintained constant. The governing equation may thus be expressed as

$$
\partial \sigma_{\mathrm{v}} / \partial \mathrm{t}=\mathrm{C}_{\mathrm{v}}\left(\partial^{2} \mathrm{u} / \partial \mathrm{z}^{2}\right)
$$

Taking the second derivation of Equation 21 with respect to $\mathrm{z}$ yields

$$
\partial^{2} \mathrm{u} / \partial \mathrm{z}^{2}=-2 \mathrm{u}_{\mathrm{b}} / \mathrm{H}^{2}
$$

and substituting Equation 27 into Equation 26 and rearranging terms gives a solution for $\mathrm{C}_{\mathrm{V}}$ :

$$
\mathrm{C}_{\mathrm{v}} \quad=\left(\partial \sigma_{\mathrm{v}} / \partial \mathrm{t}\right) \mathrm{H}^{2} / 2 \mathrm{u}_{\mathrm{b}} \text {. }
$$

\section{Constant-Rate-of-Strain Theory}

Boundary conditions imposed on the consolidating sample in the CRS test are the same as in the CG test (see Figure 9) with the exception that the strain rate is held constant instead of holding constant the pore-pressure gradient. It therefore becomes more convenient to solve the differential equation if it is written in terms of strain rather than stress. In terms of strain, the equation becomes 


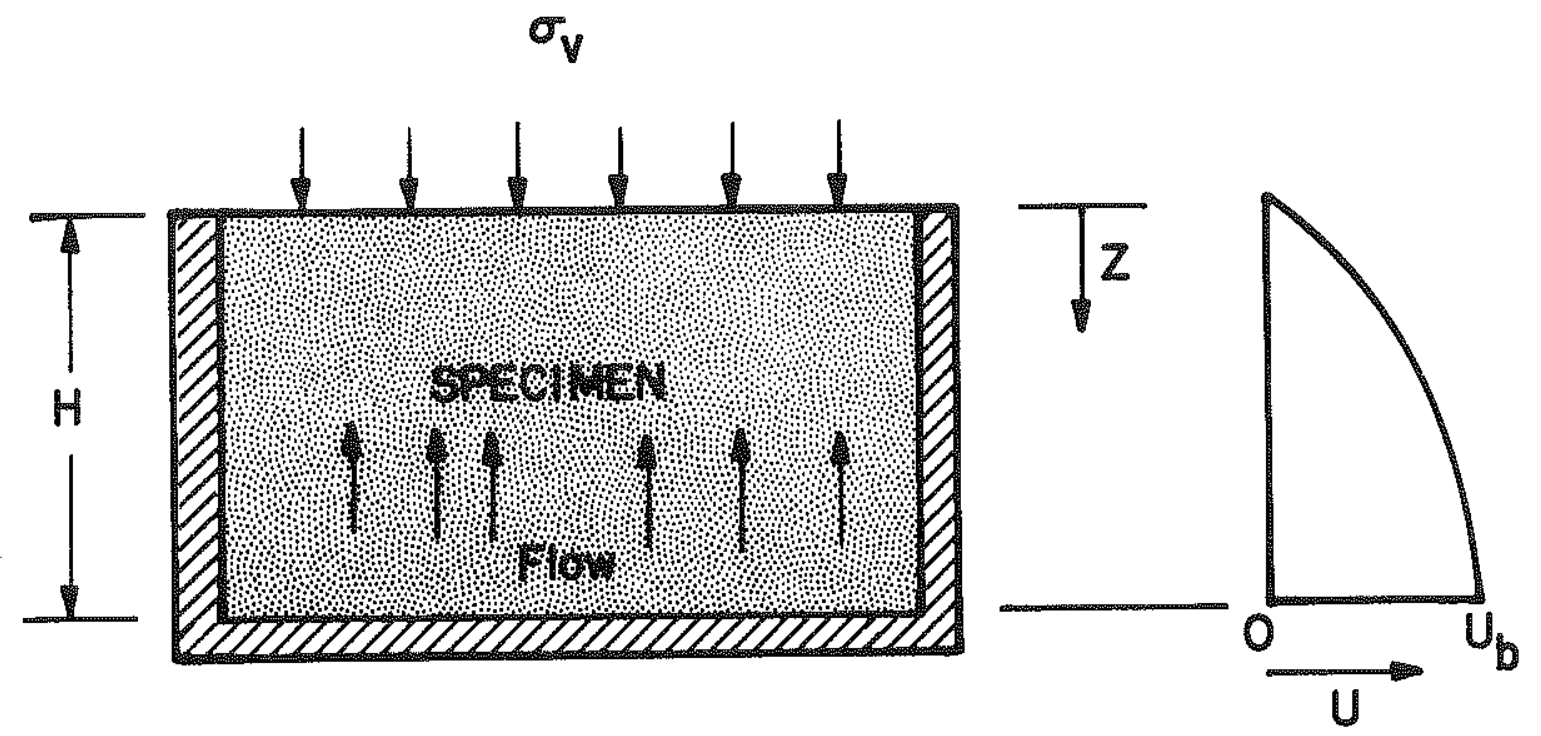

Figure 9. Boundary Conditions for the CG Test. 


$$
\partial \epsilon / \partial \mathrm{t}=\mathrm{C}_{\mathrm{v}}\left(\partial^{2} \epsilon / \partial \mathrm{z}^{2}\right) \text {, }
$$

where $\epsilon=$ strain. Solution for the boundary conditions of the CRS test has been given by Wissa et al. (5) in terms of $\mathrm{T}$ and $\mathrm{r}$, where

$$
\text { I } \quad=\partial \epsilon / \partial \mathrm{t} \text {. }
$$

The solution for strain at any point in the specimen as a function of time factor and drainage path length is given by

$$
\begin{aligned}
\epsilon= & \text { rt }\left[1+(1 / 6 \mathrm{~T})\left\{2-6 \mathrm{z} / \mathrm{H}+3(\mathrm{z} / \mathrm{H})^{2}\right\} \cdot\left(2 / \pi^{2} \mathrm{~T}\right) \sum_{\mathrm{n}=1}^{\infty}\left(\cos \mathrm{n} \pi(\mathrm{z} / \mathrm{H}) / \mathrm{n}^{2}\right)\right. \\
& \left.\exp \left(-\mathrm{n}^{2} \pi^{2} \mathrm{~T}\right)\right] .
\end{aligned}
$$

Considering only the steady-state component of this equation yields

$$
\epsilon=\mathrm{rt}+\left(\mathrm{rH}^{2} / \mathrm{C}_{\mathrm{v}}\right)\left[(1 / 6)\left\{3(\mathrm{z} / \mathrm{H})^{2}-6(\mathrm{z} / \mathrm{H})+2\right\}\right] .
$$

It can be seen that the strain is parabolically distributed through the sample, as shown in Figure 10 . Thus, the average strain, $\epsilon_{\mathrm{avg}}$, in the sample may be calculated from

$$
\epsilon_{\text {avg }}=\left(2 \epsilon_{\text {bottom }}+\epsilon_{\text {top }}\right) / 3 \text {. }
$$

Assuming $m_{v}$ is constant allows the average, vertical effective stress, $\sigma_{v}{ }_{v}$, in the sample to be expressed

as

$$
\sigma_{\mathrm{v}}{ }^{\prime} \quad=\left(2 \sigma_{\mathrm{v}}^{\prime}{ }_{\text {bottom }}^{\prime}+\sigma_{\mathrm{v}}^{\prime}{ }_{\text {top }}^{\prime) / 3 .}\right.
$$

Given the boundary conditions of drainage at the top of the specimen and $\mathrm{u}_{\mathrm{b}}$ measured at the base, the top and bottom effective stresses may be expressed in terms of $\sigma_{\mathrm{v}}$; this allows Equation 34 to be rewritten as

$$
\sigma_{\mathrm{v}}^{\prime}=\left[2\left(\sigma_{\mathrm{v}} \cdot \mathrm{u}_{\mathrm{b}}\right)+\sigma_{\mathrm{v}}\right] / 3
$$

or

$$
\sigma_{\mathrm{v}}{ }^{\prime}=\sigma_{\mathrm{v}} \cdot 2 \mathrm{u}_{\mathrm{b}} / 3 .
$$

An equation for $\mathrm{C}_{\mathrm{v}}$ may also be obtained, given the definition of

$$
\mathrm{C}_{\mathrm{v}} \quad=\mathrm{k} / \mathrm{m}_{\mathrm{v}} \gamma_{\mathrm{w}} \text {. }
$$

The foregoing discussion has shown that the change in vertical effective stress between the top and bottom of the specimen is equal to the pore pressure measured at the specimen base:

$$
\Delta \sigma_{\mathrm{v}}^{\prime} \quad=u_{\mathrm{b}} \text {. }
$$

Since $\mathrm{m}_{\mathrm{v}}$ has been assumed constant, it may be expressed as

$$
\mathrm{m}_{\mathrm{v}} \quad=\Delta \epsilon / \Delta \sigma_{\mathrm{v}}{ }^{\prime} \text {. }
$$

Substituting into Equation 39 for $\Delta \sigma_{\mathrm{v}}{ }^{\prime}$ from Equation 38 and for $\Delta \epsilon$ from Equation 32 evaluated at the top and bottom of the specimen yields

$$
\mathrm{m}_{\mathrm{v}}=\mathrm{rH}^{2} / 2 \mathrm{C}_{\mathrm{v}} \mathrm{u}_{\mathrm{b}} \text {. }
$$

Next, substituting into Equation 40 for $\mathrm{C}_{\mathrm{v}}$ from Equation 37 yields 


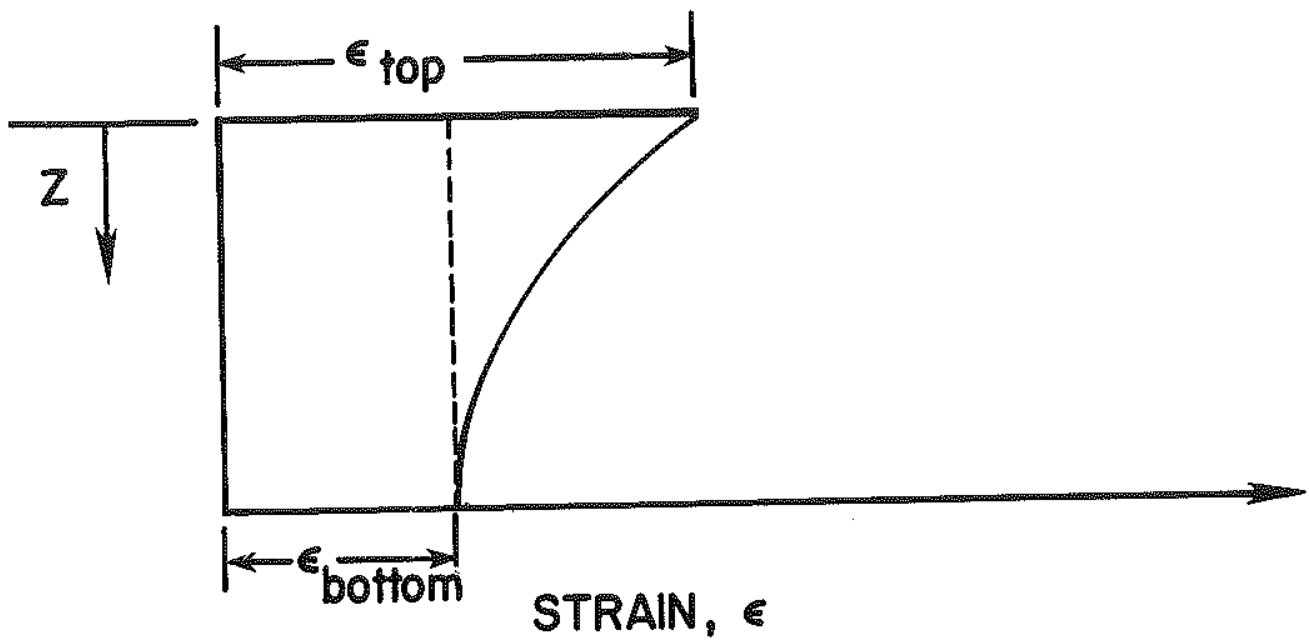

Figure 10. Strain Distribution during the CRS Test. 


$$
\mathrm{k}=\mathrm{rH}^{2} \gamma_{\mathrm{w}} / 2 \mathrm{u}_{\mathrm{b}} \text {. }
$$

Since the rate of change of strain, $\partial \epsilon / \partial t$, is constant and a linear stress-strain relation has been assumed, the rate of change of $\sigma_{\mathrm{v}}{ }^{\prime}$ and hence pore-pressure distribution must also be constant. Therefore,

$$
\mathrm{m}_{\mathrm{v}} \quad=\Delta \epsilon / \Delta \sigma_{\mathrm{v}}=\mathrm{r} \Delta \mathrm{t} / \Delta \sigma_{\mathrm{v}}
$$

Substituting for $\mathrm{k}$ and $\mathrm{m}_{\mathrm{v}}$ in Equation 37 from Equations 41 and 42, respectively, yields

$$
\mathrm{C}_{\mathrm{v}} \quad=\left(\Delta \sigma_{\mathrm{v}} / \Delta \mathrm{t}\right) \mathrm{H}^{2} / 2 \mathrm{u}_{\mathrm{b}}
$$

which is the same equation used in the CG test. Research by Wissa et al. (5) has shown that if $\mathrm{m}_{\mathrm{v}}$ is assumed to vary linearly with vertical effective stress rather than remain constant, then $\mathrm{C}_{\mathrm{V}}$ as calculated by Equation 43 will be within 10 percent of the correct solution if the pore pressure generated at the base of the sample is less than 15 percent of the total applied stress.

Equations derived for $\mathrm{C}_{\mathrm{V}}$ in both the $\mathrm{CG}$ and $\mathrm{CRS}$ theory are based on the steady-state solution of the differential equation of consolidation. In the initial phases of the CG and CRS tests, steady-state conditions do not exist. Some time is required to allow pore pressure to buildup. Therefore, calculation of $\mathrm{C}_{\mathrm{v}}$ in the early stages of the CG and CRS tests using Equation 43 may produce erroneous values. The problem is discussed further in the section entitled "ANALYSIS AND DISCUSSION".

\section{Data Reduction}

STD test data are reduced according to procedures presented by Casagrande (9, 10), Taylor (8), and Schmertmann (11). Reduced data are presented as plots of $\epsilon$ and $\mathrm{C}_{\mathrm{v}}$ versus logarithm of $\sigma_{\mathrm{v}}{ }^{\prime}$, as shown in Figure 11. Values of preconsolidation pressure, $\mathrm{P}_{\mathrm{c}}$, compression ratio, $\mathrm{CR}$, and swell ratio, $\mathrm{SR}$, are used to compute settlement magnitude; $\mathrm{C}_{\mathrm{V}}$ is used to compute rate of settlement.

Since the equations derived for the reduction of CG and CRS test data are the same, both tests may be reduced using the same procedure. Readings of time, deflection, load, and pore pressure are taken at various intervals during the test and are used with Equations 36 and 43 to calculate $\epsilon, \sigma_{\mathrm{v}}{ }^{\prime}$, and $\mathrm{C}_{\mathrm{V}}$. The plots shown in Figure 11 are then produced and $\mathrm{P}_{\mathrm{c}}, \mathrm{CR}$, and $\mathrm{SR}$ may be determined using graphical constructions proposed by Casagrande (10) and Schmertmann (11) for the STD test. Plots of $\sigma_{\mathrm{v}}$ versus time from the CG test and $u_{\mathrm{b}}$ versus $\sigma_{\mathrm{v}}{ }^{\prime}$ from the CRS test are also helpful in the determination of $\mathrm{P}_{\mathrm{c}}$; these are discussed in the section entitled "BACKGROUND". 


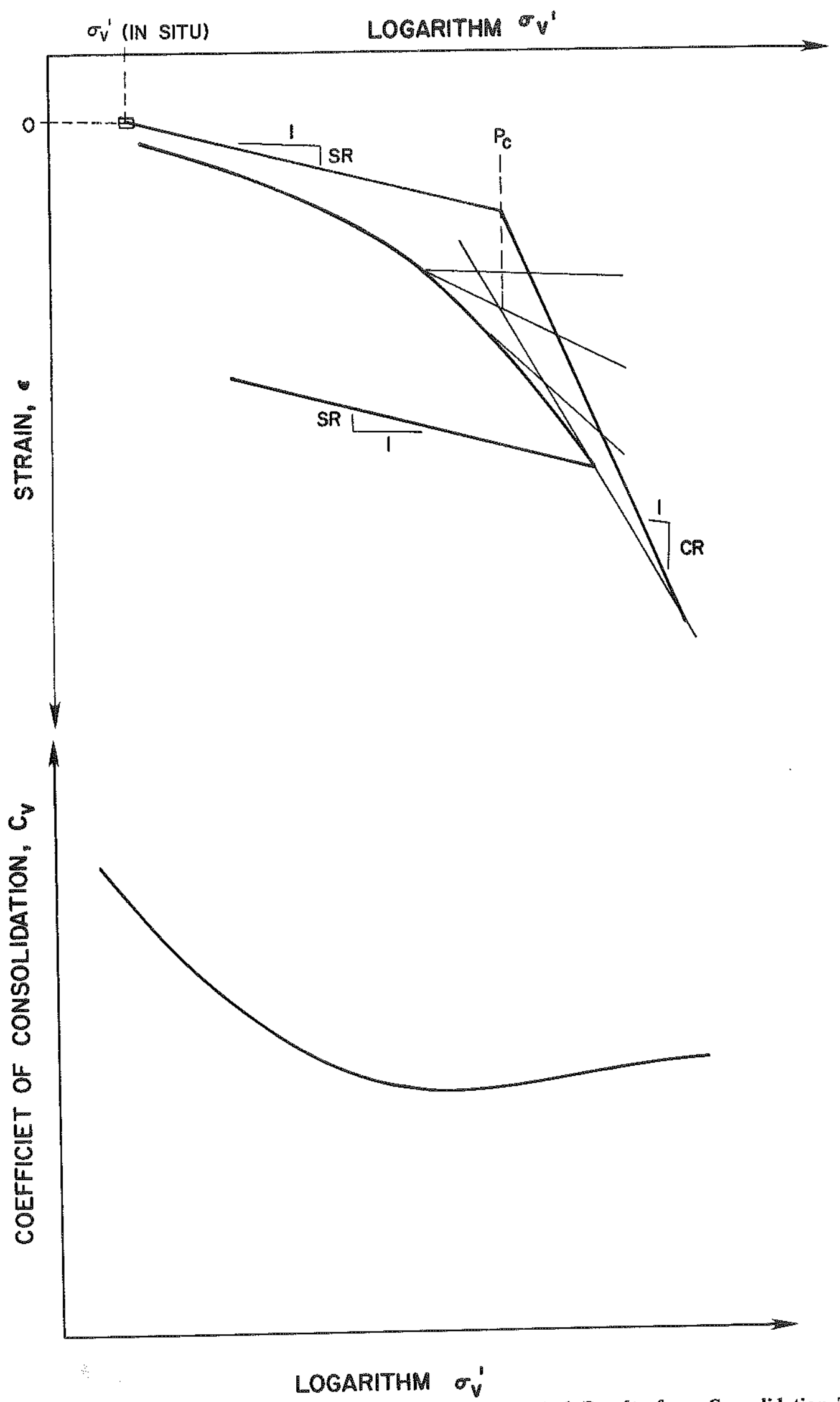

Figure 11. Graphical Presentation and Interpretation of Typical Results from Consolidation Tests. 


\section{EQUIPMENT}

\section{Controlled-Gradient Equipment}

Equipment capable of performing a CG consolidation test was obtained from Soils Mechanics Equipment of Spring Valley, New York, and is shown in Figure 12. The equipment was intended to perform CG, CRS, and STD consolidation tests and was hence termed the "Universal" Consolidometer. However, only CG tests were performed with this equipment because STD tests were more easily performed using conventional equipment and because the response of the pore-pressure measuring system was too slow in CRS tests. Slow response of the pore-pressure measuring system was attributed to the fact that no provision was made for de-airing the pore-water lines; air trapped in the lines created a slow response to pressure changes, or pore pressure lag. In the CG test, pore pressure was maintained constant (or nearly so); consequently, pore-pressure lag was not a significant problem.

A simplified schematic of the CG test control portion of the equipment is shown in Figure 13. The basic function of the equipment is to load the sample at a rate that will maintain a constant pore pressure, $u_{b}$, at the base of the sample. Provision is also made for saturating samples by back pressure.

The pore-pressure duplicator converts the pore pressure plus back pressure at the base of the specimen to an equal air pressure $(\mathrm{PP}+\mathrm{BP})$. The difference between this pressure and the back pressure is the excess pore pressure generated by loading the specimen. Excess pore pressure is displayed on the differential pressure gage. The PP + BP (air) pressure is also input to the load pacer, which regulates the load applied to the sample such that $\mathrm{PP}+\mathrm{BP}$ remains at a constant, preset value. For example, if $\mathrm{PP}+\mathrm{BP}$ is greater than the preset value, a valve in the load pacer closes and prevents further pressurization of the pneumatic loading chamber; when PP + BP drops below the preset value, the valve opens and pressurizes the loading chamber until PP + BP rises to the preset value. The schematic of the Universal consolidometer is shown in Figure 14.

\section{Constant-Rate-of-Strain Equipment}

The modified triaxial equipment shown in Figure 15 was used to perform CRS tests. A triaxial chamber was fitted with an oedometer ring, and a triaxial loading press was used to deform the sample at a constant rate. A schematic of the CRS consolidometer is shown in Figure 16. The sample may be back-pressured, top and bottom, to insure saturation. The load, applied to the specimen by the loading ram, was measured by a strain-gage-type load cell and signal-conditioning equipment. Pore pressure was measured at the undrained end (bottom) of the specimen by means of a strain-gage-type pressure transducer mounted directly in the base of the apparatus. Length change was measured by a linear variable displacement transducer which recorded the movement of the chamber as it was moved upward on the loading ram by the loading press. 


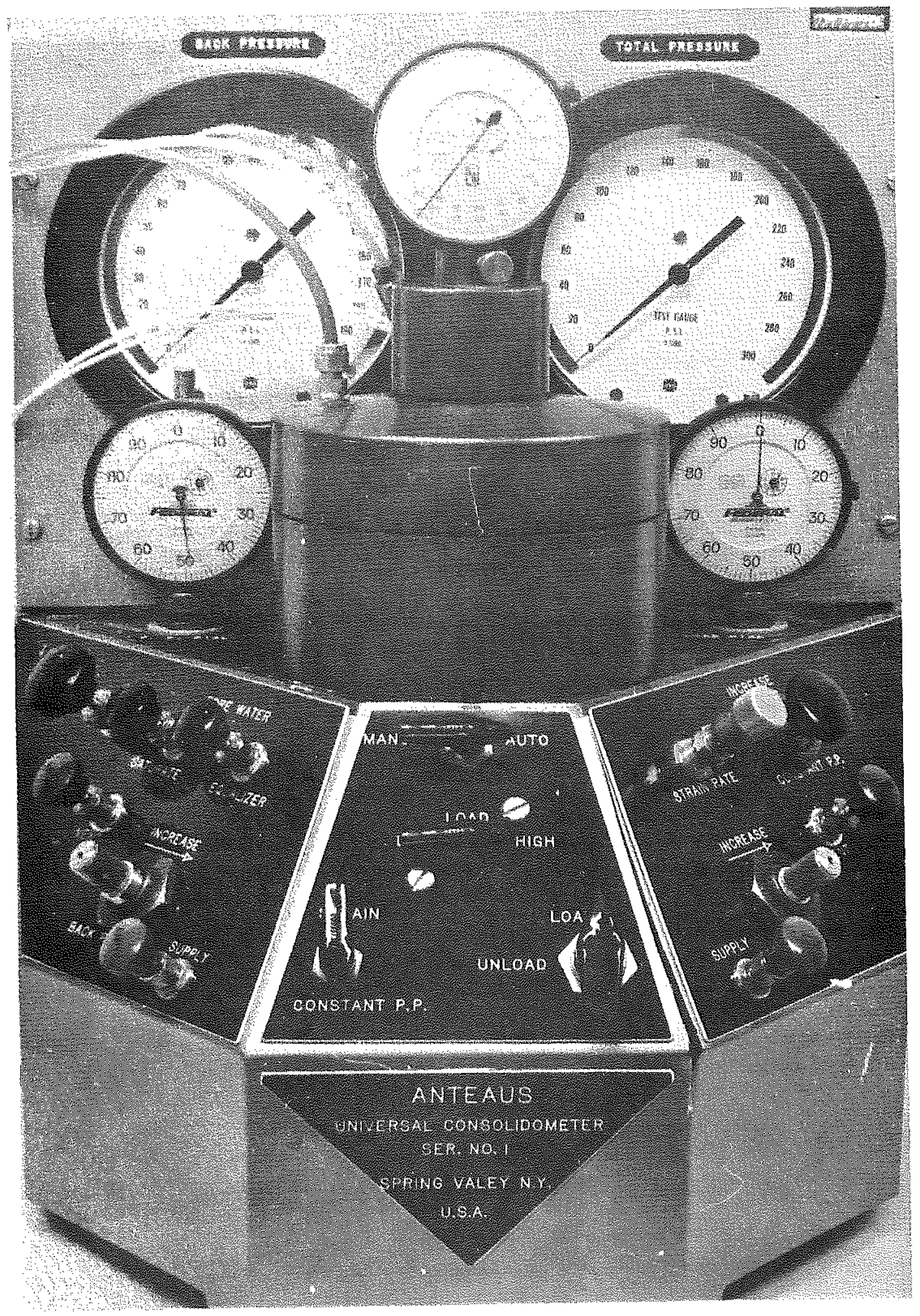

Figure 12. CG Test Equipment. 
Figure 13. Simplified Schematic of CG Test Equipment.

(a) SPECIMEN

(b) CONSOLIDATION RING

(c) BACK PRESSURE CHAMBER

(d) UPPER POROUS STONE

(o) OUTFLOW LINE

(f) RESERVOIR

(g) BOTTOM POROUS STONE

(h) BACK PRESSURE REGULATOR

(i) PNEUMATIC LOADING CHAMBER

(j) PORE PRESSURE LINE

(k) PORE PRESSURE DUPLICATOR

(i) LOAD PACER

(m) TOTAL LOAD GAUGE

(n) DIFFERENTIAL PRESSURE GAUGE BETWEEN BACK PRESSURE AND PRESSURE IN BOTTOM POROUS STONE

(o) BACK PRESSURE LINE

(p) LOAD REGULATOR

(r) EXTENSOMETER

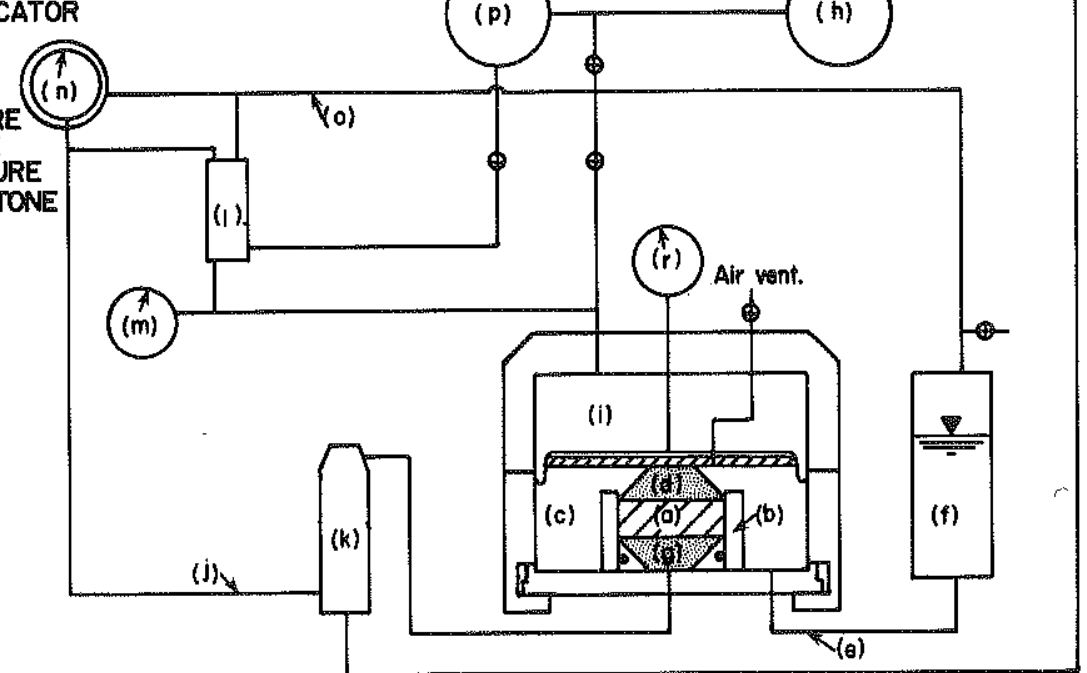




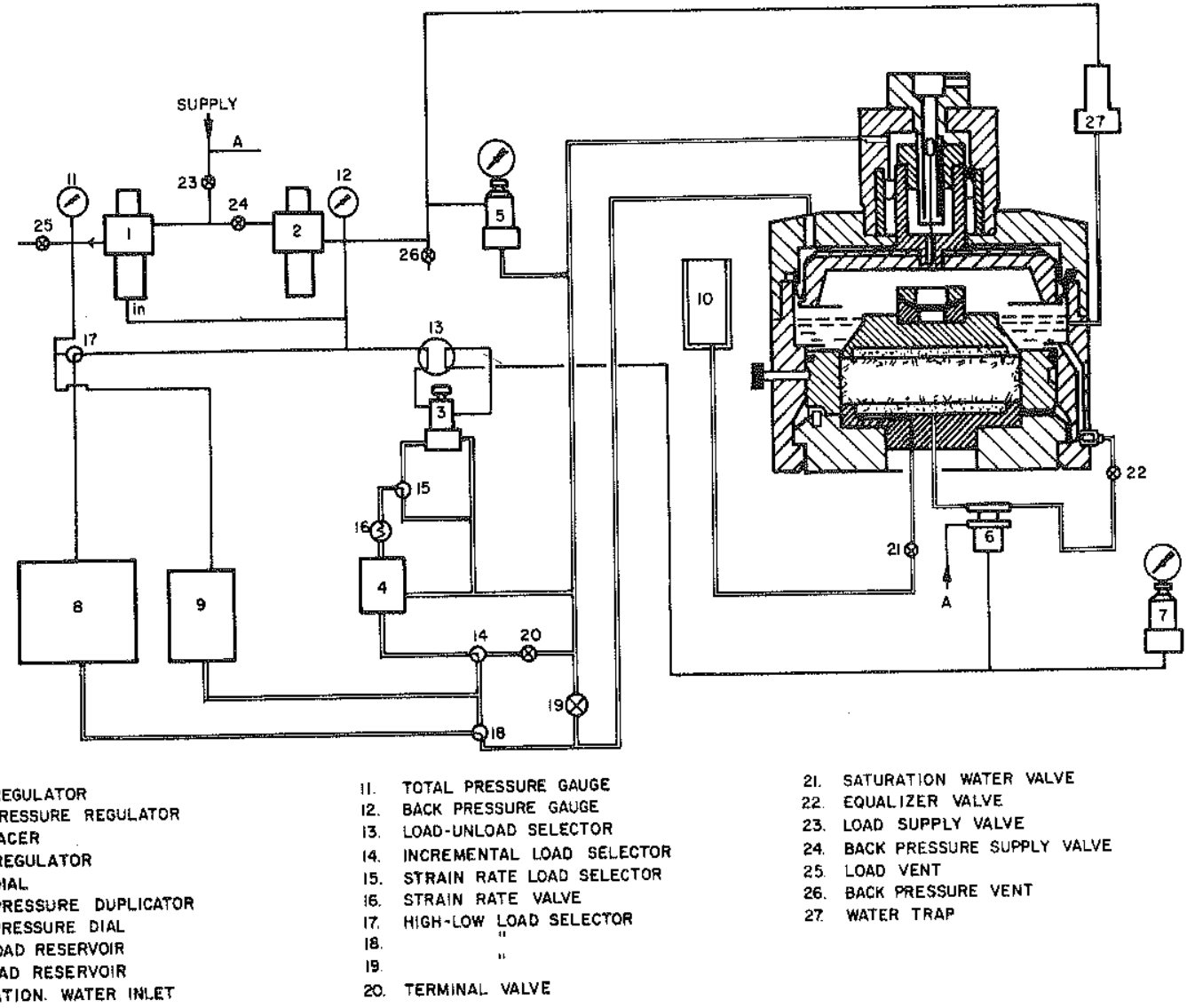

Figure 14. Schematic of CG Test Equipment. 
Figure 15. CRS Test Equipment.

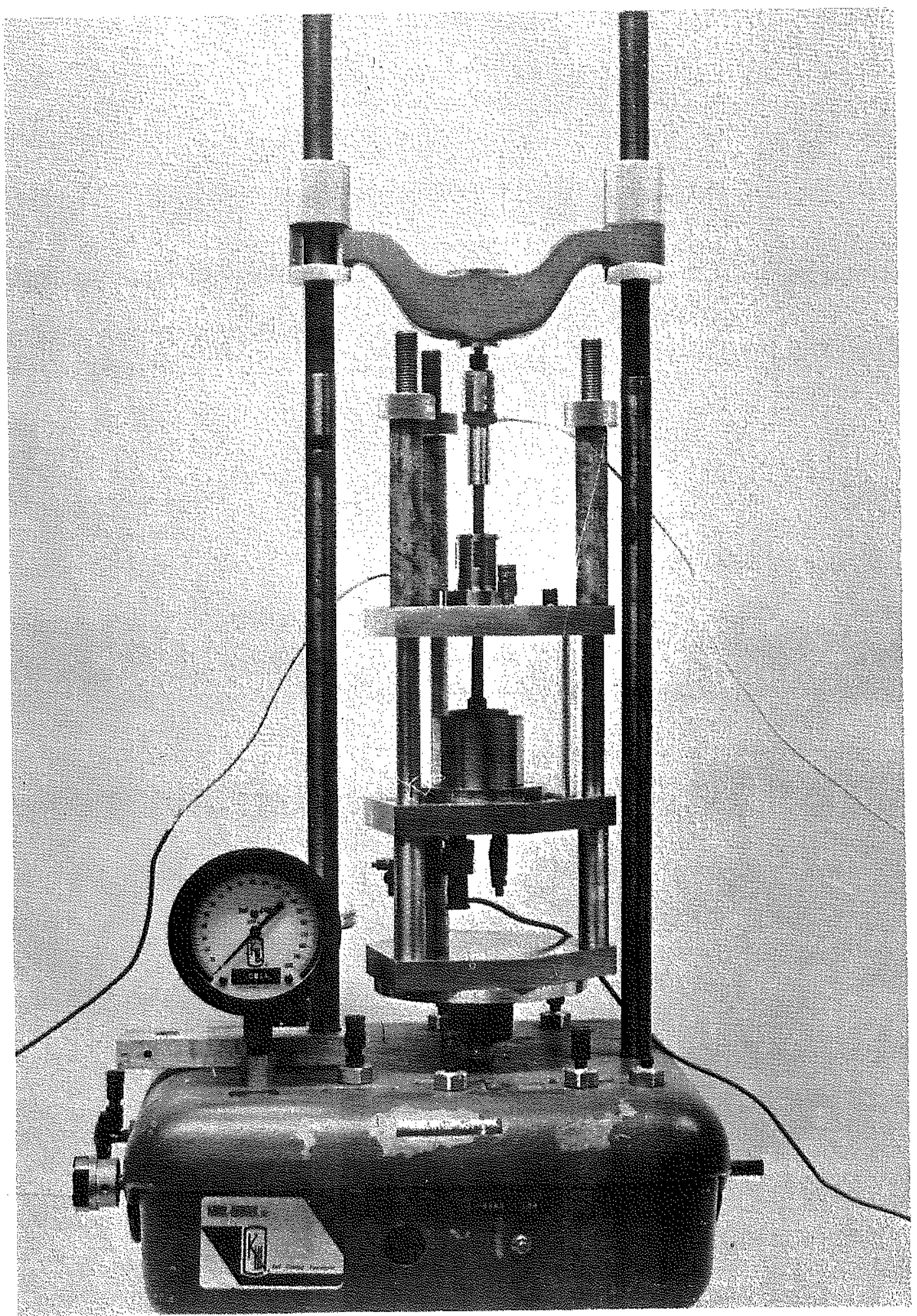


Figure 16. Schematic of CRS Test Equipment.
(a) SPECIMEN
(b) CONSOLIDATION RING
(c) CHAMBER
(d) POROUS STONE
(e) PORE PRESSURE TRANSDUCER
(f) RESERVOIR
(g) DISPLACEMENT TRANSDUCER
(h) LOADING RAM
(i) BACK PRESSURE REGULATOR
(j) AIR VENT

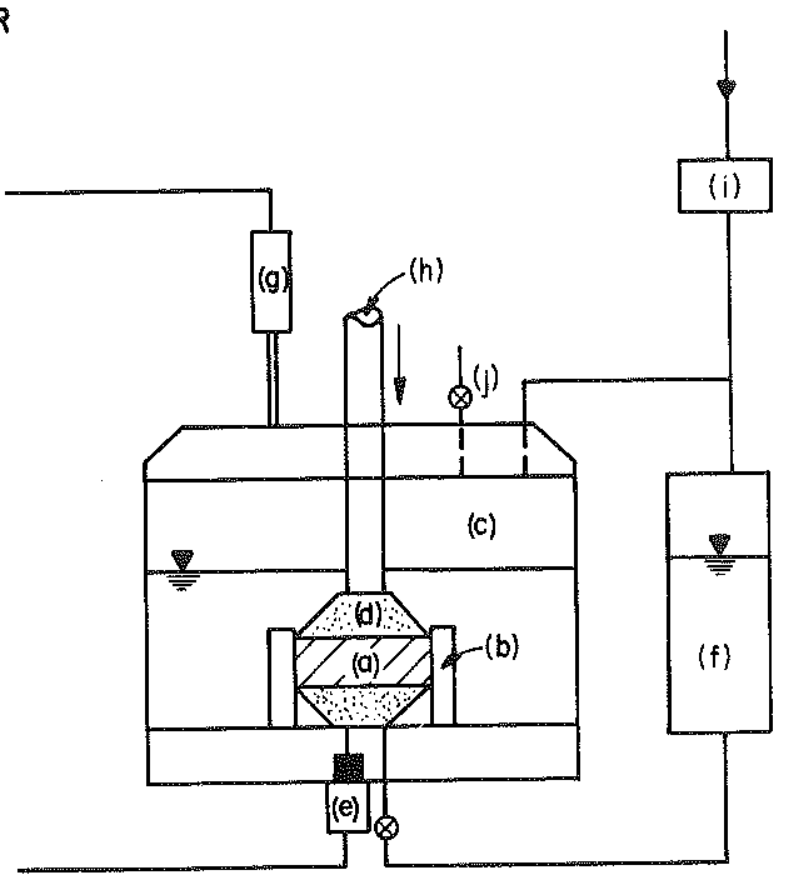


Complete saturation of the pore-pressure cavity and back-pressure line was achieved by filling the chamber with de-aired water and applying a vaccum to the water, thus displacing the air in the cavities with de-aired water. This eliminated the problem of pore-pressure lag.

\section{Conventional Equipment}

STD consolidation tests were performed using Karol-Warner and Anteus pneumatic loading equipment. The Anteus pneumatic loading chamber had provision for back-pressuring samples to insure saturation. Photographs of the Karol-Warner and Anteus equipment are shown in Figures 17 and 18, respectively. Load was applied to the specimens by applying a constant, regulated air pressure to the pneumatic-hydraulic loading assembly and measuring the specimen deflection with a dial gage having a resolution of 0.0001 inches $(0.0025 \mathrm{~mm})$. The back-pressure system of the Anteus consolidometer was similar in all respects to that shown in the CRS schematic (Figure 16). 


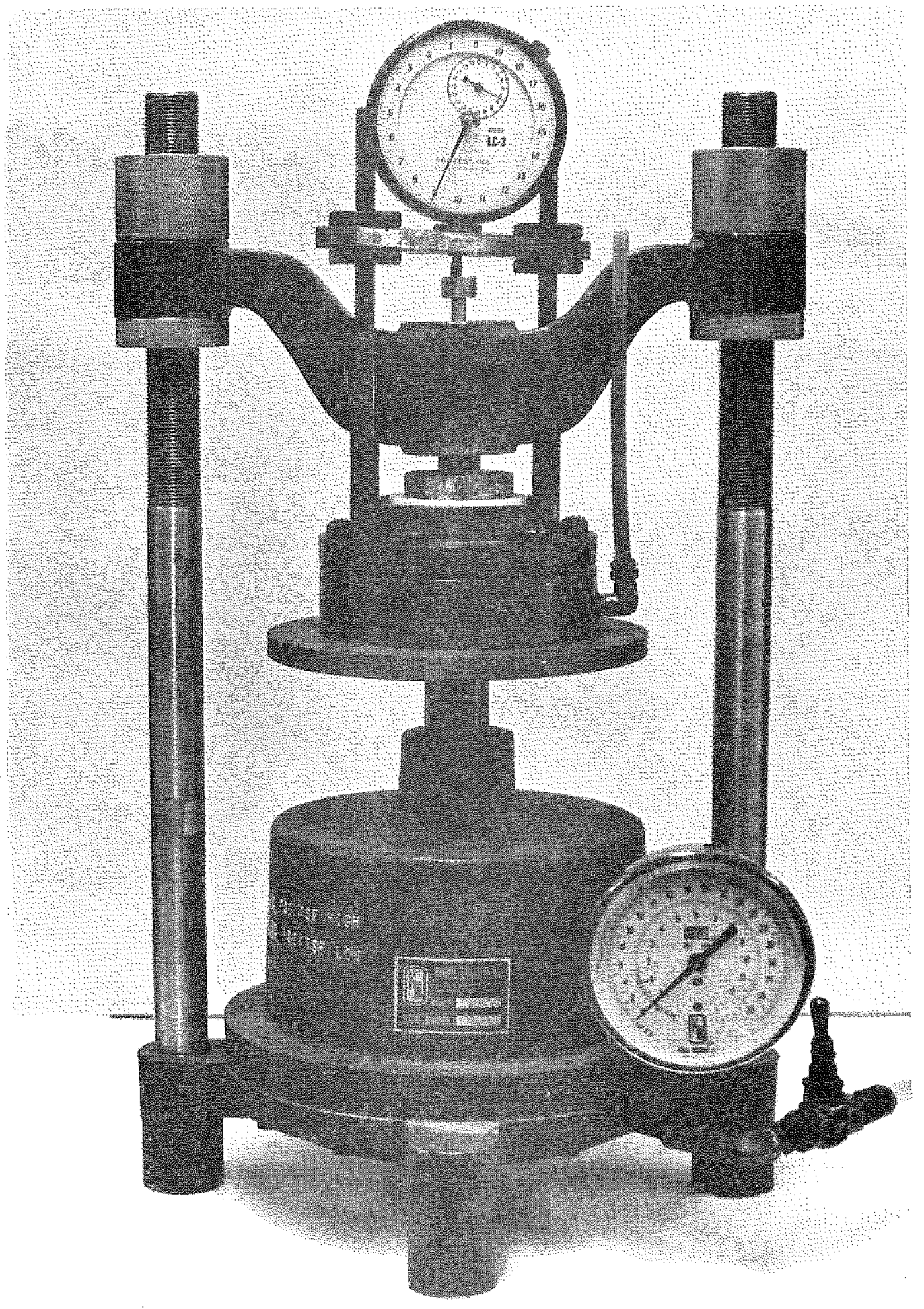

Figure 17. STD Test Equipment. 




Figure 18. STD Test Equipment with Provision for Back Pressure. 


\section{TEST PROCEDURE}

In all tests, the soil specimens were trimmed to 2.5 inches $(64 \mathrm{~mm})$ diameter by 1.0 inch $(25$ $\mathrm{mm}$ ) high using a stainless steel trimming shoe and then transferred to a teflon-lined consolidation ring in the apparatus. A small seating load of approximately $0.1 \mathrm{tsf}(1 \mathrm{kPa})$ was applied to the specimen. In cases where back pressure was used, the chamber was filled with distilled water and a back pressure was applied to the top and bottom of the specimen. A back pressure of $10 \mathrm{psi}(69 \mathrm{kPa})$ was used in all CG and CRS tests and in some STD tests. The value of $10 \mathrm{psi}(69 \mathrm{kPa})$ for back pressure was chosen since it was greater than the maximum pore pressure which existed in the samples, in situ, yet was small enough not to affect the maximum load capability of the equipment. Back pressure was applied at least 12 hours before testing. Initial readings were taken before the loading phase of the test. In all cases, primary consolidation under the seating load was completed before beginning the loading phase.

\section{Controlled-Gradient Loading}

Following the back-pressure (saturation) phase, the drainage line to the bottom of the sample was closed, creating one-way drainage at the top of the specimen. Pore-pressure buildup was measured at the bottom of the specimen. Although the loading system in the CG apparatus automatically adjusted the load to maintain a constant pore pressure at the bottom of the specimen, it was necessary to load the specimen by manual adjustment of the controls, until the desired excess pore pressure (2-3 psi (14-21 $\mathrm{kPa})$ ) was attained, to prevent overreaction by the automatic loading system. Once the desired pore pressure was attained, automatic control was restored; and loading continued to a preset load (usually 32 tsf (3MPa)). When the preset load was reached, the load was held constant at this value, pore pressure was allowed to dissipate, and compression under constant load with zero excess pore pressure (secondary compression) was recorded. The sample was then unloaded manually in small increments to generate rebound data. Throughout the test, readings were taken of load, pore pressure, and deflection at various time intervals. The time interval between readings is arbitrary.

\section{Constant-Rate-of-Strain Loading}

Drainage of pore water from the sample base was prevented, prior to loading, as in the CG test. The sample was loaded by compressing it at a constant, predetermined rate using a gear-driven loading frame. The loading machine was stopped at a preset load (32 tsf (3MPa)), and excess pore pressure was allowed to dissipate at the final, constant deformation. Thus, secondary compression data could not be obtained. The sample was finally unloaded at the same rate at which it was loaded. Readings were taken of load, pore pressure, and deformation in the same manner as in the CG test.

\section{Incremental Loading}

The STD tests were performed in accordance with ASTM D 2435-70, Standard Method of Test 
for One-Dimensional Consolidation Properties of Soils. Two-way drainage (top and bottom of the sample) was allowed; load increments of $0.25,0.50,1.0,2.0,4.0,8.0,16.0$, and 32.0 tsf $(0.025,0.05,0.1$, $0.2,0.4,0.8,1.6,3.2 \mathrm{MPa})$ were applied; and the specimens were rebounded to $1.0 \mathrm{tsf}(0.1 \mathrm{MPa})$. STD tests in which back pressure was used were loaded only to 16 tsf (1.6 MPa). Each load increment was allowed to bear on the sample for 24 hours before the next increment was applied. $\mathrm{D}_{100}$ and $\mathrm{C}_{\mathrm{V}}$ were obtained from plots of deformation versus square root of time and deformation versus logarithm of time as recommended in the ASTM standard. These are the same methods proposed by Taylor (8) and Casagrande (9). 


\section{SITE AND SOIL DESCRIPTION}

Much of the research with CG and CRS consolidation testing has been conducted using remolded soil samples and soils which are not commonly found in Kentucky. In an effort to compare and evaluate CG, CRS, and STD consolidation testing techniques for typical Kentucky soils, undistrubed (2.5-foot (0.8-m) long Shelby tube) soil samples were taken from three physiographic regions in Kentucky. It is realized that soil samples from one location in each of three regions within the state do not represent all "typical" Kentucky soils. In fact, considerable soil variability exists not only across the state but also within a particular physiographic region. Rather, it is intended that the particular soils sampled will provide suitable materials for the comparison of the various tests. With this in mind, three soils which exhibited a wide range of engineering properties were chosen for testing. Samples were obtained from the Western Coal Field, Mississippian Plateaus, and Bluegrass Regions. These physiographic regions and the approximate location of the sampling sites are shown in Figure 19.

The end product of any consolidation test is the estimation of settlement magnitude and rate. Therefore, the evaluation of different methods of consolidation testing should focus on how well the method predicts magnitude and rate of settlement. To evaluate the CG, CRS, and STD tests in this manner, a site was chosen for which considerable settlement data existed. Thus, direct comparison of observed and predicted settlement records could be made. This site was located in the Western Coal Field Region and is referred to hereafter as Site Number One.

\section{Site Number One}

Site Number One is at the north approach to the Green River Bridge, Bowling Green - Owensboro Parkway, in Butler County. The exact locations of the boreholes from which samples were taken and the settlement-monitoring instrumentation are shown in Figure 20. The 60-foot (18.3-m) high north approach embankment was constructed in December 1970 and was instrumented at that time with mercury-filled settlement gages (12) such that settlement of the foundation soils could be monitored. Settlement instrumentation and results are discussed in detail in the section entitled "SETTLEMENT ANALYSIS". Undisturbed samples were taken in September 1973. These samples were taken at a location where they would not have been compressed by the embankment load, and thus it must be assumed that they were representative of the foundation soils beneath the monitoring site.

The Green River Valley is a significant feature of the Western Coal Field Region. This wide valley was formed in weak shales of the area and has been filled with alluvial material to depths of 175 feet $(53 \mathrm{~m})$. "Alluviation by glacial waters has been regarded as an important cause of the valley filling. The Ohio River and other major streams serving the glacier-occupied region northward were built-up by valley trains deposited by glacial flood waters. Ponding of tributaries from the south by aggrading of the river valleys added to backwater from the flooded rivers and resulted in their alluviation." (13) 


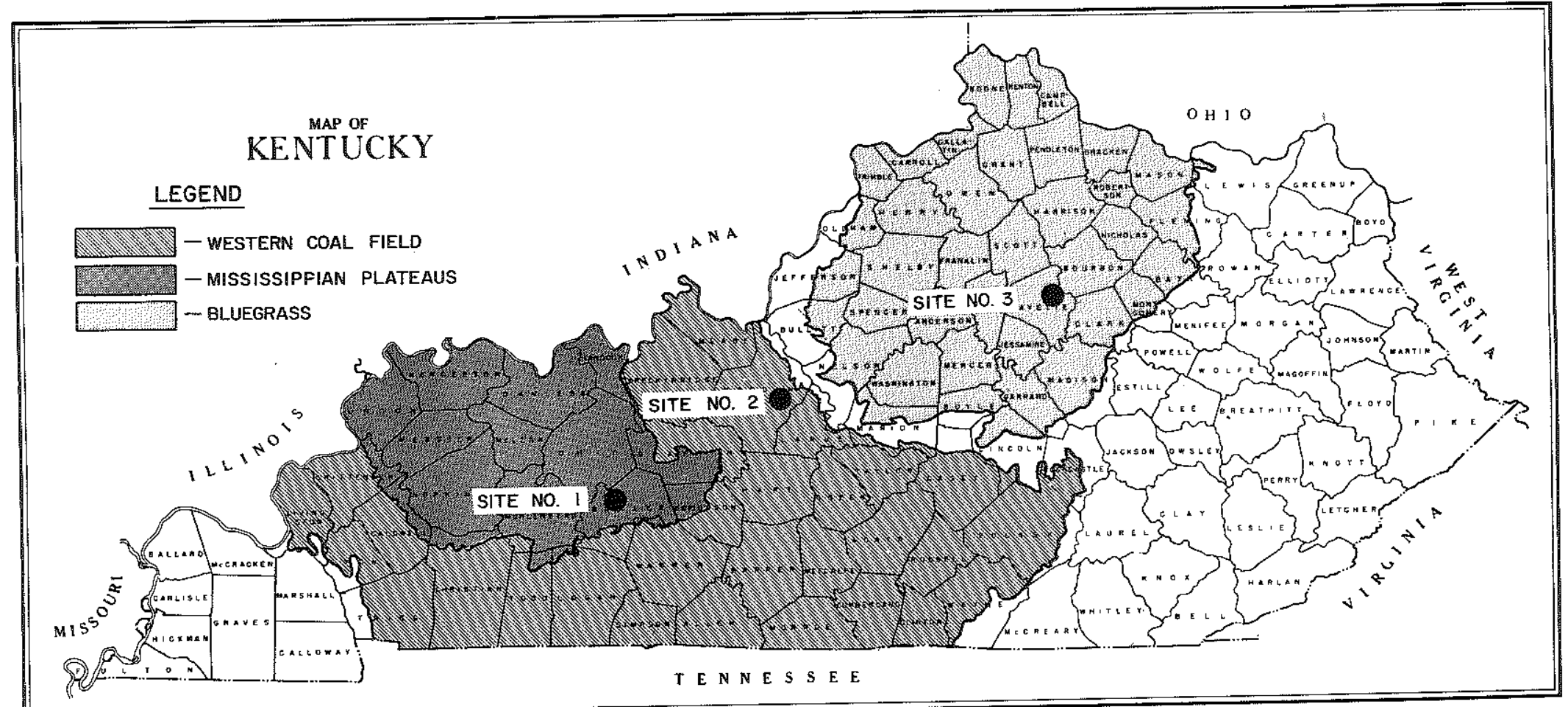

Figure 19. Sampling Sites. 


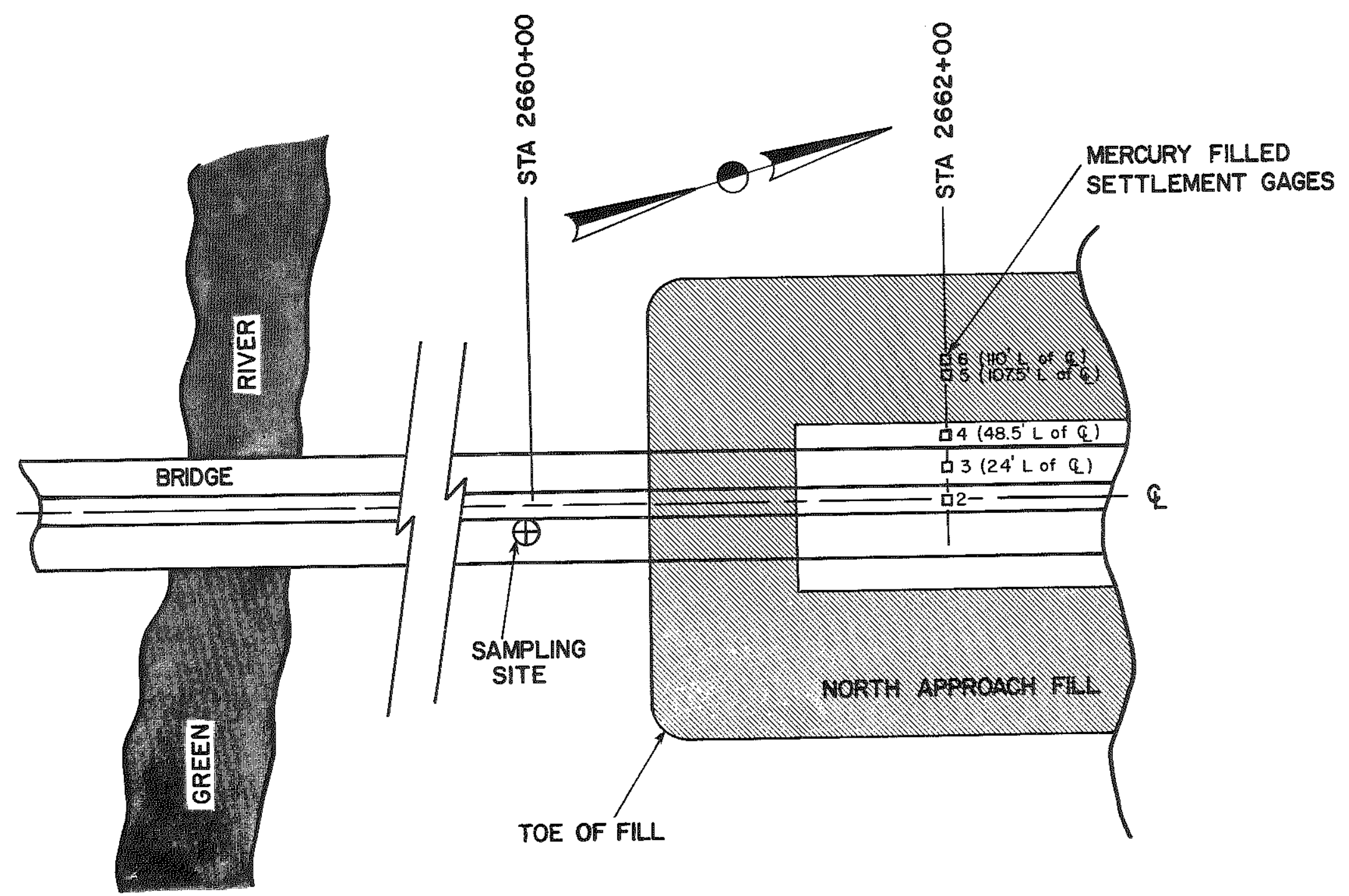

Figure 20. Site Number One, Bowling Green - Owensboro Parkway, Green River Bridge. 
The foundation soil profile at Site Number One consisted of a thick sand layer overlain by approximately 30 feet $(9 \mathrm{~m})$ of silt-clay material. The clay content of the silt-clay layer decreased with depth whereas the sand content increased. All consolidation settlement was assumed to occur in this layer because the underlying sand was freely draining. Index properties of the samples taken at Site Number One are shown in Table 1.

\section{Site Number Two}

Site Number Two is in the Mississippian Plateaus Region, near Station $8525+00$ of the Western Kentucky Parkway, in Elizabethtown (Hardin County), Kentucky. Samples were taken of the undisturbed natural soil profile at this site in October 1973.

The Mississippian Plateaus Region is characterized by a deep residual soil profile weathered from cherty Mississippian limestones of the area. The level-to-rolling terrain and lack of surface drainage contribute to the weathering process. Many soils are red in color and contain large amounts of nontronite, an iron-rich montmorillonitic clay.

The soil profile at the sampling site was approximately 40 feet $(12 \mathrm{~m})$ thick and ranged from a firm sandy clay at the surface to a soft clay at the bottom. Index properties of Site Number Two soils are given in Table 1.

\section{Site Number Three}

Site Number Three is in the Bluegrass Region, approximately 1.5 miles $(2.4 \mathrm{~km})$ south of the Fayette-Bourbon County line on US 27. Samples of the undisturbed natural soil profile at this site were taken in June 1974.

Like the soils of the Mississippian Plateaus Region, the Bluegrass Region soils are residual. However, they are weathered from the Lexington and Cynthiana Limestones producing a brown, phosphate-rich soil. The soil profile is usually well drained internally, due to joints and cracks in the limestone, creating a fragmentary structure.

A uniform soil profile approximately 8 feet $(2 \mathrm{~m})$ thick, consisting of firm, brown silty clay was found at the site. Index properties are shown in Table 1. 
TABLE 1. INDEX PROPERTIES OF SOILS

\begin{tabular}{|c|c|c|c|c|c|c|c|c|c|c|}
\hline \multirow[b]{2}{*}{$\begin{array}{l}\text { DEPTH } \\
\text { (FEET) }\end{array}$} & \multirow[b]{2}{*}{$\begin{array}{c}\text { DEPTH } \\
\text { (METERS) }\end{array}$} & \multirow[b]{2}{*}{$\begin{array}{l}\text { SAMPLE } \\
\text { NUMBER }\end{array}$} & \multirow[b]{2}{*}{$\begin{array}{l}\text { LIQUID } \\
\text { LIMET }\end{array}$} & \multirow[b]{2}{*}{$\begin{array}{l}\text { PLASTICITY } \\
\text { INDEX }\end{array}$} & \multirow{2}{*}{$\begin{array}{l}\text { NATURAL } \\
\text { MOISTURE } \\
\text { CONTENT } \\
(\%)\end{array}$} & \multicolumn{2}{|c|}{ CLASSIFICATION } & \multicolumn{3}{|c|}{ GRADATHON (\%) } \\
\hline & & & & & & UNIFIED & AASHTO & SAND & SILT & CLAY \\
\hline \multicolumn{11}{|c|}{ SITE NUMBER ONE } \\
\hline $5 \cdot 7$ & $1.5-2.1$ & 1 & 32 & 11 & 13 & $\mathrm{CL}$ & A. 6 & 25 & 45 & 30 \\
\hline $9-11.5$ & $2.7-3.5$ & 2 & 28 & 6 & 26 & ML-CL & $A-4$ & 11 & 54 & 35 \\
\hline $14 \cdot 16.5$ & $4.3-5.0$ & 3 & 31 & 9 & 22 & ML-CL & $\mathrm{A}-4$ & 13 & 54 & 33 \\
\hline $20-22.5$ & $6.1 \cdot 6.9$ & 4 & 27 & 1 & 22 & $\mathrm{ML}$ & A-4 & 19 & 55 & 26 \\
\hline $25-26.5$ & $7.6-8.1$ & 5 & 27 & 1 & 23 & $\mathrm{ML}$ & $\mathrm{A}-4$ & 24 & 54 & 22 \\
\hline $30-31.5$ & $9.1-9.6$ & 6 & NP & $\mathrm{N} 2$ & 23 & SM & $A-4$ & 64 & 23 & 13 \\
\hline \multicolumn{11}{|c|}{ SITE NUMBER TWO } \\
\hline $5-7.5$ & $1.5-2.3$ & 1 & 47 & 24 & 21 & $\mathrm{CL}$ & A-7-6 & 44 & 12 & 44 \\
\hline $10-12.5$ & $3.0-3.8$ & 2 & 54 & 35 & 25 & $\mathrm{CH}$ & A-7-6 & 32 & 12 & 56 \\
\hline $15-17.5$ & $4.6-5.3$ & 3 & 54 & 28 & 25 & $\mathrm{CH}$ & $A \cdot 7-6$ & 32 & 14 & 54. \\
\hline $20 \cdot 22.5$ & $6.1-6.9$ & 4 & 48 & 33 & 27 & CL & A-7.6 & 28 & 24 & 48 \\
\hline $25 \cdot 27.5$ & $7.6 \cdot 8.4$ & 5 & 62 & 17 & 32 & $\mathrm{MH}$ & A-7-5 & 10 & 26 & 64 \\
\hline $30-32.5$ & $9.1 \cdot 9.9$ & 6 & 26 & 13 & 27 & CL & $A-6$ & 44 & 29 & 27 \\
\hline $35-37.5$ & $10.7-11.4$ & 7 & 84 & 36 & 48 & MH & $A \cdot 7-5$ & 0 & 18 & 82 \\
\hline \multicolumn{11}{|c|}{ SITE NUMBER THREE } \\
\hline $0.5-3$ & $0.2-0.9$ & 1 & 42 & 14 & 24 & $\mathrm{ML}$ & A-7-6 & 20 & 35 & 45 \\
\hline $3 \cdot 5.5$ & $0.9-1.7$ & 2 & 41 & 11 & 25 & ML & A-7.5 & 20 & 32 & 48 \\
\hline $5.5-8$ & $1.7-2.4$ & 3 & 50 & 14 & 29 & ML & A-7-5 & 12 & 32 & 56 \\
\hline
\end{tabular}




\section{TEST RESULTS}

Undisturbed, 2 1/2-foot $(0.76-\mathrm{m})$ long, $27 / 8$-inch (73-mm) diameter. thin-walled tube (Shelby tube) samples were taken on 5 -foot $(1.5-\mathrm{m})$ centers at Site Numbers One and Two and continuously at Site Number Three. The disturbed material in the tube was removed, and samples from the tubes were cut into 6-inch (152-mm) lengths, waxed, and labeled according to site number, borehole number, and sample number. For instance, Site No. 1, H-1, S-5, denotes Site Number One, Borehole Number Ore, and Sample Number Five.

STD tests, STD tests with back pressure, CG tests, and CRS tests were performed on these samples. The tests were numbered in three categories: STD, CG, and CRS. Data from several of the tests were not used because equipment or recording system malfunctioned; therefore, there are some gaps in the numbering system. Results of 22 STD tests without back pressure, 10 STD tests with back pressure, $15 \mathrm{CG}$ tests, and $14 \mathrm{CRS}$ tests are presented herein. To minimize effects of inhomogeneity, only test results from samples from the same tube were compared, except for Site Number Three where a uniform profile and close borehole spacing permitted comparison between sampling tubes. Five such comparisons were made for Site Number One, six for Site Number Two, and two for Site Number Three. Results of these comparisons are shown in the graphical form of $\epsilon$ versus $\sigma_{\mathrm{v}}{ }^{\prime}$ and $\mathrm{C}_{\mathrm{v}}$ versus $\sigma_{\mathrm{v}}{ }^{\prime}$ in Figures 21 through 32 .

In addition to the comparisons, plots of $\sigma_{\mathrm{v}}$ versus time from the CG tests and $\mathrm{u}_{\mathrm{b}}$ versus $\sigma_{\mathrm{v}}{ }^{\prime}$ from the CRS tests are also shown in Figures 21 through 32 . These plots can be used to determine $P_{\mathfrak{c}}$, as explained in the section entitled "BACKGROUND". The STD tests with back pressure are denoted by the letters $\mathrm{BP}$ in parentheses following the test number.

Readings taken in each test are indicated by individual points in Figure 21 only. This serves to demonstrate that $\mathrm{CG}$ and CRS tests produce well-defined curves, since continuous data may be obtained from these tests, while the number of data points in the STD test is limited to the number of load increments applied. Individual points are eliminated in the remaining plots for the sake of clarity. Values of $\mathrm{CR}, \mathrm{SR}$, and $\mathrm{P}_{\mathrm{C}}$ determined from these data by the 'Casagrande (10) and Schmertmann (11) procedures mentioned earlier are summarized for each comparison in Table 2.

Significant differences in the time required to complete the tests were noted. The average number of days required to complete each type of test is shown in Figure 33. The STD tests with back pressure required one less day to complete because the loading system was limited to 16 tsf (1.6 MPa). The STD tests without back pressure were loaded an additional 24-hour increment (32 tsf, (3.2 MPa)) and thus required 9 days to complete. The time required to complete a STD test with load increments is always the same; the time required to complete a CG or CRS test is variable. In the CG test, the time 

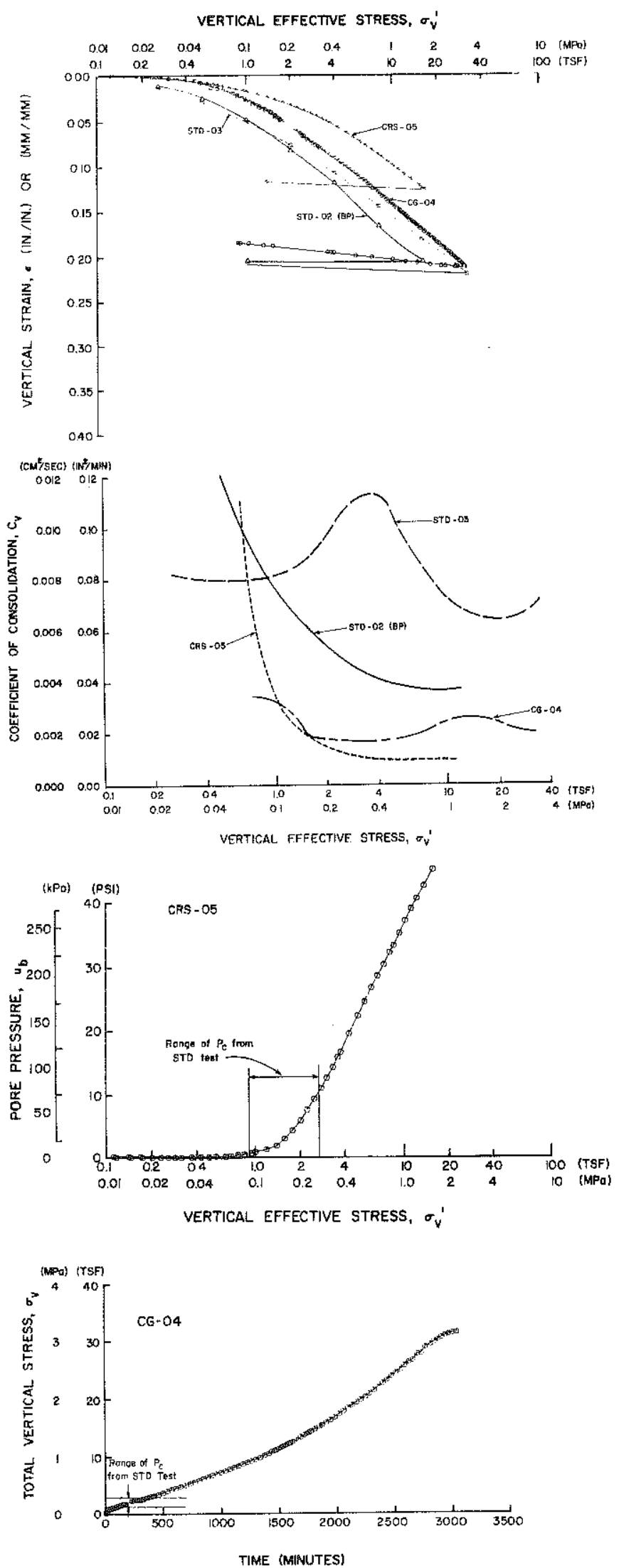

Figure 21. Comparison of STD, CG, and CRS Test Results; Site Number One, H-2, S-2. 

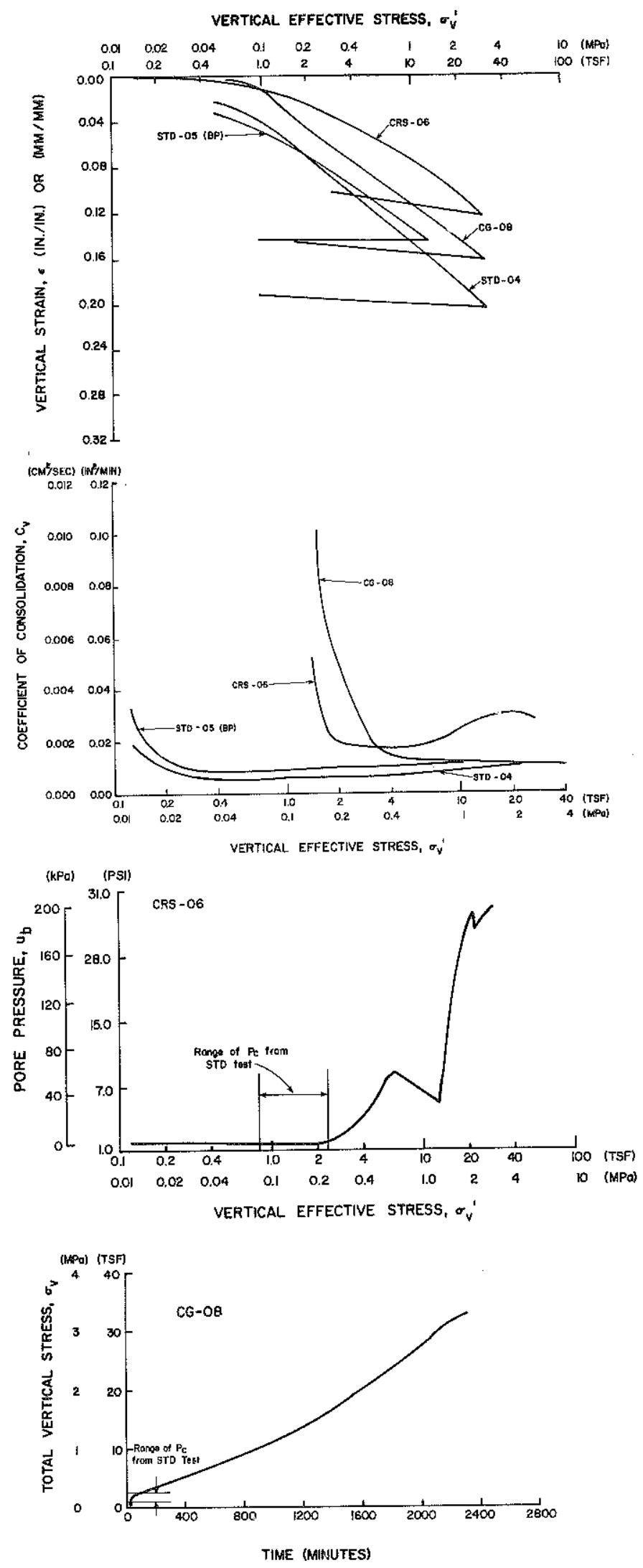

Figure 22. Comparison of STD, CG, and CRS Test Results; Site Number One, H-1, S-2. 

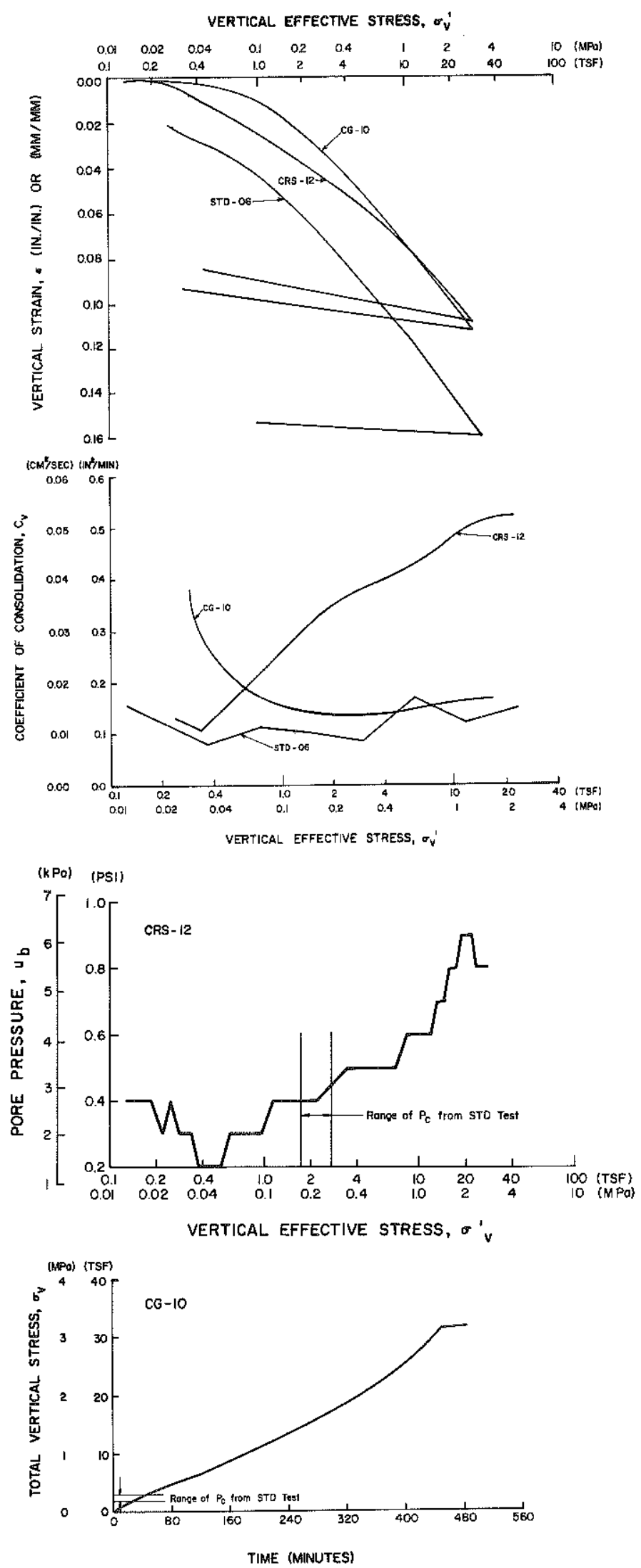

Figure 23. Comparison of STD, CG, and CRS Test Results; Site Number One, H-2, S-3. 

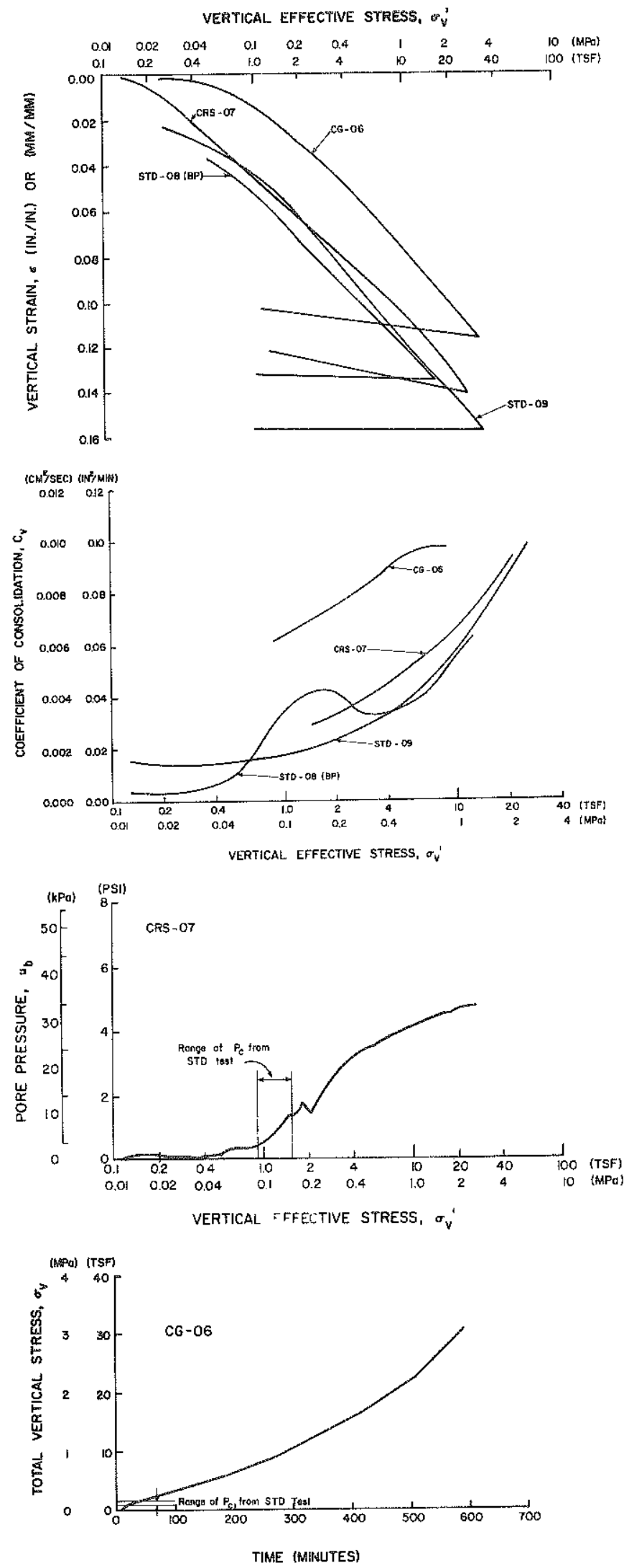

Figure 24. Comparison of STD, CG, and CRS Test Results; Site Number One, H-1, S-5. 

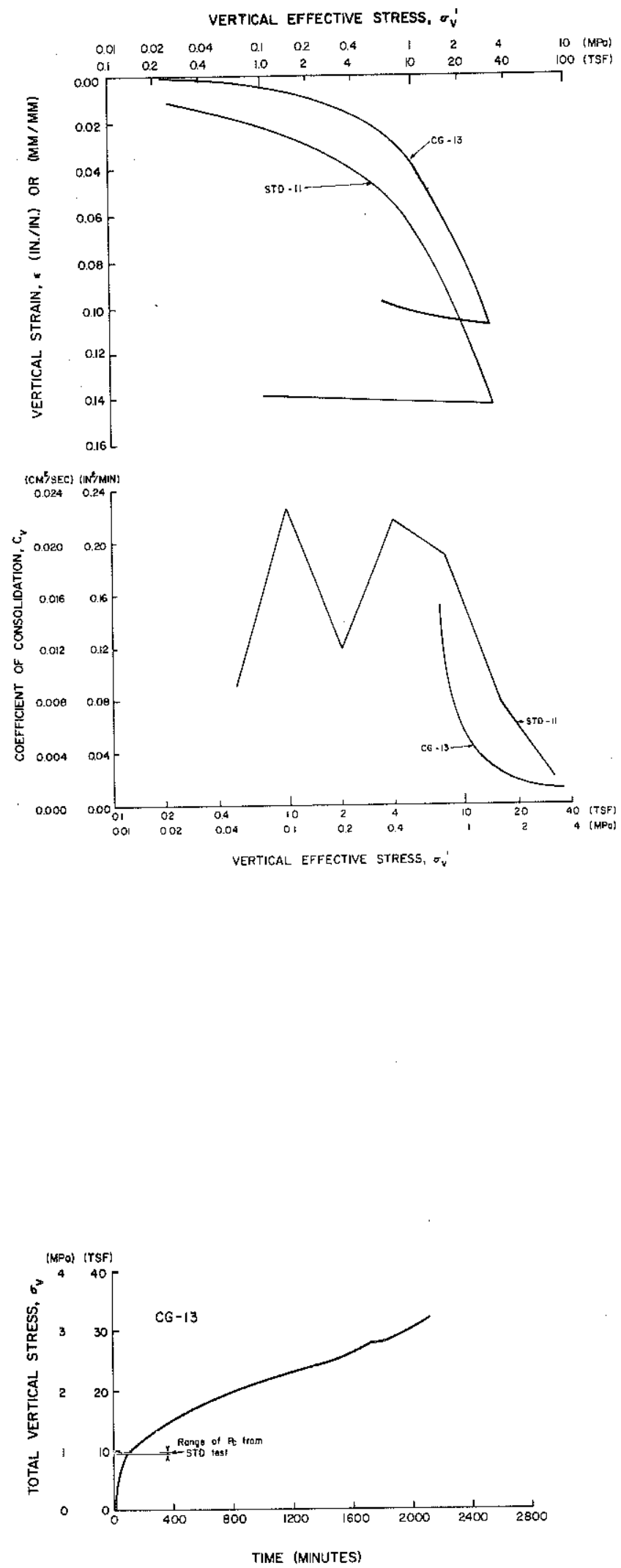

Figure 25. Comparison of STD and CG Test Results; Site Number Two, H-3, S-2. 

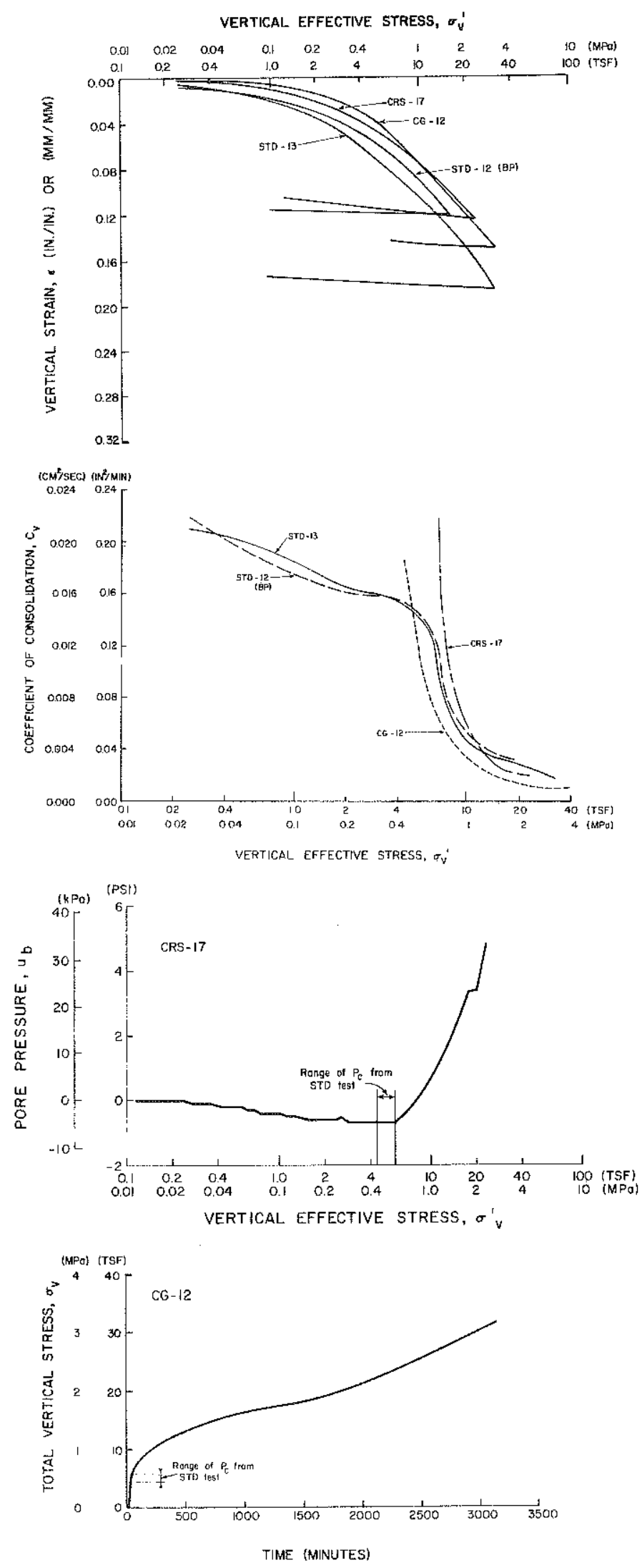

Figure 26. Comparison of STD, CG, and CRS Test Results; Site Number Two, H-3, S-4. 

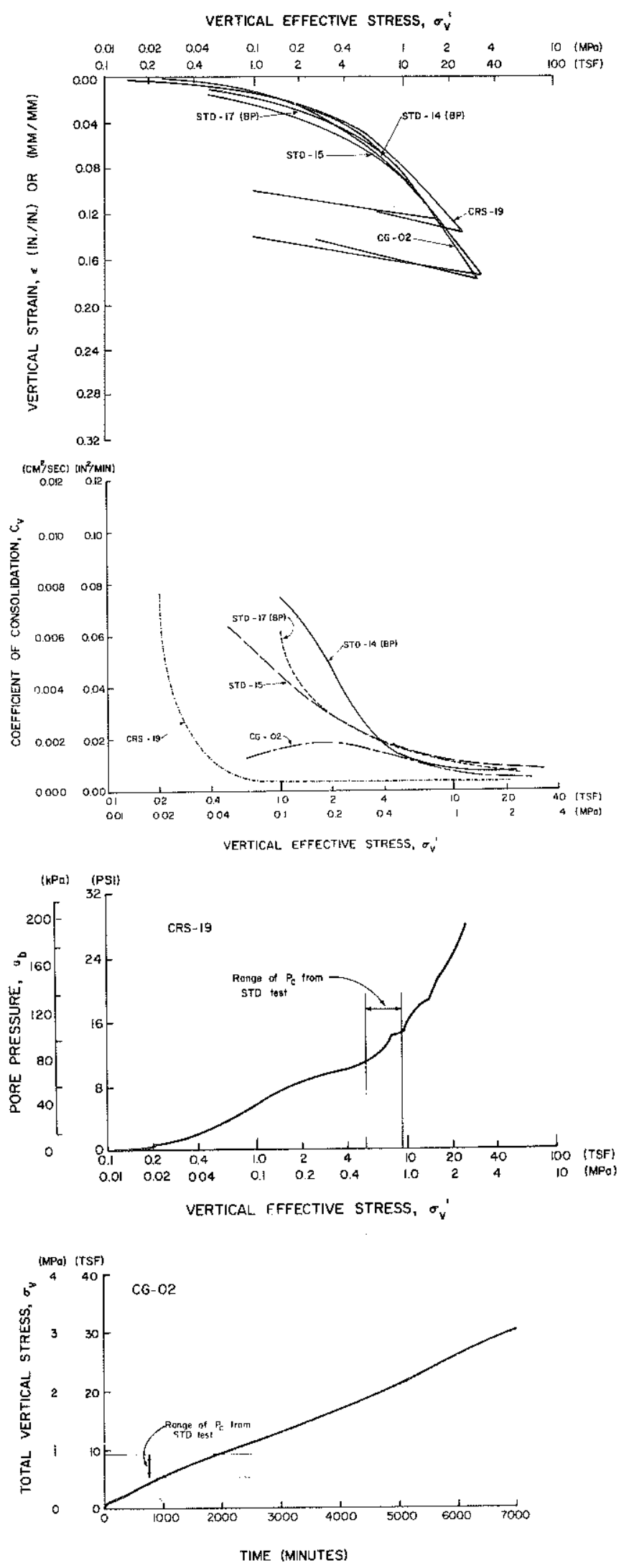

Figure 27. Comparison of STD, CG, and CRS Test Results; Site Number Two, H-3, S-5. 
46
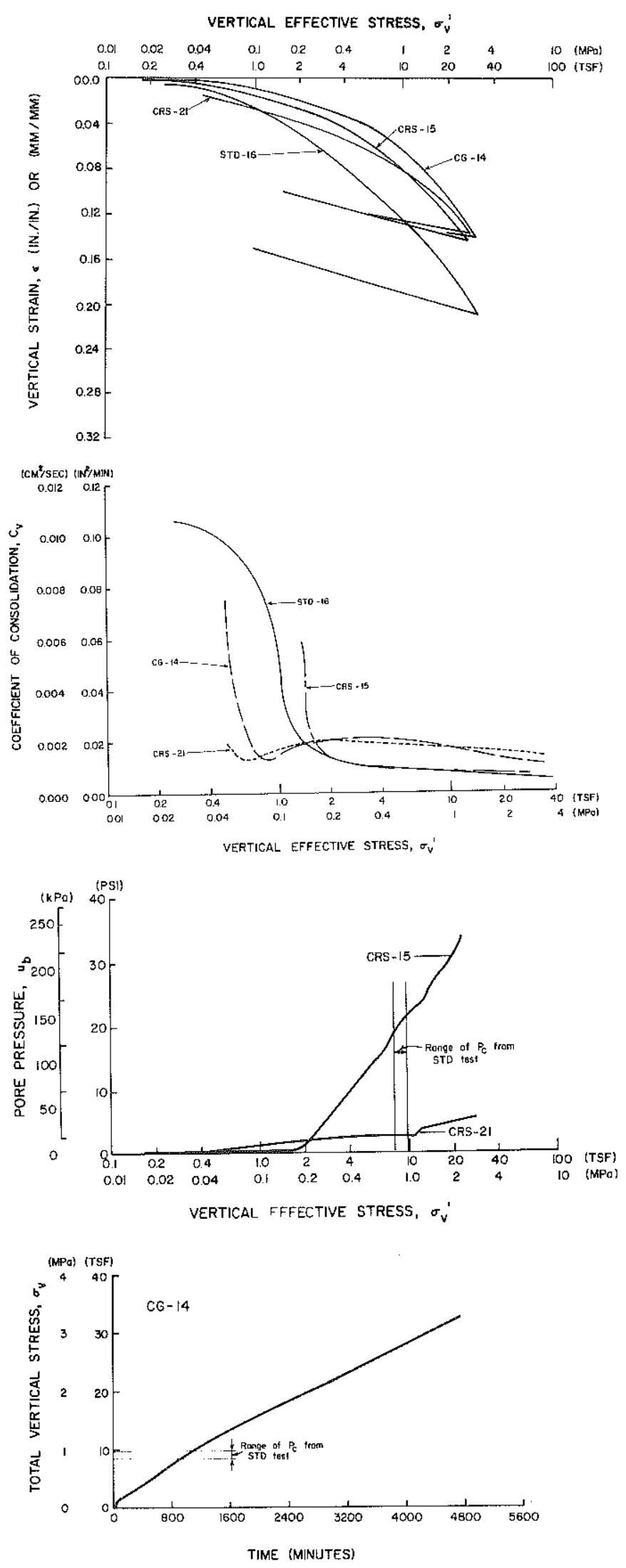

Figure 28. Comparison of STD, CG, and CRS Test Results; Site Number Two, H-2, S-5. 

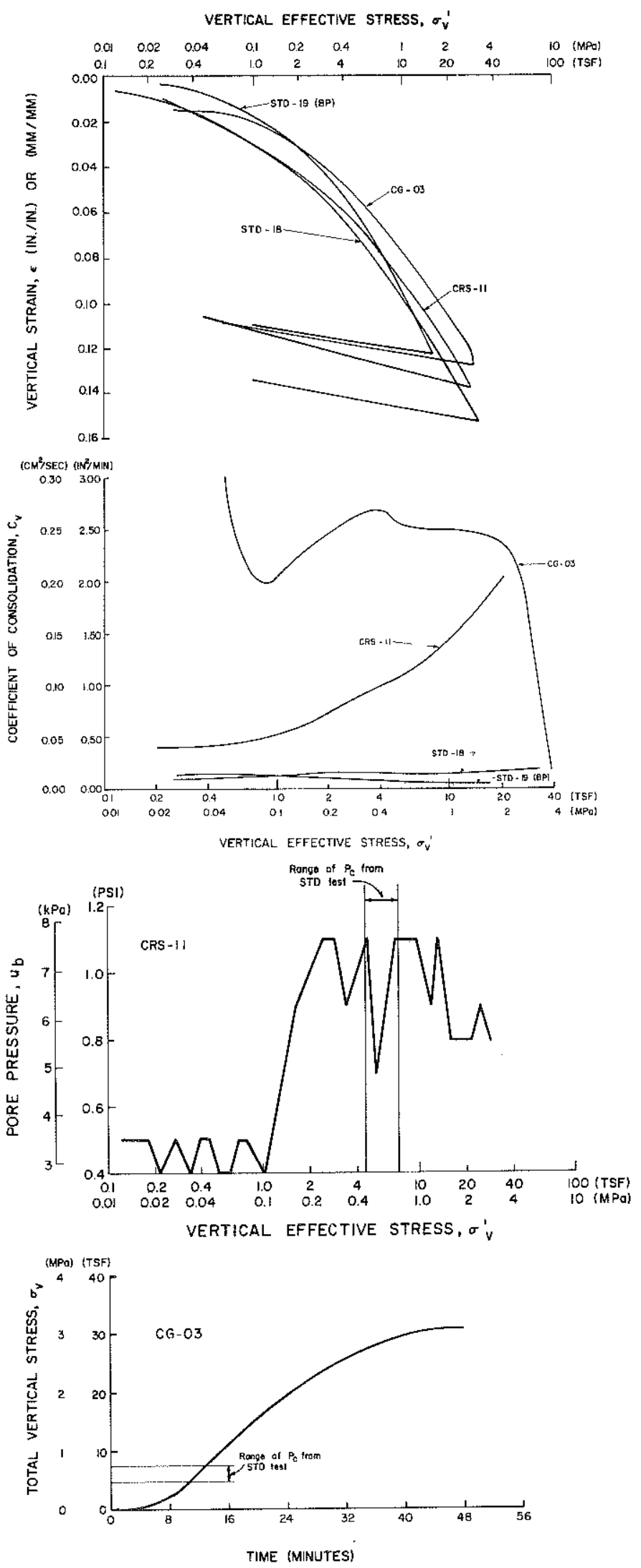

Figure 29. Comparison of STD, CG, and CRS Test Results; Site Number Two, H-3, S-6. 

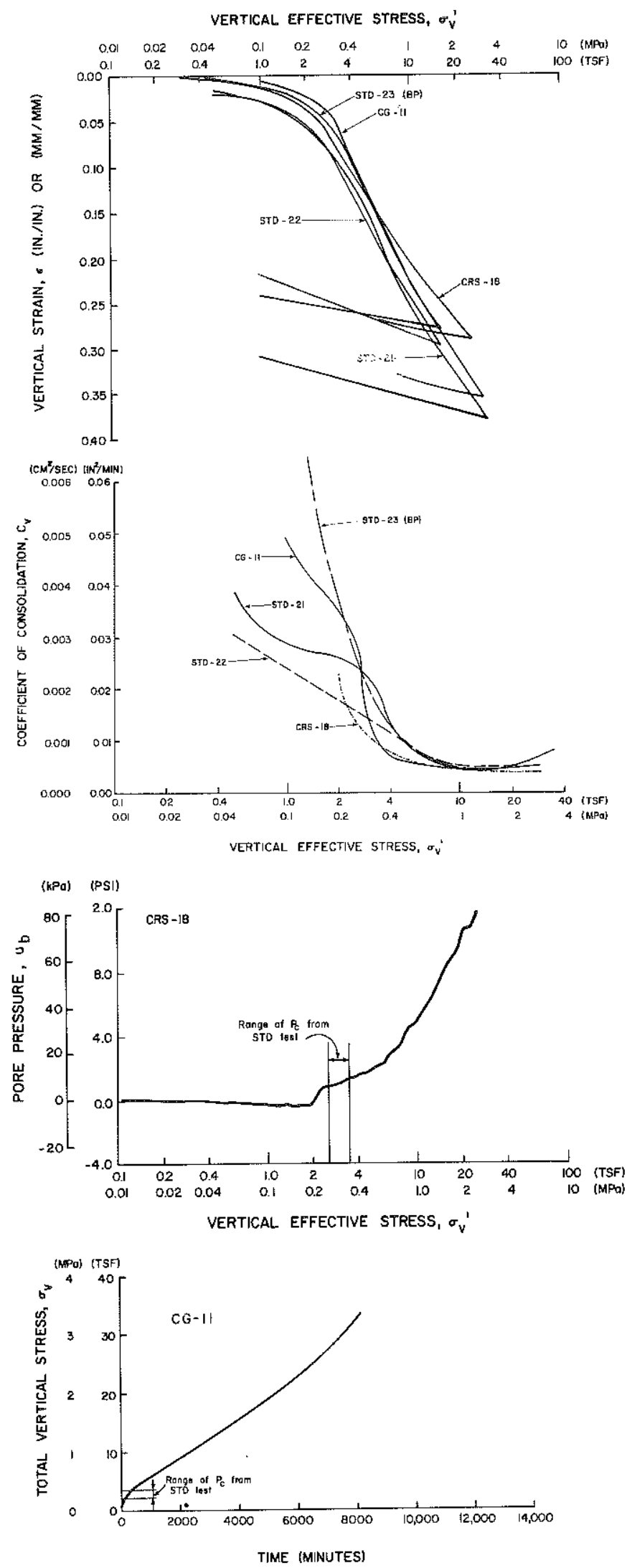

Figure 30. Comparison of STD, CG, and CRS Test Results; Site Number Two, H-3, S-7. 

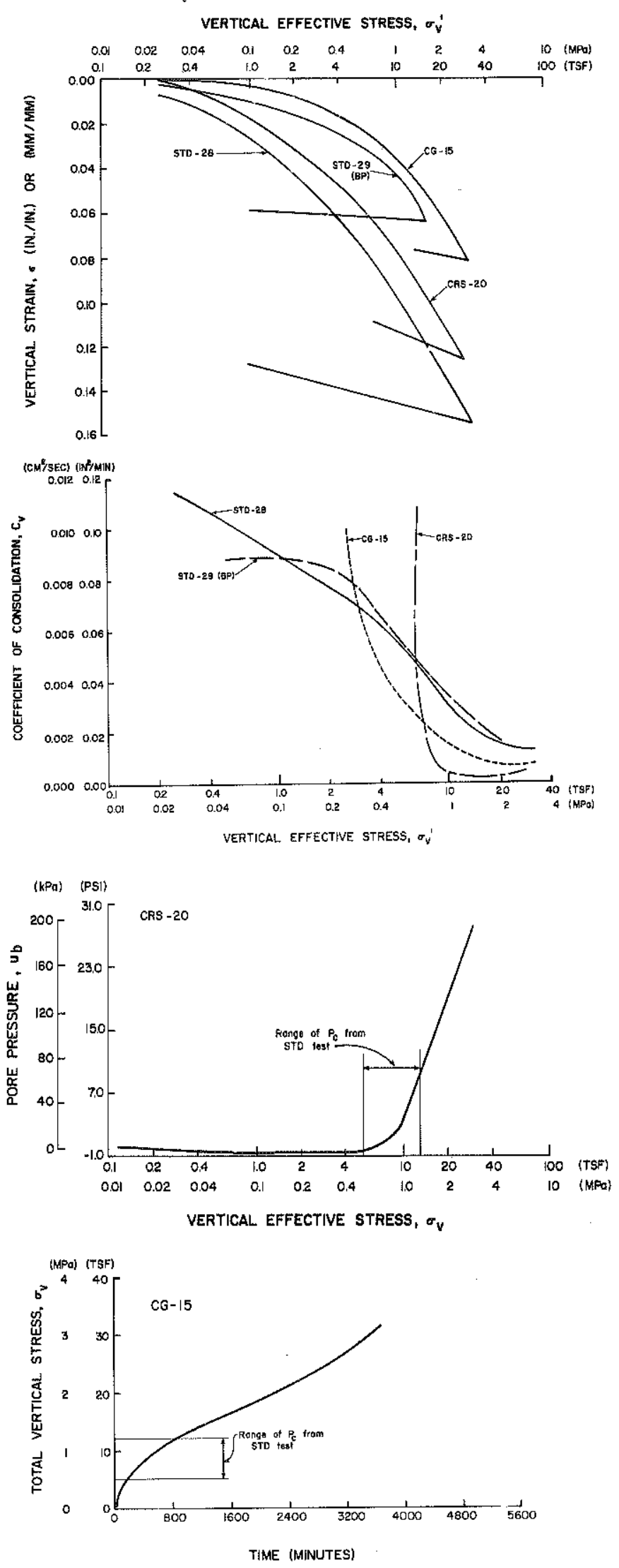

Figure 31. Comparison of STD, CG, and CRS Test Results; Site Number Three, H-2 \& 3, S-3. 

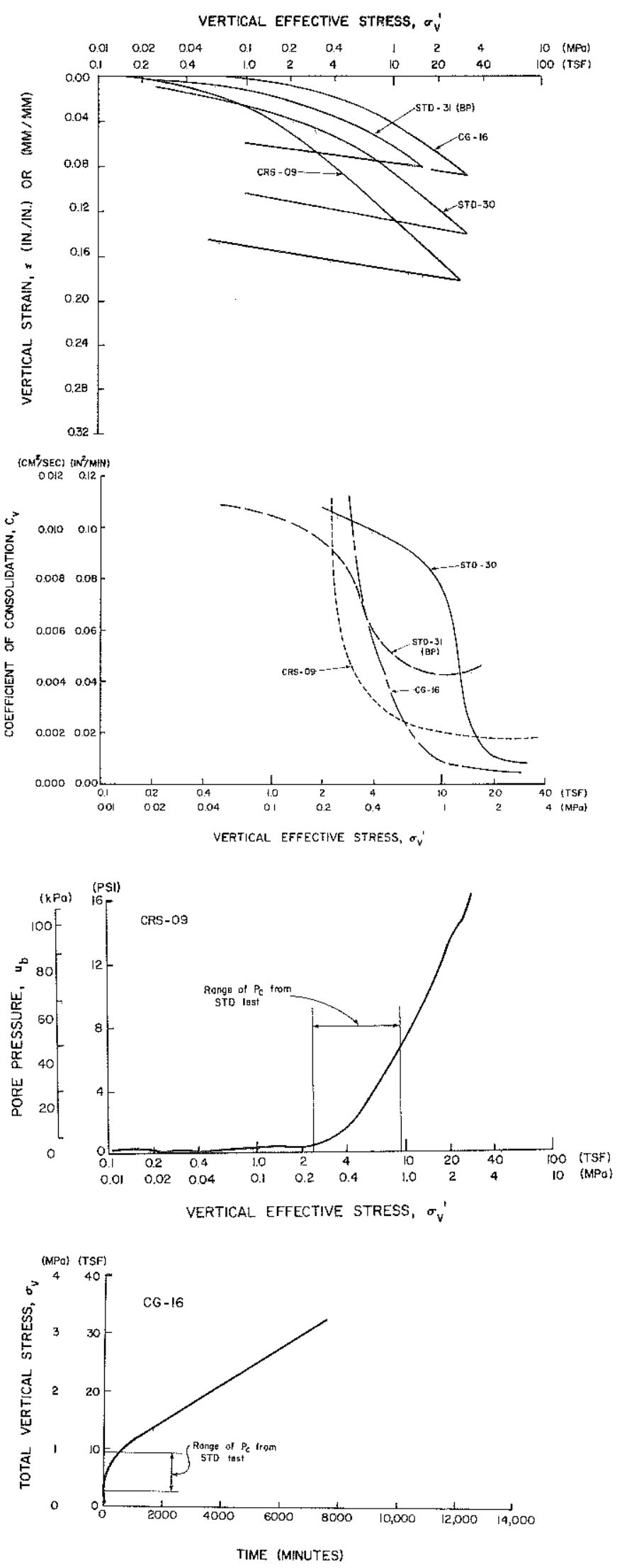

Figure 32. Comparison of STD, CG, and CRS Test Results; Site Number Three, H-2 \& 3, S-3. 


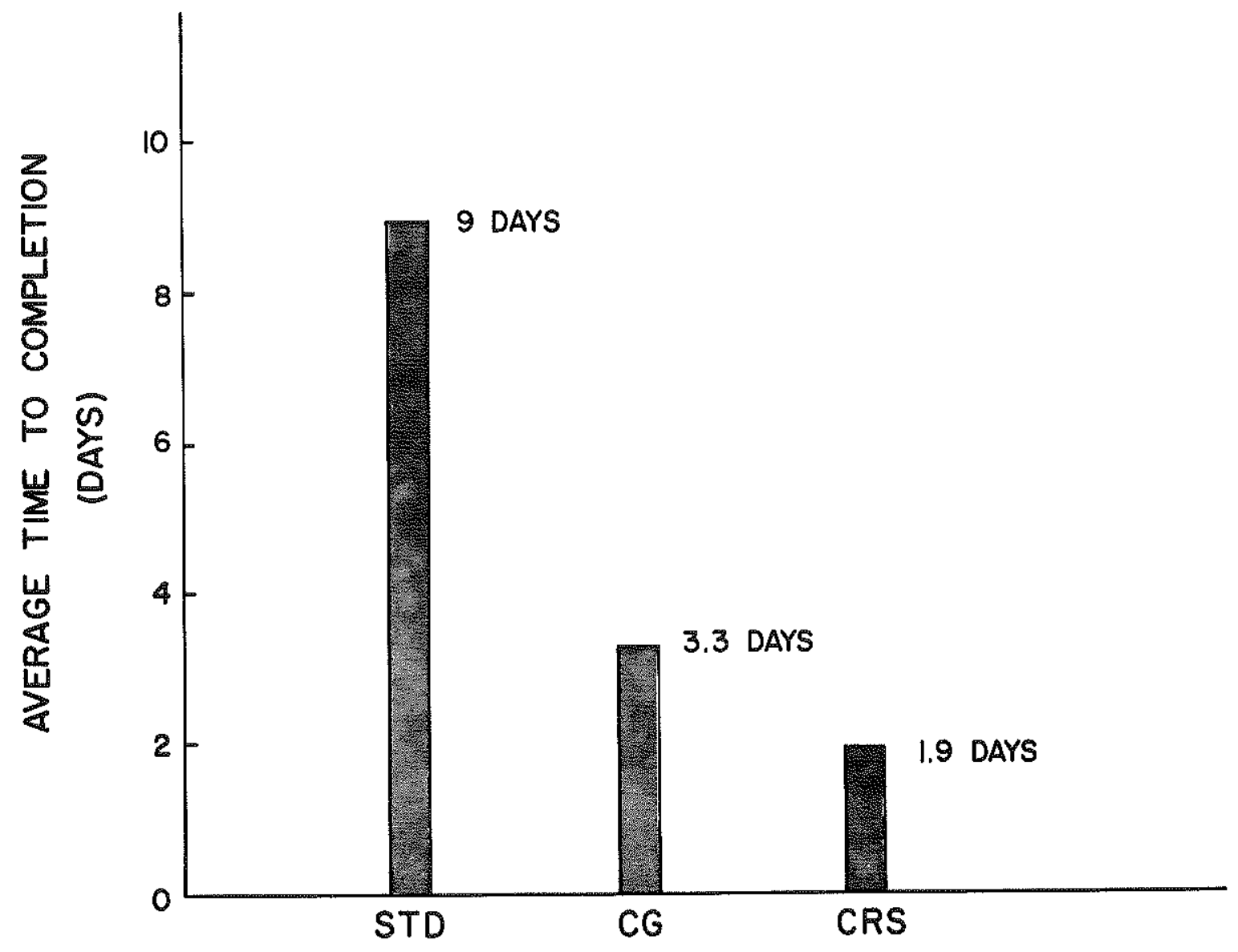

Figure 33. Average Time Required To Complete STD, CG, and CRS Tests. 
TABLE 2. COMPARISON OF STD, CG, and CRS TEST RESULTS

\begin{tabular}{|c|c|c|c|c|c|c|c|}
\hline \multicolumn{8}{|c|}{ SITE NUMBER ONE } \\
\hline \multirow{5}{*}{$\mathrm{H} \cdot 2, \mathrm{~S} \cdot 2$} & \multirow{2}{*}{\multicolumn{2}{|c|}{$\mathrm{CR}$}} & \multirow{2}{*}{$\begin{array}{l}\text { STD-02* } \\
0.138\end{array}$} & \multirow{2}{*}{$\begin{array}{l}\text { STD } 03 \\
0.112\end{array}$} & \multirow{2}{*}{$\begin{array}{l}\text { CG.04 } \\
0.129\end{array}$} & \multicolumn{2}{|l|}{ CRS-05 } \\
\hline & & & & & & 0.112 & \\
\hline & SR & & 0.001 & 0.006 & 0.013 & 0.007 & \\
\hline & $P_{c}$ & (tsf) & 0.945 & 0.910 & 1.83 & 2.84 & \\
\hline & & (kPa) & 90.5 & 87.1 & 175 & 272 & \\
\hline \multirow{5}{*}{$\mathrm{H} \cdot \mathrm{I}, \mathrm{S}-2$} & & & STD-04 & STD.05* & CG-08 & CRS.06 & \\
\hline & $\mathrm{CR}$ & & 0.122 & 0.102 & 0.107 & 0.087 & \\
\hline & SR & & 0.007 & 0.001 & 0.012 & 0.019 & \\
\hline & & (tsf) & 0.881 & 0.840 & 0.997 & 2.33 & \\
\hline & & $(\mathrm{kPa})$ & 84.4 & 80.4 & 95.5 & 223 & \\
\hline \multirow{5}{*}{$\mathrm{H}-2, \mathrm{~S}-3$} & & & STD-06 & $C G=10$ & CRS-12 & & \\
\hline & $\mathrm{CR}$ & & 0.112 & 0.092 & 0.085 & & \\
\hline & SR & & 0.004 & 0,009 & 0.013 & & \\
\hline & $P_{c}$ & $(\mathrm{tsf})$ & 1.18 & 2.00 & 2.86 & & \\
\hline & & $(\mathrm{kPa})$ & 173 & 192 & 2.74 & & \\
\hline \multirow{5}{*}{$\mathrm{H}-1, \mathrm{~S}-5$} & & & STD.08* & STD-09 & CG -06 & CRS-07 & \\
\hline & $\mathrm{CR}$ & & 0.088 & 0.115 & 0.085 & 0.093 & \\
\hline & $\mathrm{SR}$ & & 0.002 & 0.001 & 0.009 & 0.015 & \\
\hline & & (tsf) & 0.878 & 1.55 & 1.49 & 1.26 & \\
\hline & & $(\mathrm{kPa})$ & 841 & 148 & 143 & 121 & \\
\hline \multicolumn{8}{|c|}{ SITE NUMBER TWO } \\
\hline \multirow{4}{*}{$\mathrm{H}-3, \mathrm{~S}-2$} & $\mathrm{CR}$ & & $\begin{array}{l}\text { STD-11 } \\
0.219\end{array}$ & $\begin{array}{l}\text { CG-13 } \\
0.163\end{array}$ & & & \\
\hline & SR & & 0.003 & $0.01 \%$ & & & \\
\hline & $P_{c}$ & (tsf) & 9.59 & 9.76 & & & \\
\hline & & $(\mathrm{kPa})$ & 918 & 935 & & & \\
\hline \multirow{5}{*}{$\mathrm{H}-3, \mathrm{~S}-4$} & & & STD-12* & STD-13 & CG.12 & CRS-17 & \\
\hline & CR & & 0.171 & 0.223 & 0.175 & 0.154 & \\
\hline & $\mathrm{SR}$ & & 0.006 & 0,009 & 0.015 & 0.018 & \\
\hline & $P_{c}$ & $(\mathrm{tsf})$ & 4.37 & 5.77 & 5.88 & 5.49 & \\
\hline & & $(\mathrm{kPa})$ & 418 & 553 & 563 & 526 & \\
\hline \multirow{5}{*}{$\mathrm{H} \cdot 3, \mathrm{~S} \cdot 5$} & & & STD-14* & STD-15 & STD. $17^{*}$ & CG. 02 & CRS-19 \\
\hline & $C R$ & & 0.201 & 0.241 & 0.184 & 0.210 & 0.148 \\
\hline & SR & & 0.021 & 0.023 & & 0.039 & 0,036 \\
\hline & $\mathrm{P}_{\mathrm{c}}$ & $(\mathrm{ts})$ & 5.25 & 9.12 & 5.48 & 6.73 & 5.15 \\
\hline & & $(\mathrm{kPa})$ & 503 & 874 & 525 & 644 & 493 \\
\hline & & & STD-16 & $\mathrm{CG} \cdot 14$ & CRS-15 & CRS-21 & \\
\hline $\mathrm{H}-2, \mathrm{~S}-5$ & $\mathrm{CR}$ & & 0.279 & 0.207 & 0.179 & 0.169 & \\
\hline & SR & & 0.039 & 0.020 & 0.036 & 0.025 & \\
\hline & $P_{c}$ & (tsi) & 8.56 & 9.81 & 8.11 & 8.38 & \\
\hline & & $(\mathrm{kPa})$ & 820 & 939 & 777 & 802 & \\
\hline & & & STD-18 & STD-19" & CG.03 & CRS-11 & \\
\hline $\mathrm{H}-3, \mathrm{~S}-6$ & CR & & 0.150 & 0.194 & 0.126 & 0.151 & \\
\hline & SR & & 0.012 & 0.011 & 0.012 & 0.017 & \\
\hline & $P_{c}$ & $(\mathrm{ts} S)$ & 4.43 & 7.24 & 5.26 & 6.11 & \\
\hline & & $(\mathrm{kPa})$ & 424 & 693 & 504 & 585 & \\
\hline & & & STD.21 & STD-22 & STD $23^{*}$ & CG.11 & CRS-18 \\
\hline $\mathrm{H} \cdot 3, \mathrm{~S} \cdot 7$ & $\mathrm{CR}$ & & 0.435 & 0.381 & 0.446 & 0.392 & 0.308 \\
\hline & SR & & 0.048 & & 0,032 & 0.043 & 0.044 \\
\hline & $P_{c}$ & (tsf) & 3.17 & 2.61 & 3.40 & 2.92 & 2.36 \\
\hline & & $(\mathrm{kPa})$ & 304 & 250 & 326 & 280 & 226 \\
\hline SITE NUMBE & THRE & & & & & & \\
\hline & & & STD-28 & STD.29* & CG.15 & CRS.20 & \\
\hline$H \cdot 2 \& 3, S-2$ & $\mathrm{CR}$ & & 0.147 & 0.113 & 0.118 & 0.133 & \\
\hline & SR & & 0.018 & 0.004 & 0.013 & 0.028 & \\
\hline & $P_{c}$ & $(\mathrm{ts})$ & 5.15 & 6.13 & 12.1 & 7.04 & \\
\hline & & $(\mathrm{kPa})$ & 493 & 587 & 1159 & 674 & \\
\hline & & & STD-30 & STD-31* & GC-16 & CRS-09 & \\
\hline $\mathrm{H}-2 \& 3, \mathrm{~S}-3$ & $\mathrm{CR}$ & & 0.131 & 0.095 & 0.108 & 0.137 & \\
\hline & SR & & 0.024 & 0.017 & 0.019 & 0.021 & \\
\hline & $P_{c}$ & $(\mathrm{ts})$ & 5.95 & 4.33 & 9.07 & 2.22 & \\
\hline & & $(\mathrm{kPa})$ & 570 & 415 & 869 & 213 & \\
\hline
\end{tabular}

*Back Pressured 


\section{RECOMMENDATIONS}

1. CRS consolidation test equipment for routine testing should be designed. This equipment should also be able to apply constant loads to the specimen so that secondary consolidation properties may be determined.

2. A standard testing procedure, which includes methods for strain-rate selection, should be written.

3. Techniques for determining $\mathrm{C}_{\mathrm{v}}$ in the early stages of the $\mathrm{CG}$ and CRS tests should be developed. One possible technique would be to establish an initial pore-pressure gradient prior to loading the specimen.

4. Until further investigation into the selection of strain rate in the CRS test is conducted, the following guidelines may be used:

If the liquid limit of the soil to be tested is greater than 60 , use a strain rate of $50 \times 10^{-4}$ percent/minute.

If the liquid limit of the soil to be tested is less than 60 , use a strain rate of $100 \times 10^{-4}$ percent/minute.

5. A decision as to whether or not to use CRS consolidation testing in a particular operation should be based on the time and manpower savings which will result from CRS testing, the initial cost of equipment and data-acquisition system, and the quality of data obtained. 


\section{REFERENCES}

1. Hamilton, J. J. and Crawford, C. B., Improved Determination of Preconsolidation Pressure of a Sensitive Clay, Special Technical Publication No. 254, ASTM, Philadelphia, 1959.

2. Lowe, III, J., Zaccheo, P. F., and Feldman, H. S., Consolidation Testing with Back Pressure, Journal of the Soil Mechanics and Foundations Division, ASCE, Vol 90, No. SM5, September 1964.

3. Crawford, C. B., Interpretation of the Consolidation Test, Journal of the Soil Mechanics and Foundations Division, ASCE, Vol 90, No. SM5, September 1964.

4. Smith, R. E. and Wahis, H. E., Consolidation Under Constant Rates of Strain Iournal of the Soil Mechanics and Foundations Division, ASCE, Vol 95, No. SM2, March 1969.

5. Wissa, A.E.Z., Christian, J. T., Davis, E. H., and Heiberg, S., Consolidation at Constant Rate of Strain, Journal of the Soil Mechanics and Foundations Division, ASCE, Vol 97, No. SM10, October 1971

6. Lowe III, J., Jonas, E. and Obrician, V., Controlled Gradient Consolidation Test Journal of the Soil Mechanics and Foundations Division, ASCE, Vol 95, No. SM1, January 1969.

7. Sallfors, G., Preconsolidation Pressure of Soft, High Plastic Clays, Thesis presented to Chalmers University of Technology in partial fulfillment of the requirements for the degree of Doctor of Philosophy, October 1975.

8. Taylor, D. W., Research on Consolidation of Clays, Serial 82, Massachusetts Institute of Technology, Department of Civil and Sanitary Engineering, August 1942.

9. Casagrande, A. and Fadum, R. E., Notes on Soil Testing for Engineering Purposes, Harvard University, Graduate School of Engineering, Soil Mechanics Series No. 8, No. 268, 1939.

10. Casagrande, A., The Determination of the Preconsolidation Load and Its Practical Significance, Proceedings, International Conference on Soil Mechanics and Foundation Engineering, Vol III, 1936.

11. Schmertmann, J. H., The Undisturbed Consolidation Behavior of Clay, Transactions, ASCE, Vol 120, Paper No. $2775,1955$.

12. Hopkins, T. C., and Deen, R. C., Mercury-Filled Settlement Gage, Research Record 457, Highway Research Board, 1973.

13. McCann, W., Hopkins, T. C., and Deen, R. C., Engineering Geognosy of the Western Coal Field, Division of Research, Kentucky Depariment of Transportation, May 1973.

14. Terzaghi, K., and Peck, R. B., Soil Mechanics in Engineering Practice, John Wiley and Sons, 1967.

15. Schiffman, R. L., Whitman, R. V., and Jordan, J. C., Settlement Problem Oriented Computer Language, Journal of Soil Mechanics and Foundations Division, ASCE, Vol 96, No. SM2, March 1970. 


\section{NOTATION}

b $=$ constant relating void-ratio change with depth

$\mathrm{b} / \mathrm{r}=$ dimensionless void-ratio change parameter

$\mathrm{C}_{\mathrm{v}}=$ coefficient of consolidation

$\mathrm{CR}=$ compression ratio

$\mathrm{D}_{100}=$ deflection dial reading at 100 -percent consolidation

$\mathrm{e} \quad=$ void ratio

$\mathrm{H}=$ drainage-path length

$\mathrm{h}=$ pore-pressure head

$i=$ pore-pressure gradient

$\mathrm{k}=$ permeability

LL = liquid limit

$\mathrm{m}_{\mathrm{v}} \quad=$ coefficient of volume change

$\mathbf{P}_{\mathrm{c}} \quad=$ preconsolidation pressure

$r=$ rate of change of average void ratio

SR $\quad=$ swell ratio

$\mathrm{T}=$ time factor

$\mathrm{t}=$ time

$\mathrm{U}=$ degree of consolidation

$\mathrm{u} \quad=$ pore pressure

$\mathrm{u}_{\mathrm{avg}}=$ average pore pressure in specimen

$\mathrm{u}_{\mathrm{b}}=$ pore pressure at the base of specimen

$\mathrm{v} \quad=$ velocity

$\mathrm{z}=$ vertical distance from top of specimen

$a \quad=\quad u_{\mathrm{avg}} / \mathrm{u}_{\mathrm{b}}$

$\gamma=$ density

$\gamma_{\mathrm{W}} \quad=\quad$ unit weight of water

$\epsilon \quad=$ strain

$\epsilon_{\text {avg }}=$ average strain in specimen

$\sigma_{\mathrm{v}} \quad=\quad$ vertical stress

$\sigma_{\mathrm{v}}{ }^{\prime}=$ average vertical effective stress 
to completion depends on the value of the pore-pressure gradient selected and the compressibility and permeability of the soil being tested. CG tests reported herein required between 1 and 6 days to complete, with 3.3 days being the average time to completion. Time to completion in the CRS test depends on the selected strain rate and the compressibility and permeability of the soil being tested. CRS tests reported herein required between 1 and 4 days to complete, with 1.9 days being the average time to completion. 


\section{SETTLEMENT ANALYSIS}

Comparison of predictions, based on laboratory test results, with field behavior is an important step in determining the applicability of new laboratory methods. As in most cases in which laboratory results are applied to field conditions, the accuracy of predictions is influenced by two factors. The first factor is, of course, the quality of the laboratory results. The second is the extent to which the theory and assumptions used to apply the results represent field conditions. One-dimensional consolidation theory as proposed by Terzaghi (14) and discussed in the section entitled "THEORY" was used to estimate the magnitude and rate of settlement at Site Number One based on results from STD, CG, and CRS consolidation tests. It was assumed that pore water drained from both top and bottom of the consolidating layer (two-way drainage). Stress distributions throughout the consolidating layer were estimated by assuming the embankment loading was an infinite strip load (in the direction of the roadway centerline) resting on an elastic half-space. Since the same theory was used in applying all the test results, the relative values of predicted settlement and rate of settlement for the STD, CG, and CRS tests should serve as a basis for comparing the test procedures. The accuracy of the predictions, on the other hand, depends on theory, test results, and possible offsetting errors.

The dimensions and densities of the embankment and foundation are shown in cross-sectional view in Figure 34. The embankment consisted of a compacted clay-shale, 60 feet $(18 \mathrm{~m})$ high, with 2:1 side slopes. All consolidation settlement was assumed to occur in the 30-foot (9-m) thick top layer of the foundation soil. This layer was underlain by a free-draining sand layer approximately 40 feet $(12 \mathrm{~m})$ thick. Locations of the five settlement gages (numbered 2 through 6 ) are also shown in the figure. Settlement magnitudes were predicted at each of these points. Settlement rate was predicted only at the centerline (settlement point number 2).

The embankment was constructed over a period of 240 days. The actual construction rate is shown in Figure 35 as embankment height versus logarithm of time. The nonuniform construction rate was taken into account in the computation of settlement rate. ICES SEPOL (15), a computer program developed at the Massachusetts Institute of Technology, was used to compute all settlement rates. A constant value of $\mathrm{C}_{\mathrm{V}}$ was used for each set of test data. For instance, an "average" value of $\mathrm{C}_{\mathrm{V}}$ from CG test results was used to compute a CG-predicted settlement rate. This "average" value was determined by averaging $\mathrm{C}_{\mathrm{v}}$ values in the range of effective stresses to which the soil would be subjected in the field. As can be seen from the $\mathrm{C}_{\mathrm{v}}-\sigma_{\mathrm{v}}{ }^{\prime}$ curves in Figures 21 through 32, there was much variability in values of $\mathrm{C}_{\mathrm{V}}$; and estimates of average $\mathrm{C}_{\mathrm{V}}$ values should be considered approximate. In general, $\mathrm{C}_{\mathrm{v}}$ values from the CG and CRS tests were higher than those from the STD tests; this trend is reflected in the averages. The following values of $\mathrm{C}_{\mathrm{V}}$ were used in the settlement rate analysis: STD test, $\mathrm{C}_{\mathrm{v}}=0.016$ 
Figure 34. Site Number One - Embankment and Foundation Cross Section at Settlement-Monitoring Site.
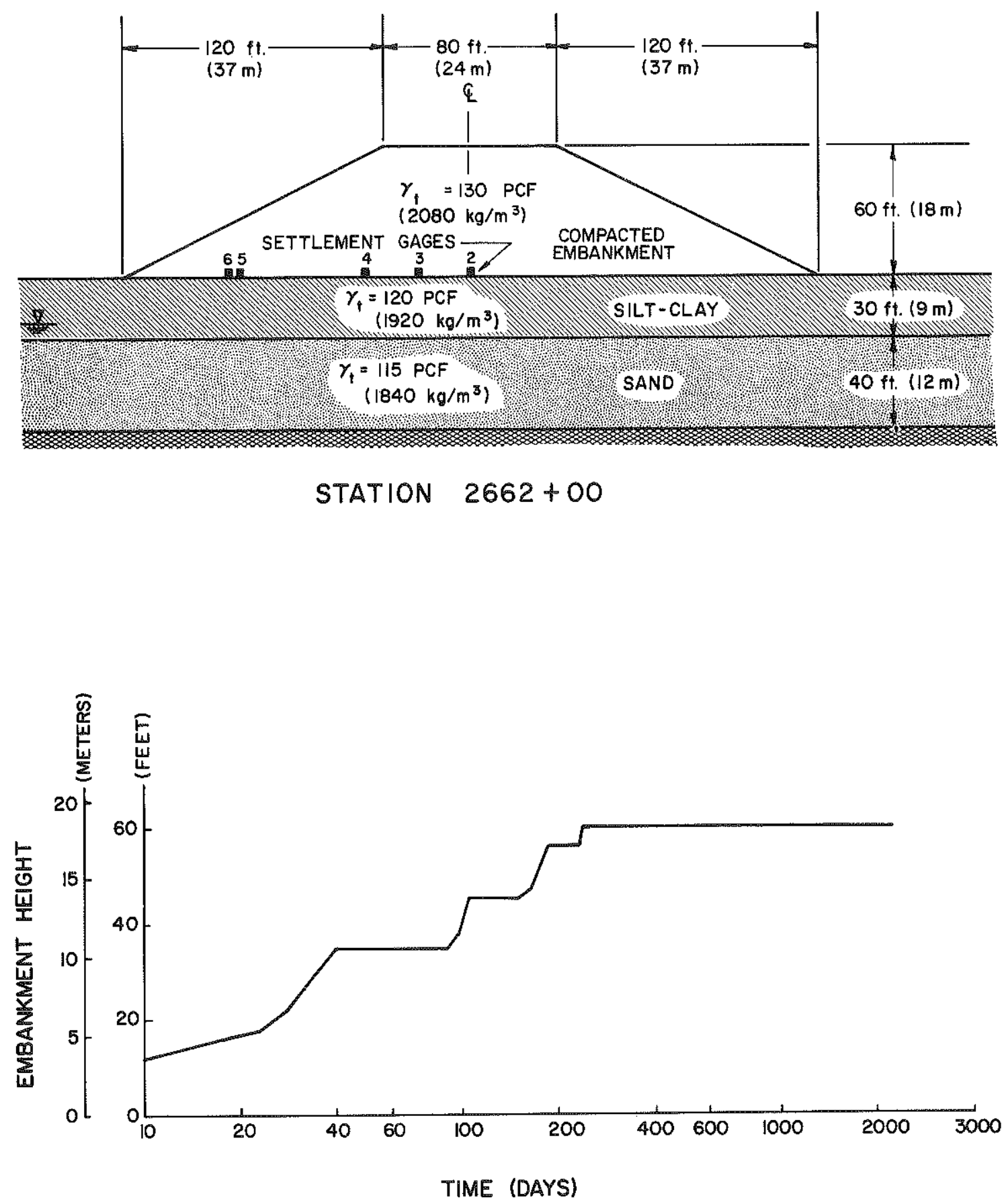

Figure 35. Rate of Embankment Construction. 
in. $2 / \min \left(0.0017 \mathrm{~cm}^{2} / \mathrm{sec}\right) ; \mathrm{CG}$ test, $\mathrm{C}_{\mathrm{v}}=0.036 \mathrm{in}^{2} / \mathrm{min}\left(0.0039 \mathrm{~cm}^{2} / \mathrm{sec}\right) ;$ CRS test, $\mathrm{C}_{\mathrm{v}}=0.033 \mathrm{in}^{2} / \mathrm{min}$ $\left(0.0035 \mathrm{~cm}^{2} / \mathrm{sec}\right)$.

The observed and predicted settlements are shown in Table 3. All tests (STD, CG, and CRS) predicted settlement magnitudes very close to those actually observed. Comparisons of observed and predicted settlement rates are shown in Figure 36 as plots of settlement versus logarithm of time. All tests predicted rates which were slower than the rate observed; however, both the CG and CRS test predictions were closer to the actual rate than the STD prediction.

TABLE 3. COMPARISON OF SETTLEMENTS PREDICTED BY STD, CG, AND CRS TESTS WITH OBSERVED SETTLEMENT

\begin{tabular}{|c|c|c|c|c|c|c|c|c|}
\hline \multirow{3}{*}{$\begin{array}{c}\text { POINT } \\
\text { NUMBER }\end{array}$} & \multicolumn{8}{|c|}{ SETTLEMENT } \\
\hline & \multicolumn{2}{|c|}{ OBSERVED } & \multicolumn{2}{|c|}{ STD TEST } & \multicolumn{2}{|c|}{ CG TEST } & \multicolumn{2}{|c|}{ CRS TEST } \\
\hline & (in.) & $(\mathrm{mm})$ & (in.) & $(\mathrm{mm})$ & (in.) & $(\mathrm{mm})$ & (in.) & $(\mathrm{mm})$ \\
\hline 2 & 20 & 510 & 22 & 560 & 21 & 530 & 23 & 580 \\
\hline 3 & 22 & 560 & 22 & 560 & 21 & 530 & 23 & 580 \\
\hline 4 & 20 & 510 & 21 & 530 & 20 & 510 & 22 & 560 \\
\hline 5 & 12 & 300 & 13 & 330 & 10 & 250 & 13 & 330 \\
\hline 6 & $1 !$ & 280 & 12 & 300 & 9 & 230 & 13 & 330 \\
\hline
\end{tabular}




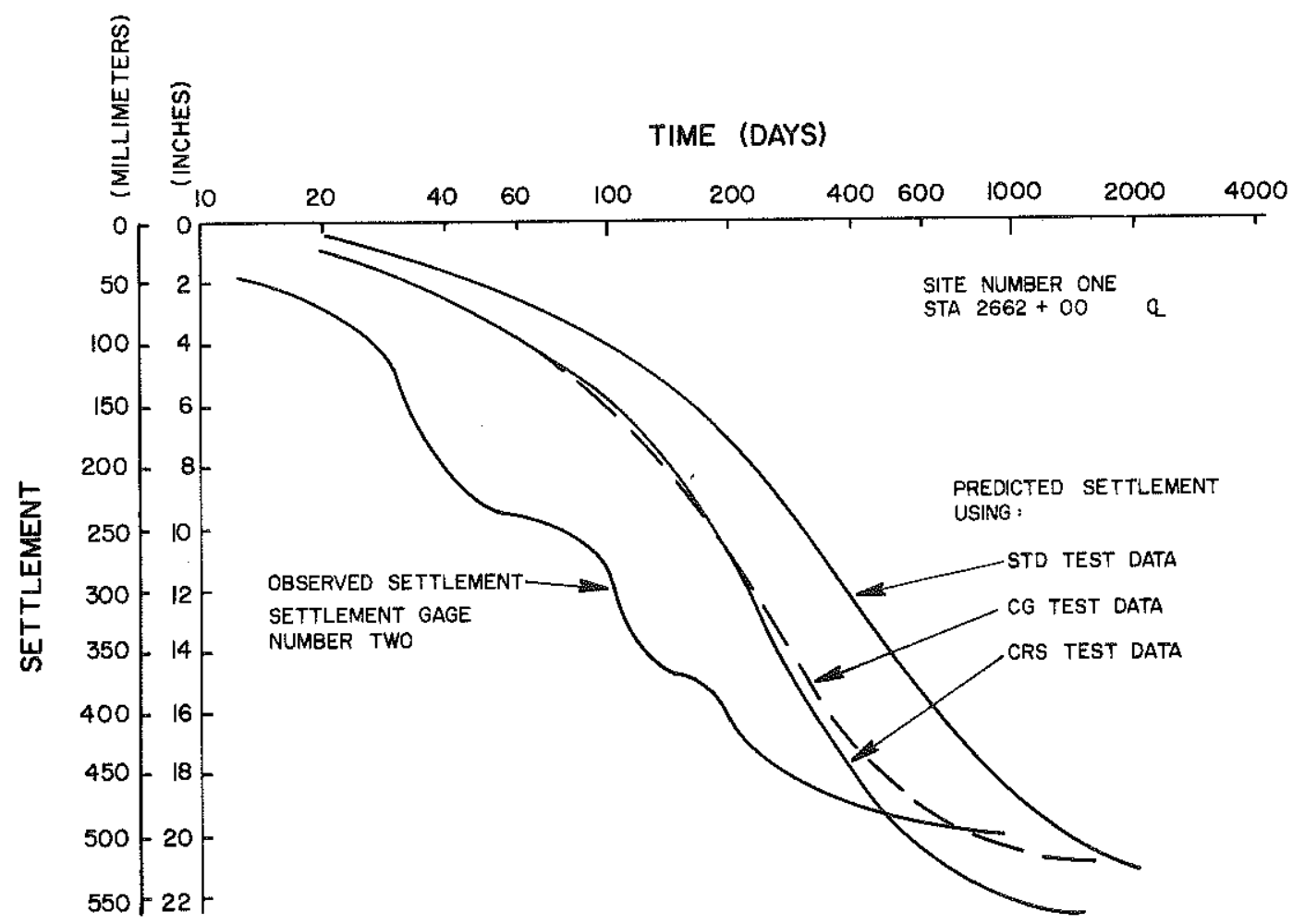

Figure 36. Comparison of Settlement Rates Predicted by STD, CG, and CRS Tests with Observed Rate. 


\section{ANALYSIS AND DISCUSSION}

The objectives of this research were (1) to compare CG and CRS consolidation test results with those obtained from STD test procedures and (2) based on the comparison, to determine the feasibility of CG and(or) CRS tests for routine consolidation testing. Two types of data are obtained from consoljdation tests: stress-strain data and rate of consolidation $\left(\mathrm{C}_{\mathrm{v}}\right)$ data. Stress-strain data are used to predict magnitude of consolidation settlement; rate data are used to predict how fast this settlement will occur. Comparison of the data, therefore, includes graphical comparison of stress-strain data, comparison of the numerical quantities obtained from these data, graphical comparison of $\mathrm{C}_{\mathrm{V}}$ data, and comparison of predicted magnitude and rate of settlement under a highway embankment with the observed magnitude and rate of settlement. Factors which affect test results are also discussed.

The feasibility of either or both of the new test methods for routine testing depends not only on the comparison of data but also on the equipment required to run the test(s), the degree of difficulty in performing the test(s), and the time required to complete the test(s). Therefore, these factors are also considered in the discussion which follows.

Comparisons of stress-strain curves produced by the different test methods are shown in Figures 21 through 32 in the section entitled "TEST RESULTS". The curves are labeled by test type and and identifying test number. In most cases, more than one STD test was run, usually with and without back pressure, to show the effect of back pressure and determine the repeatability of STD tests. The effect of back pressure will be discussed later. Repeatability of STD tests may be shown by comparing STD-14 and STD-17 from Site Number Two, H-3, S-5 (Figure 27), which were STD tests with back pressure, and STD-21 and STD-22 from Site Number Two, H-3, S-7 (Figure 30), which were STD tests without back pressure. In both cases, repeatability was good.

In general, the agreement among CG, CRS, and STD stress-strain curves at Site Number Two was very good. Some scatter was shown in the stress-strain curves for the different test methods at Site Numbers One and Three. Factors related to test methods which could have caused some of the scatter will be discussed individually; however, differences in test samples (sample inhomogeneity) could well be a contributing factor. Even though undisturbed soil samples taken from the same sampling tube may appear homogeneous, small differences in structure may produce different compressibility characteristics. Since most curves do agree well, it is doubtful that this effect was pronounced; however, it should not be discounted.

A more quantitative method of comparing CG, CRS, and STD stress-strain data is to compare the numerical values obtained from the stress-strain curves for use in settlement analysis. The values of compression ratio, $\mathrm{CR}$, swell ratio, $\mathrm{SR}$, and $\mathrm{P}_{\mathrm{c}}$ from each test are summarized in Table 2 . The table 
groups the tests in the same way as they are grouped in Figures 21 through 32. That is, tests performed on samples from the same site, borehole, and sampling tube are compared. Numerical comparisons are also shown in graphical form in Figures 37 through 45. Horizontal bars on the plots indicate the scatter in STD test data. Since only one CG and one CRS test were ran on samples from each sampling tube (except in the case of Site Number Two, H-2, S-5, in which case two CRS tests were run), it was not possible to determine scatter in CG or CRS test data.

CR obtained from CG test data is compared with CR from STD test data in Figure 37, and CR from CRS test data is compared with CR from STD test data in Figure 38. CR from CG test data agrees more closely with CR from the STD test than does CR from the CRS test. The CRS test gave slightly lower values of CR than did the STD test; however, the discrepancy in values is not significant.

The same type of comparisons are made in Figures 39 and 40 of the values of SR obtained from the various tests. Again, the horizontal bars indicate scatter in the STD test data; the vertical bar, shown in Figure 40, indicates scatter in SR from two CRS tests. Scatter in SR data is significant. The CG and CRS tests gave somewhat higher values of SR than did STD tests. It appears the method of unloading the specimen can affect SR values significantly. The CG test was unloaded in small increments; the STD test was unloaded to a pressure of 1.0 tsf $(10 \mathrm{kPa})$ instantaneously; and the CRS test was unloaded at a constant strain rate. Considerable scatter also exists in SR values from STD tests at Site Numbers One and Three. The scatter in STD test results may be due to back-pressure effects and will be discussed later.

Finally, the same type of comparison is shown in Figures 41 and 42 for values of $P_{c}$ obtained from the various tests using the Casagrande procedure. Scatter in values of $\mathrm{P}_{\mathrm{c}}$ obtained from STD test results is considerable and is not due to back-pressure effects, as will be shown later. In most cases, the agreement is good, considering the scatter in $P_{c}$ values from the STD tests. The largest discrepancies in values of $P_{c}$ given by the different tests occurred in the highly overconsolidated soils of Site Number Three. The purpose of comparing $\mathrm{P}_{\mathrm{c}}$ values obtained from the Casagrande procedure is mainly to compare stress-strain data obtained from the various tests. Other methods of arriving at $P_{c}$ from $C G$ and $C R S$ data were discussed in the section entitled "BACKGROUND", and the results of these methods will be discussed later.

Perhaps the best way to compare stress-strain results obtained from the various tests is to apply these results to a field situation. This was done for Site Number One, as discussed in the section entitled "SETTLEMENT ANALYSIS". Comparison of the predicted magnitudes of settlement at the site are a direct reflection of the comparison of stress-strain data; agreement between the predicted and observed settlement magnitudes is indicative of the applicability of the stress-strain data. All comparisons are shown 


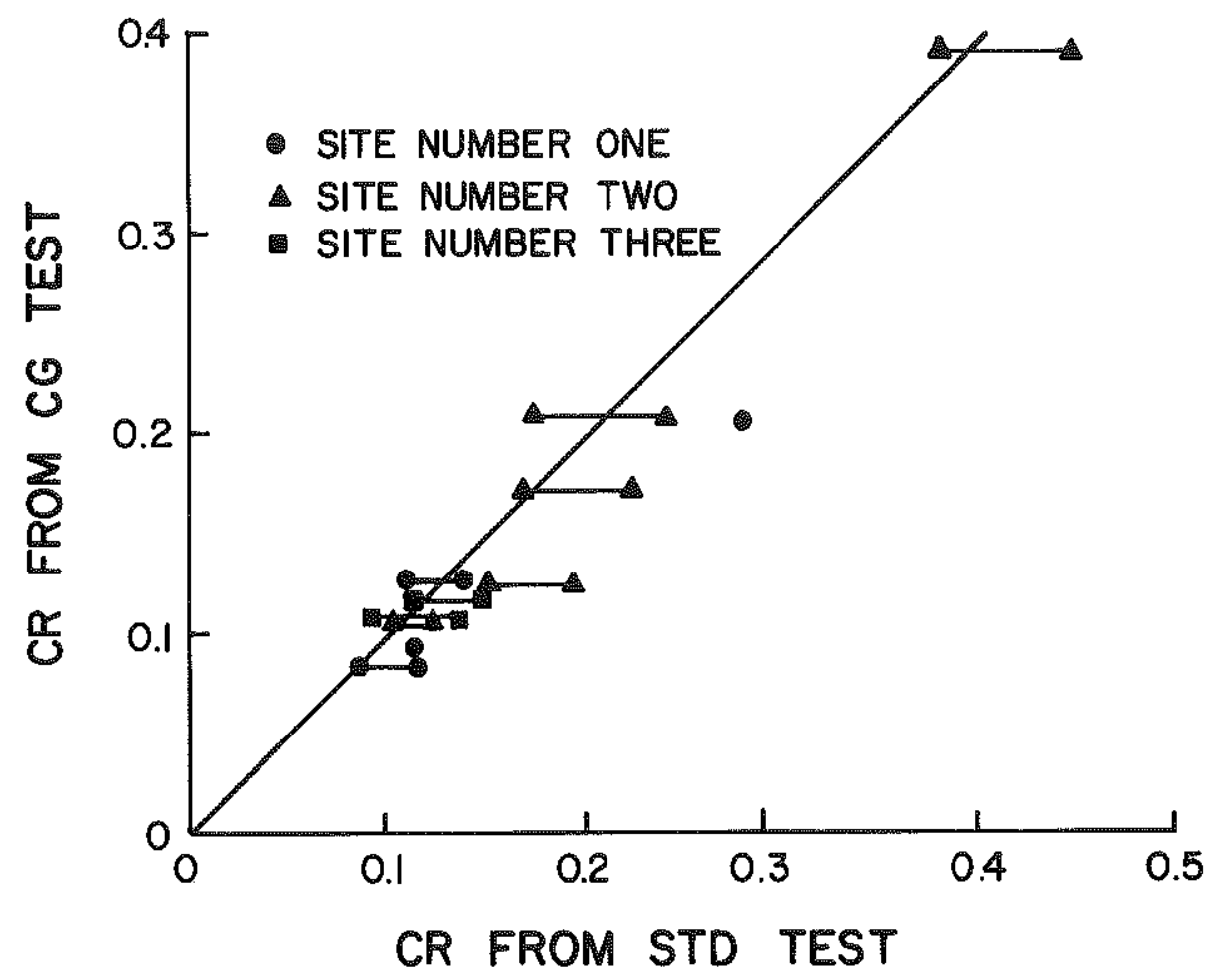

Figure 37. CR Comparison, CG Test and STD Test.

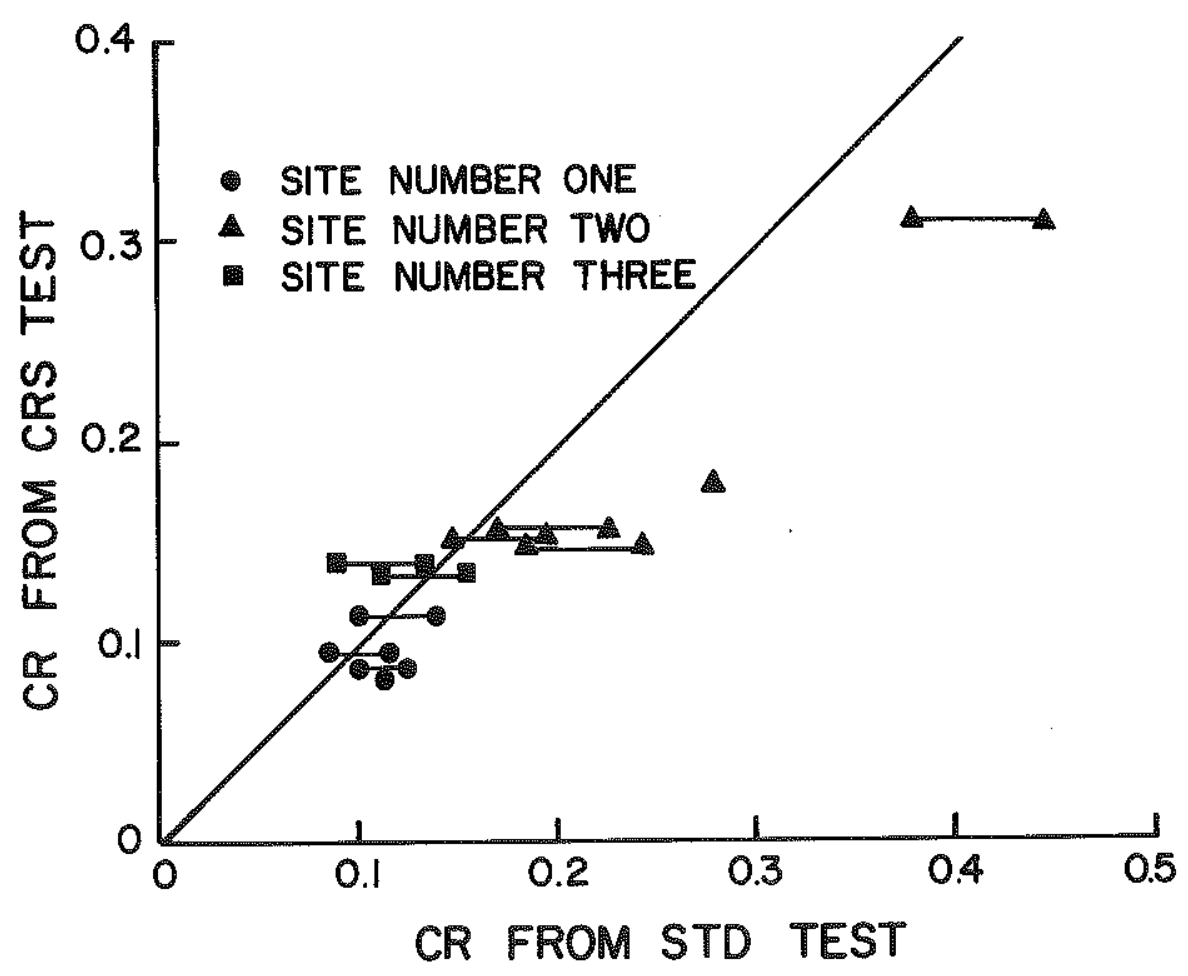

Figure 38. CR Comparison, CRS Test and STD Test. 


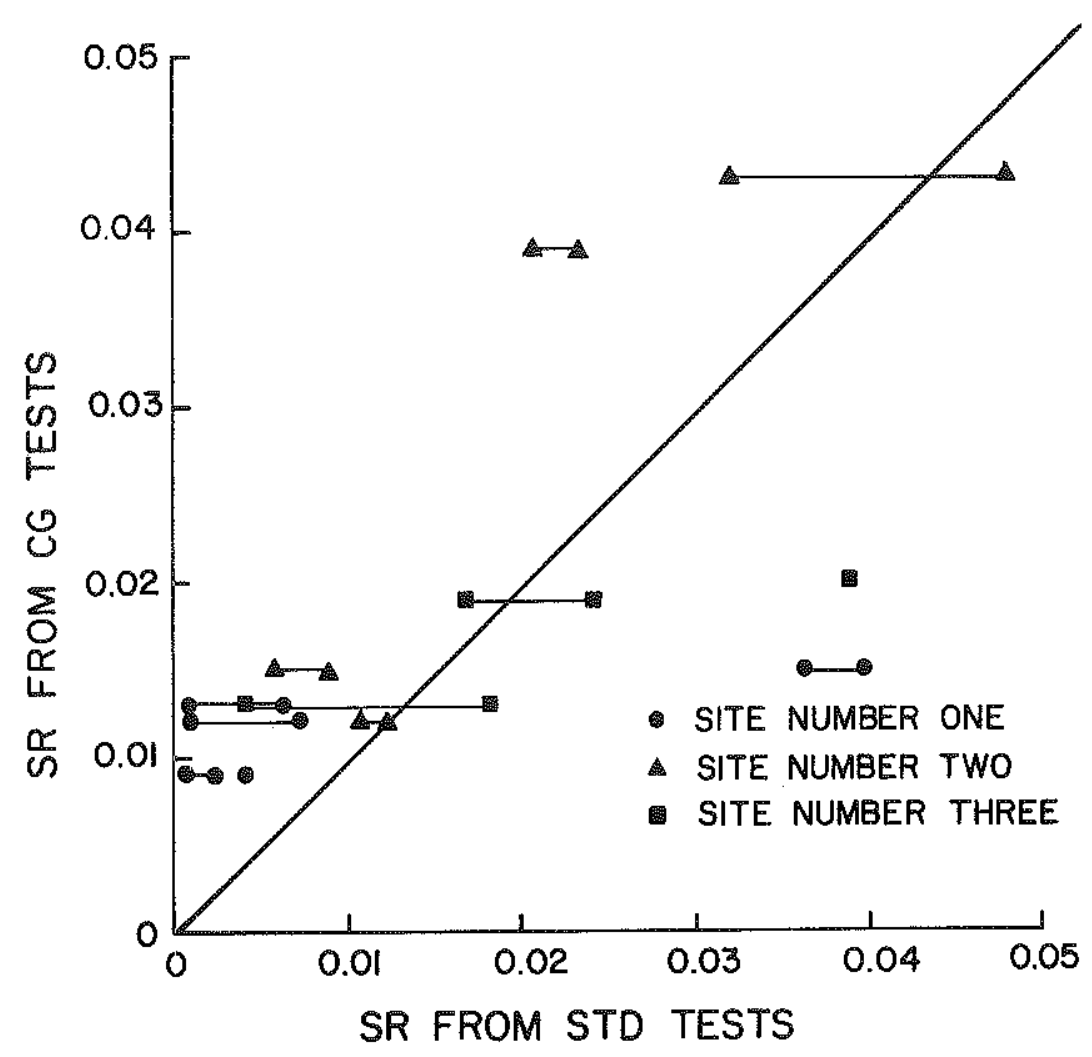

Figure 39. SR Comparison, CG Test and STD Test.

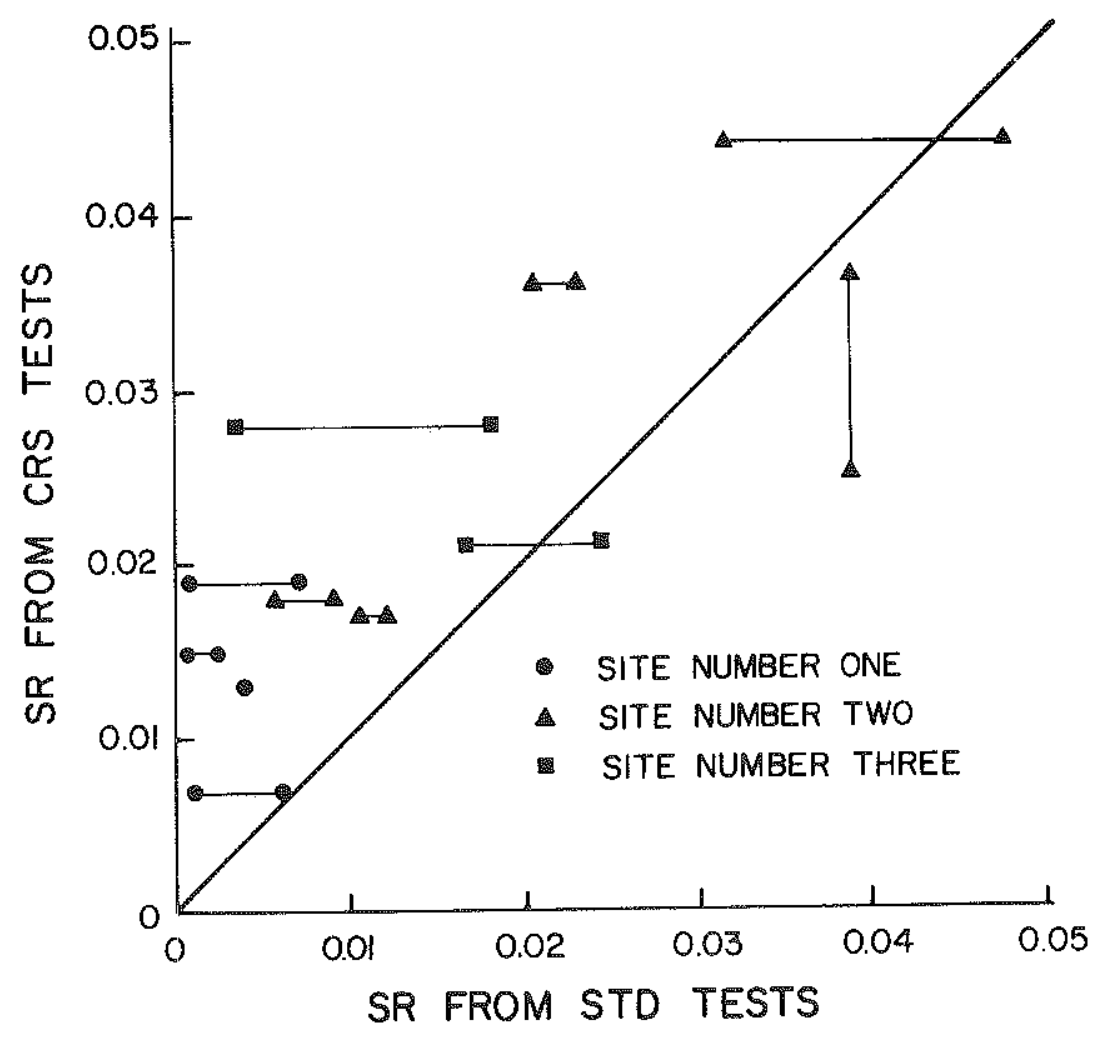

Figure 40. SR Comparison, CRS Test and STD Test. 


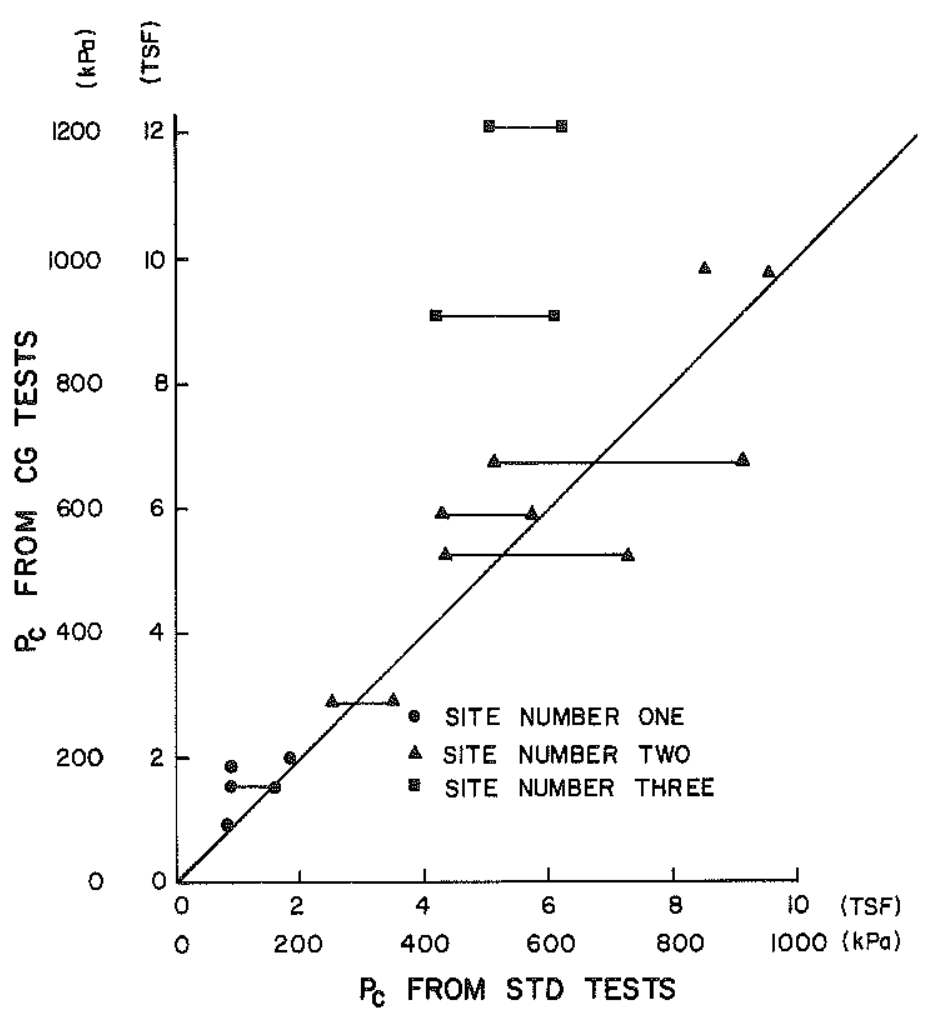

Figure 41. $\quad P_{\mathfrak{c}}$ Comparison, CG Test and STD Test.

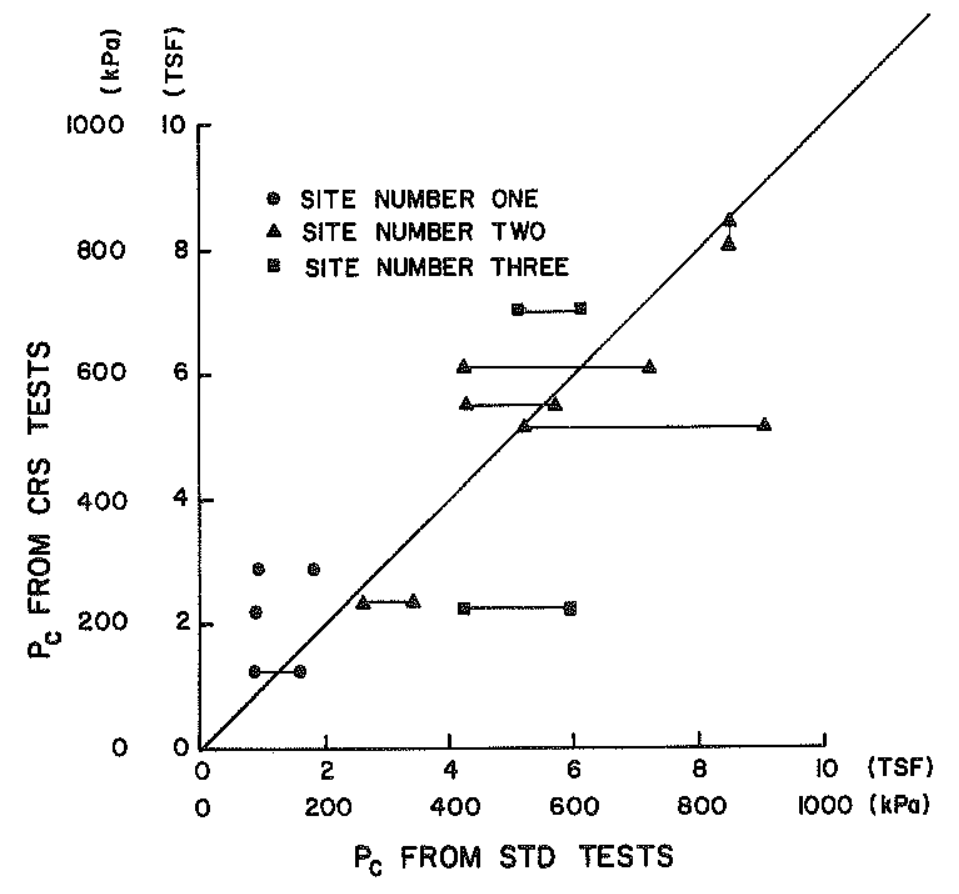

Figure 42. $\quad P_{c}$ Comparison, CRS Test and STD Test. 


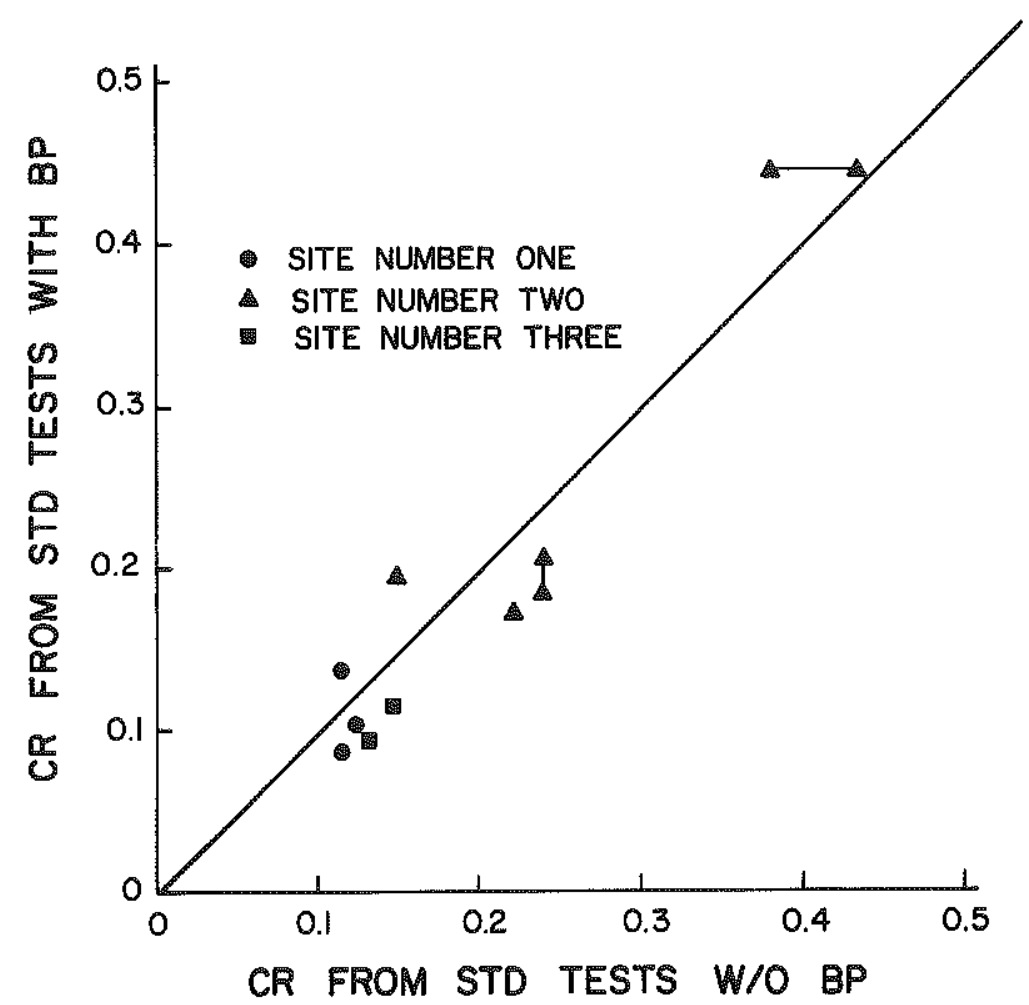

Figure 43. CR Comparison, STD Test with Back Pressure and STD Test without Back Pressure.

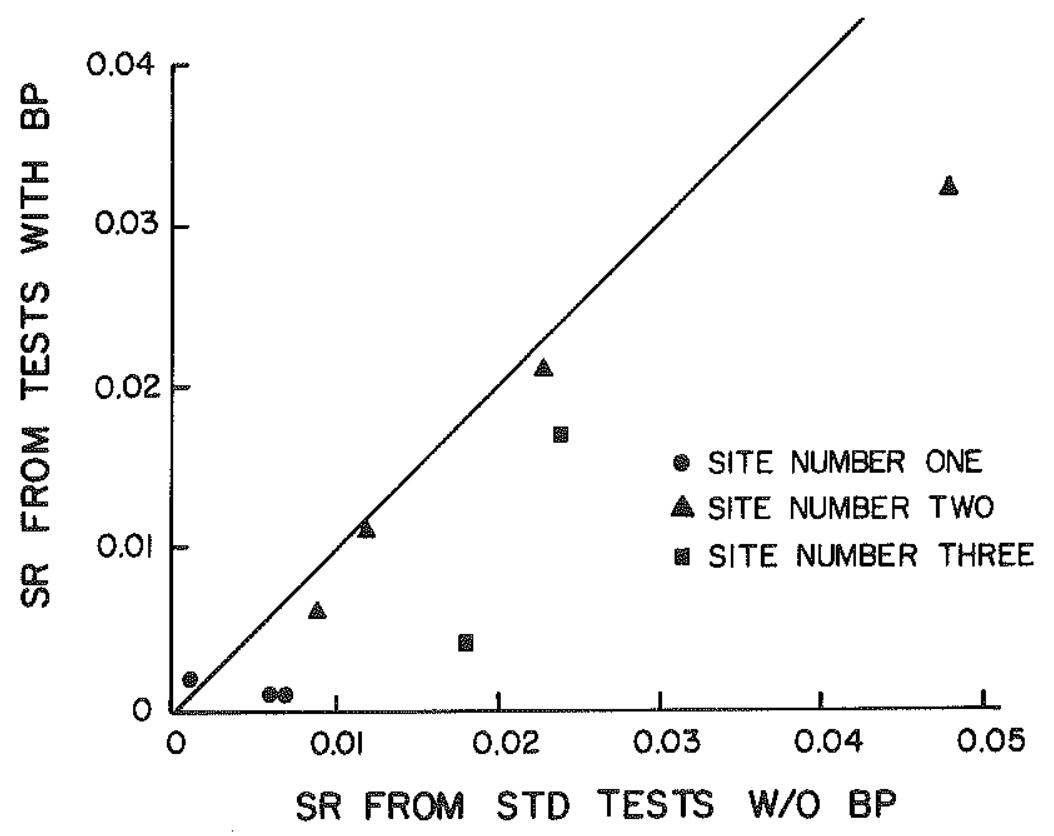

Figure 44. SR Comparison, STD Test with Back Pressure and STD Test without Back Pressure. 


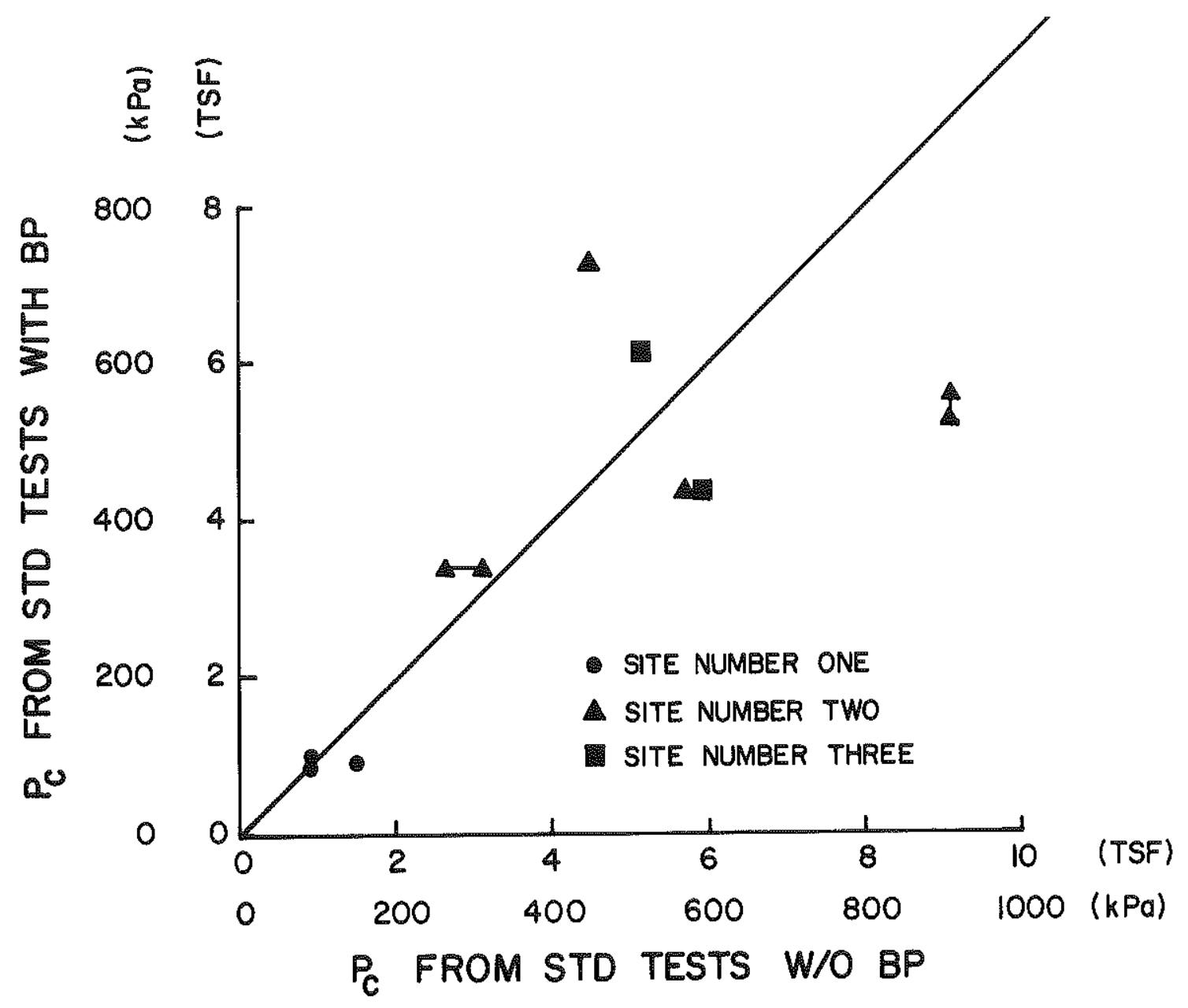

Figure 45. $\quad P_{c}$ Comparison, STD Test with Back Pressure and STD Test without Back Pressure. 
in Table 3.

Both the comparison of magnitudes as predicted by CG, CRS, and STD tests and the agreement of these predictions with the observed settlement were very good. Thus, the scatter which exists in the stress-strain curves at Site Number One may be considered negligible based on results of the settlement analysis.

All CG and CRS tests were performed under a back pressure of 10 psi (69 $\mathrm{kPa})$. To determine the effect, if any, that back pressure had on the data for the samples tested, STD tests were performed both with a back pressure of $10 \mathrm{psi}(69 \mathrm{kPa})$ and without back pressure. Results of these tests are shown along with other comparisons in Figures 21 through 32 . To show the effect of back pressure more clearly, STD tests with and without back pressure were compared in the same manner as $\mathrm{CG}_{\text {, }}$ CRS, and STD test results were compared. Figure 43 shows a comparison of CR from STD tests with and without back pressure. The vertical and horizontal bars indicate range of CR for two tests with back pressure and two tests without back pressure, respectively. The comparison is good, which shows that back pressure has little or no effect on the value of CR for the solls tested. Figure 44 shows the same comparison for $\mathrm{SR}$. In this case, the tests without back pressure consistently gave higher values of SR. Although the mechantsm of thes phenomenon ts not understood, the backepressure effect observed Ln these STD tests does not explatn the higher SR values observed in the $\mathrm{CG}$ and CRS tests which were backpressured. Therefore, the higher SR observed in CG and CRS tests is not die to the fact that the fests were conducted under buck pressure. Finaly, the same comparison was made for $\mathrm{P}_{\mathrm{e}}$, as shown in Figure 45; no significant back-pressure effects were observed.

The purpose of using back pressures in consolidation testing is to insure saturation and duplication of in situ pore pressures. The solls tested at Site Numbers One and Two were fully satutated; soils at Site Number Three were above the water table and, therefore, were partally saturated. Thus, the use of back pressire in têsting these sollo is questonable. Even so, the baek pressure used did not saturate the specimen; therefore, the assumption of complete saturation, used in developing the consolldation theory, was not fulfilled. Site Number Three should serve only as an indication of the effects of testing partially saturated soils.

Strain rate was shown in the section entitled "BACKGROUND" to be an important factor in consolidation testing. Strain rate determines the pore pressures that will be generated in the testing and thus the applicability of the theory. Theories used in the CG and CRS tests assume parabolic pore-pressure distributions across the consolidating sample. If a sample is strained at too slow a rate, little or no pore pressure will be generated and, although the calculation of $\sigma_{\mathrm{V}}{ }^{\prime}$ may not be affected, the effect on the determination of $\mathrm{C}_{V}$ will be pronounced. Since the term $u_{b}$ appears in the denominator of the 
expression for $\mathrm{C}_{\mathrm{V}}$, a value of $\mathrm{u}_{\mathrm{b}}$ equal to or approaching zero will cause the expression to be meaningless, as well it should be, since the theory assumes steady-state conditions which require some pore pressure buildup. On the other hand, if pore pressures become excessive, assumptions made in deriving the theory will again be violated because the pore-pressure distribution will not be parabclic. Previous work (3, 4) has shown that the term $\mathrm{u}_{\mathrm{b}} / \sigma_{\mathrm{v}}$ is a good indicator of excessive pore pressures. The maximum allowable value of $\mathrm{u}_{\mathrm{b}} / \sigma_{\mathrm{v}}$ was suggested by Smith (4) to be about 50 percent. Minimum values of pore pressure are usually not a problem since the strain rate may then be increased and testing time reduced. Pore pressures of 1 psi $(7 \mathrm{kPa})$ or greater are desirable.

Pore-pressure control through strain-rate selection is, of course, not a problem in the CG test, and herein lies the advantage of $\mathrm{CG}$ testing. Pore-pressure gradient is set to a constant value throughout the test. In the CRS test, however, a strain rate must be preselected so as to keep pore pressures within tolerable limits. This is a problem when testing a particular type of soil for the first time. Thus, a method of preselecting strain rate for the CRS test is needed.

To analyze the problem, a comparison was made of the range of strain rates in the CG test necessary to maintain a given pore-pressure gradient, the strain rate selected in the CRS test, and the maximum value of $u_{b} / \sigma_{\mathrm{v}}$ in the CRS test. Results of this comparison are shown in Table 4 . In all cases, the values of $u_{\mathrm{b}} / \sigma_{\mathrm{v}}$ in the CRS tests were below 32 percent, which is well within the 50-percent limit suggested by Smith. Furthermore, the CRS test, in which the highest value of $\mathrm{u}_{\mathrm{b}} / \sigma_{\mathrm{v}}$ (32 percent) was encountered, showed good agreement in both stress-strain data and $\mathrm{C}_{\mathrm{v}}$ data with the STD and CG tests. Thus, all strain rates shown are acceptable. The strain rate in the CG test usually decreases as the test progresses because of the tendency for pore pressures to increase as the test progresses. A typical plot of strain versus time (strain rate) for the CG test is shown in Figure 46. In almost all cases, the strain rate selected for the CRS test was between the maximum and minimum strain rate in the CG test. The samples tested from Site Number Two, H-3, S-6, contained sand lenses and were therefore highly permeable. This accounts for the extremely fast strain rate in the CG test. The effect of strain rate for a given soil type is shown by the two CRS tests performed for Site Number Two, H-2, S-5 (see Figure 28). Strain rates varied by a factor of four and produced no significant changes in the stress-strain or $\mathrm{C}_{\mathrm{V}}$ data. This seems to indicate that selection of a strain rate may not be a critical factor and that selection of a rate within a certain range of values will suffice.

It can be seen from consolidation theory that the one variable which determines how fast and how much pore pressure will increase in the CRS test (or tend to increase in the CG test) is $\mathrm{C}_{\mathrm{V}}$. Thus, any method of preselecting strain rate should be based on the value of $\mathrm{C}_{\mathrm{V}}$ for the soil to be tested. Unfortunately, the only method of determining $C_{V}$ directly is the consolidation test itself. Attempts 
TABLE 4. COMPARISONS OF STRAIN RATES AND PORE PRESSURES FROM CG AND CRS TESTS

\begin{tabular}{|c|c|c|c|c|c|}
\hline \multirow{2}{*}{$\begin{array}{c}\text { TEST } \\
\text { IDENTIFICATION }\end{array}$} & \multicolumn{2}{|c|}{$\begin{array}{c}\text { PORE-PRESSURE } \\
\text { GRADIENT IN CG TEST }\end{array}$} & \multirow{2}{*}{$\begin{array}{c}\text { RANGE OF STRAIN RATES } \\
\text { IN CG TEST } \\
\left(10^{-4} \% / \mathrm{min}\right)\end{array}$} & \multirow{2}{*}{$\begin{array}{l}\text { STRAIN RATE } \\
\text { IN CRS TEST } \\
\left(10^{-4} \% / \mathrm{min}\right)\end{array}$} & \multirow{2}{*}{$\begin{array}{c}\text { MAXIMUM } \\
\text { VALUE OF } \\
u_{\mathrm{b}} / \sigma_{\mathrm{v}} \text { IN } \\
\text { CRS TEST(\%) }\end{array}$} \\
\hline & (psi) & $(\mathrm{kPa})$ & & & \\
\hline SITE NUMBER ONE & & & & & \\
\hline $\begin{array}{l}\text { H-2 S-2 } \\
\text { SITE NUMBER ONE }\end{array}$ & 2.0 & 14 & $4 \cdot 500$ & 250 & 27 \\
\hline $\begin{array}{l}\text { H-1 S-2 } \\
\text { SITE NUMBER ONE }\end{array}$ & 2.6 & 18 & $26-600$ & 150 & 10 \\
\hline $\begin{array}{l}\text { H-2 S-3 } \\
\text { SITE NUMBER ONE }\end{array}$ & 2.1 & 14 & $160-710$ & 160 & 4 \\
\hline $\begin{array}{l}\text { H-I S-5 } \\
\text { SITE NUMBER TWO }\end{array}$ & 2.2 & 15 & $110-400$ & 150 & 7 \\
\hline $\begin{array}{l}\text { H-3 S-4 } \\
\text { SITE NUMBER TWO }\end{array}$ & 2.5 & 17 & $14-1700$ & 68 & 2 \\
\hline $\begin{array}{l}\text { H-3 S-5 } \\
\text { SITE NUMBER TWO }\end{array}$ & 3.0 & 21 & $16-38$ & 50 & 32 \\
\hline $\begin{array}{l}\text { H-2 S-5 } \\
\text { SITE NUMBER TWO }\end{array}$ & 2.8 & 19 & $18 \cdot 200$ & $160 \& 38$ & $16 \& 6$ \\
\hline $\begin{array}{l}\text { H-3 S-6 } \\
\text { SITE NUMBER TWO }\end{array}$ & 2.8 & 19 & 3200 & 870 & 1 \\
\hline $\begin{array}{l}\text { H-3 S-7 } \\
\text { SITE NUMBER THREE }\end{array}$ & 2.7 & 19 & $19-300$ & 65 & 4 \\
\hline $\begin{array}{l}\text { H-2\&3 S-2 } \\
\text { SITE NUMBER THREE }\end{array}$ & 2.8 & 19 & $13-200$ & 38 & 7 \\
\hline $\mathrm{H}-2 \quad \mathrm{~S}-3$ & 3.0 & 21 & $6-340$ & 160 & 7 \\
\hline
\end{tabular}




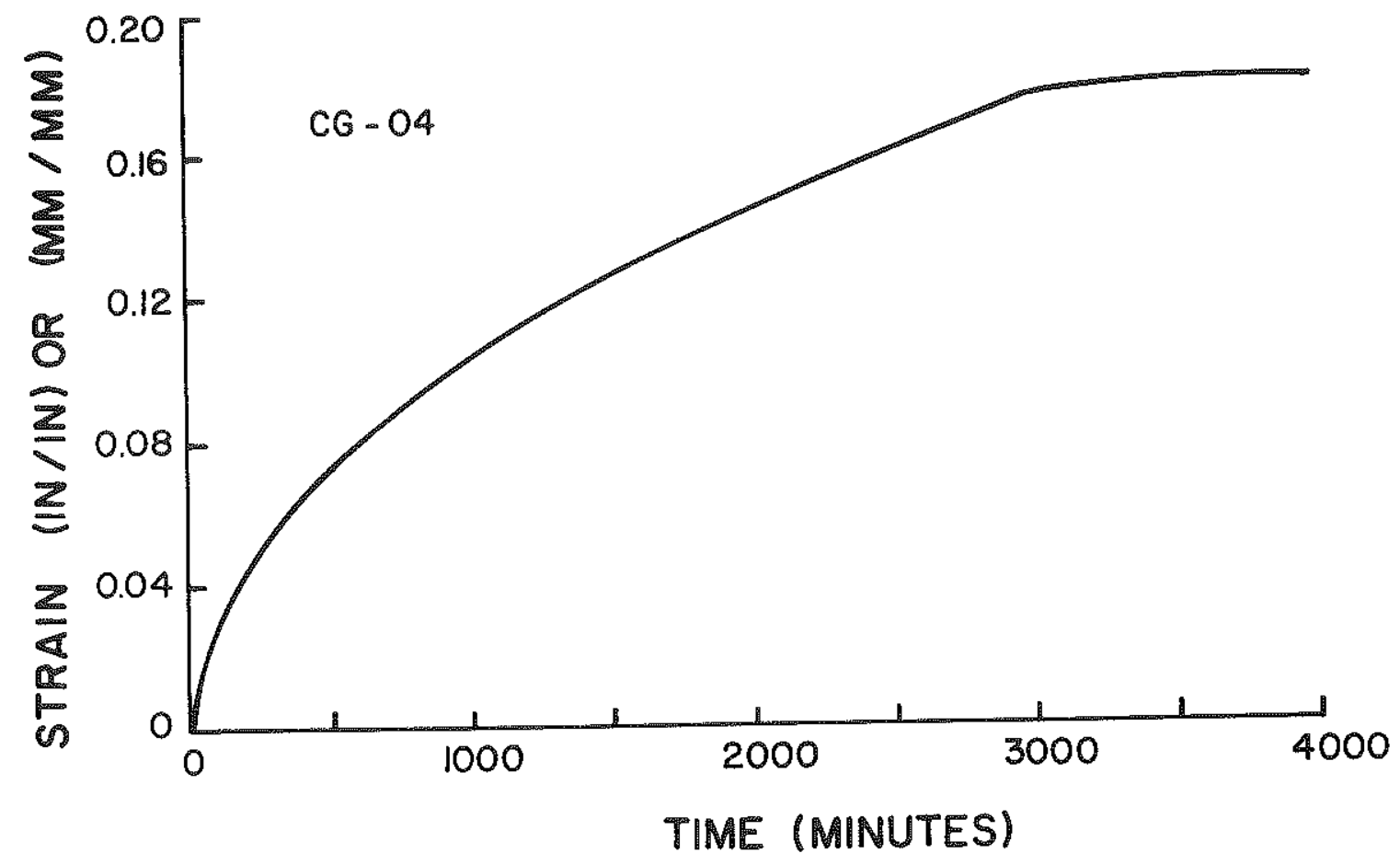

Figure 46. Typical Shape of Strain-Rate Curve, CG Test. 
have been made to correlate $\mathrm{C}_{\mathrm{V}}$ with liquid limit, LL (14), and have met with only moderate success. The $\mathrm{C}_{\mathrm{V}}{ } \mathrm{LL}$ correlation for the soils tested in this study is shown in Figure 47. $\mathrm{C}_{\mathrm{V}}$ values shown in this correlation are rough estimates of $\mathrm{C}_{\mathrm{v}}$ made above the apparent preconsolidation pressure, $\mathrm{P}_{\mathrm{C}}$. Reasons for this approach to $\mathrm{C}_{\mathrm{V}}$ determination and the scatter in $\mathrm{C}_{\mathrm{V}}$ data are discussed later. From the definition of $\mathrm{C}_{\mathrm{V}}$, it can be seen that, as $\mathrm{C}_{\mathrm{V}}$ decreases, permeability decreases and(or) compressibility increases. Thus, as $\mathrm{C}_{\mathrm{V}}$ decreases, pore pressures tend to buildup much more rapidly, and the strain rate should therefore be lower. Hence, if a correlation between $\mathrm{C}_{\mathrm{V}}$ and $\mathrm{LL}$ exists, as has been shown, then a correlation should exist between LL and strain rate. To establish this correlation, a strain rate is needed which produccs the same pore-pressure pattern in each test. Since CRS tests exhibited vastly different pore pressures, the median strain rate in the $\mathrm{CG}$ test was correlated with $\mathrm{LL}$. The result is shown in Figure 48. A poor corrclation resulted; however, the quality of the correlation is not as important as the trend shown. As LL increases, strain rate decreases. This forms the basis for preselecting strain rate since it has been shown in CRS tests on the same samples that a good deal of latitude exists in selecting strain rates which produce $u_{\mathrm{b}} / \sigma_{\mathrm{v}}$ values less than 50 percent. Thus, maximum strain rates for CRS testing may be developed from strain rate-LL correlations. The limited amount of CRS test data and strain rates presented herein permit only rough estimates for initjal strain-rate selection in CRS testing.

Comparisons of $\mathrm{C}_{\mathrm{V}}$ data obtained from $\mathrm{CG}, \mathrm{CRS}$, and $\mathrm{STD}$ consolidation tests are shown in Figures 21 through 32. Analyses of these data should include a discussion of the nature of $C_{V}$ and exactly how the value is obtained in the various tests. $\mathrm{C}_{\mathrm{v}}$ is, by definition, a function of soil compressibility, $\mathrm{m}_{\mathrm{v}}$, and soil permeability, $\mathrm{k}$. The theory used to derive the equations of consolidation assumes that $\mathrm{m}_{\mathrm{v}}$ and $\mathrm{k}$ are constant and that drainage of pore water occurs only in the vertical direction. Deviation of actual conditions from those assumed render any estimate of $\mathrm{C}_{\mathrm{v}}$ only approximate.

In general, $\mathrm{C}_{\mathrm{v}}-\sigma_{\mathrm{v}}{ }^{\prime}$ curves shown in Figure 21 through 32 appear fairly scattered but tend to show some convergence above the apparent value of $P_{C}$. The large discrepancy in values of $C_{V}$ for Site Number Two, H-3, S-6 (Figure 29), was due to sand lenses in two of the samples, and these tests should be discounted. The reason for the convergence of the curves above the apparent $P_{c}$ deserves some consideration. In the $C G$ and $C R S$ tests, values of $C_{V}$ calculated in the early portions of the tests using Equation 43 were very erratic and often very high. Due to the unreasonable nature of these values, they were subsequently omitted from the data shown in this report. Values of $\mathrm{C}_{\mathrm{V}}$ calculated using Equation 43 for the carly portions of the CG and CRS tests were unreasonable becausc the stcady-state conditions, upon which Equation 43 is based, do not exist in the early portions of the test.

In the CG test, some time is required to establish the pore-pressure gradient. This process involves manual adjustment of the load in the early phases of the test. As a result, the term $\Delta \sigma_{\mathrm{v}} / \Delta t$ in Equation 


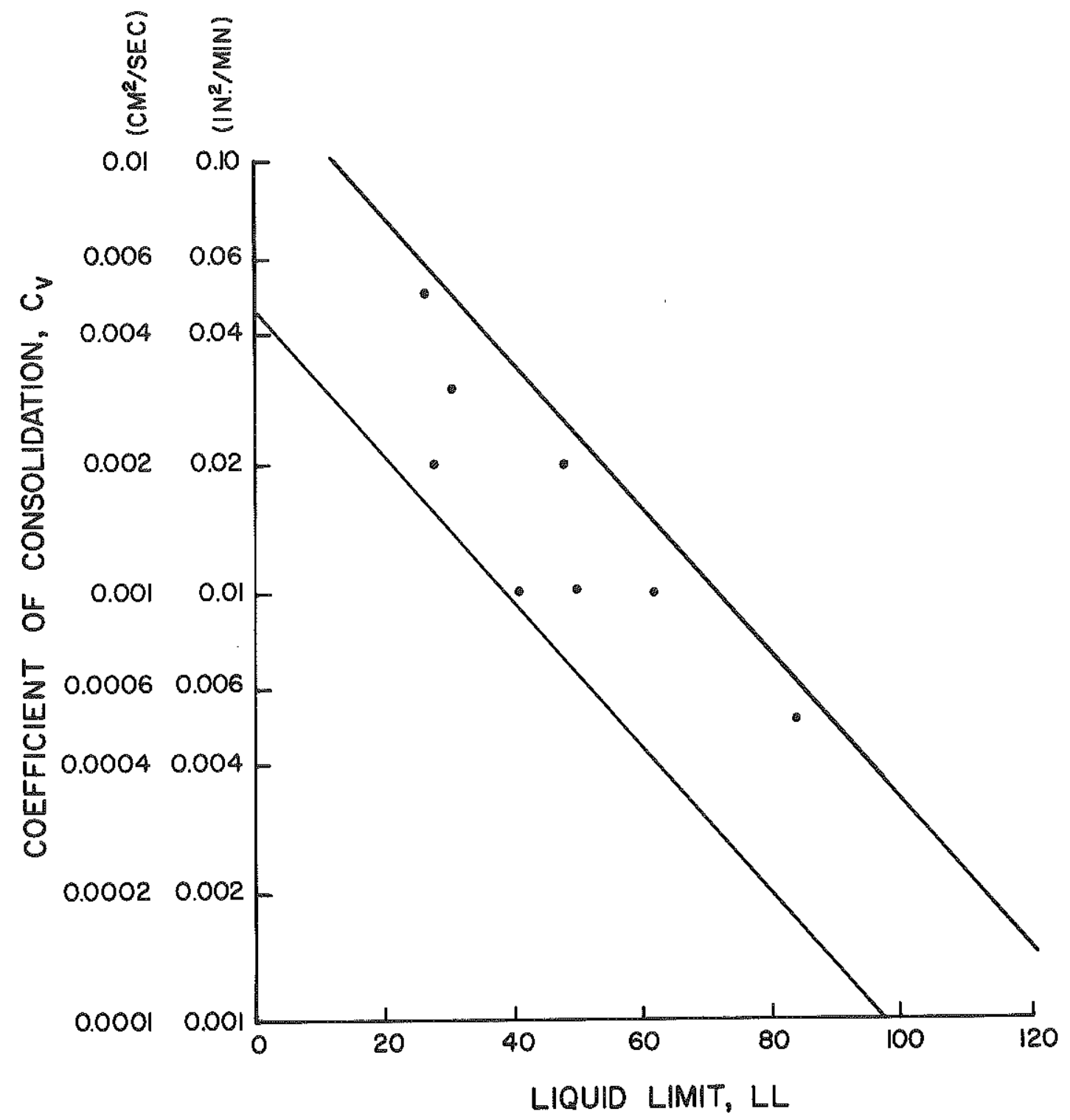

Figure 47. $\quad \mathrm{C}_{\mathrm{v}}$ from Consolidation Tests versus Liquid Limit. 


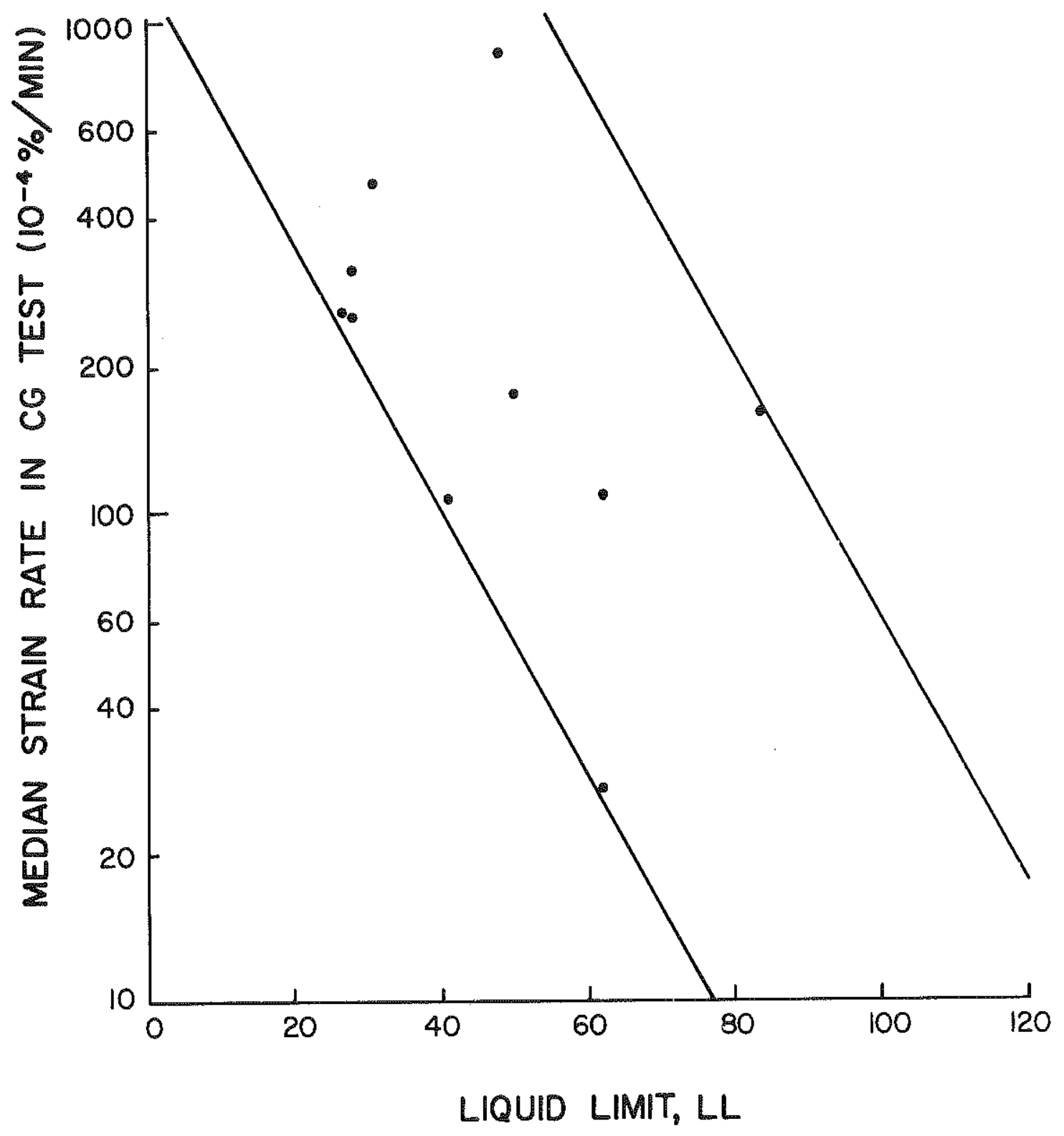

Figure 48. Median Strain Rate from CG Test versus Liquid Limit. 
43 is very small. Only when pore pressure increases and the automatic loading system takes control will the calculated values of $\mathrm{C}_{\mathrm{V}}$ make sense; this is so because the tendency for pore pressure to increase is accompanied by a decrease in the loading rate $\left(\Delta \sigma_{\mathrm{v}} / \Delta t\right)$.

In the CRS test, the same phenomenon occurs for the same reasons. Values of $\mathrm{C}_{\mathrm{V}}$ are erratic until some significant pore pressures are measured. The coincidence of the increase in pore pressure and $\mathrm{P}_{\mathrm{c}}$ will be shown later. This phenomenon points out the fact that the minimum strain rate in the CRS test is one that generates at least some measurable pore pressures. The actual magnitude of pore pressure generated, however, does not appear to affect the magnitude of $\mathrm{C}_{\mathrm{V}}$. This is shown in $\mathrm{C}_{\mathrm{V}}$ results from CRS tests on samples from Site Number Two, H-2, S-5, in Figure 28. CRS-15 reached a maximum pore pressure of $32 \mathrm{psi}(220 \mathrm{kPa})$ while CRS-21 only reached a maximum pore pressure of 5 psi (34 $\mathrm{kPa}$ ); yet both tests gave reasonably close values for $\mathrm{C}_{\mathrm{v}}$ above $\mathrm{P}_{\mathrm{c}}$.

A possible solution to the determination of $\mathrm{C}_{\mathrm{V}}$ in the early stages of the CG and CRS tests might be to impose an initial pore-pressure gradient prior to loading the sample. This could be accomplished by applying a back pressure at the base of the specimen greater than that at the top of the specimen. This would, after some time, create a steady-state flow much the same as in a constant-head permeability test. Once the steady-state condition was established, the equation for $\mathrm{C}_{\mathrm{v}}$ (Equation 43) would apply. This possible solution was not attempted in this research; and it is, therefore, recommended that future work investigate this technique.

Comparisons of rates of consolidation as predicted by CG, CRS, and STD test results and the observed settlement rate are shown in Figure 36. The trend for CG and CRS tests to predict a higher rate at this site is probably not very significant since $C_{V}$ values from CG and CRS tests at Site Numbers Two and Three were not consistently higher than STD test results at these sites. Furthermore, it appears that scatter in $\mathrm{C}_{\mathrm{V}}$ data at Site Number One is greater than the difference in $\mathrm{C}_{\mathrm{V}}$ values selected for the rate predictions. The conclusion to be drawn from the $C_{V}$ data is that, above the apparent preconsolidation pressure, $P_{c}$, there is not a significant difference in values of $C_{V}$ estimated from $C G$, CRS, or STD consolidation tests. The fact that the field rate of consolidation was much faster than that predicted is probably due to the failure of one-dimensional consolidation theory to predict rate of settlement when three-dimensional effects (i.e., horizontal and vertical drainage) actually exist.

$\mathrm{P}_{\mathrm{c}}$ from consolidation tests is an indication of the maximum, past vertical effective stress to which the soil has been subjected. A marked increase in compressibility occurs at this stress; yet, it is not so evident and abrupt that it can be precisely determined. Rather, the gradual increase in compressibility, as shown by the stress-strain data, points to a range of effective stress in which the maximum past pressure or preconsolidation pressure, $\mathrm{P}_{\mathfrak{c}}$, might lie. The graphical procedure proposed by Casagrande 
to determine $\mathrm{P}_{\mathrm{c}}$ should not be considered as rigorous or precise but rather as an aid in locating this range of values. For this reason, $\mathrm{P}_{\mathrm{c}}$ as determined by this method might be referred to as an "apparent" $P_{c}$. Values of $P_{c}$ as determined by this method have been tabulated and discussed; however, alternative methods of determining $P_{C}$ do exist for the $C G$ and CRS tests. These methods were explained in the section entitled "BACKGROUND" and will now be evaluated. The plots necessary to estimate $P_{c}$ by these methods are shown, along with stress-strain and $C_{v}$ data, in Figures 21 through 32 .

The method of estimating $P_{c}$ from $C G$ data is to plot $\sigma_{\mathrm{v}}$ versus time, as shown. The point at which a change in slope occurs is indicative of $\mathrm{P}_{\mathrm{C}}$. For purposes of comparison, the range of values of $P_{c}$ as estimated from the Casagrande construction is shown on the plots. The comparison is not bad, and the method shows some promise. However, in several cases, no break occurred in the curve. This could be due to remolding of the specimen in the trimming or sampling process.

Estimation of $\mathrm{P}_{\mathrm{c}}$ from CRS data is accomplished by noting the value of $\sigma_{\mathrm{V}}$ at which pore pressure tends to increase. Thus pore pressure, $u_{b}$ is shown plotted versus $\sigma_{v}{ }_{v}$. Again, the range of $P_{c}$ values from the Casagrande construction is shown on the plots. The coincidence of pore pressure increase and $P_{C}$ as determined by the Casagrande construction is evident.

The final considerations in evaluating CG and CRS tests are economic ones. The CG test requires very specialized equipment. The initial cost of CG testing may be anywhere from three to seven times that for CRS or STD testing. As shown in the section entitled "EQUIPMENT", conventional triaxial equipment may be modified to perform CRS tests, and the initial cost of this test may compare favorably with the cost for STD test equipment. Operator skill required for CG testing is also greater than for CRS or STD testing. Manual adjustments which must be made in the early portion of the CG test require the strict attention of an operator for 30 minutes to 1 hour. Operator skill required for CRS testing is comparable with the skill required for STD testing or triaxial testing.

The average time required to complete each type of test has been shown in Figure 33. Both the CG and CRS tests are considerably faster than the STD tests; however, they must be monitored continuously while the STD test is usually monitored only during normal work hours. To monitor the CG and CRS tests continuously, some type of data-acquisition system is needed. This may range from a simple strip-chart recorder to a computer-controlled system. The cost and complexity of such systems range accordingly. 


\section{CONCLUSIONS}

1. No significant differences were observed in CG, CRS, or STD test data. Essentially the same magnitude and rate of settlement should be predicted by these tests. This was shown to be the case for the settlement at an instrumented highway embankment at Site Number One. The tendency for $\mathrm{CG}$ and $\mathrm{CRS}$ tests to predict a higher rate at this site is probably not significant since $\mathrm{C}_{\mathrm{V}}$ values from CG and CRS tests at Site Numbers Two and Three were not consistently higher than those from STD test results at these sites.

2. Of the three test methods considered, the CRS test required the least time and was the least difficult to perform. CRS tests reported herein required an average of 1.9 days to complete and required no manual adjustments at any time during the test.

3. CG and CRS tests must be monitored at arbitrary intervals. Since the CG and CRS tests require more than one working day to complete, a data-aquisition system is needed to monitor these tests.

4. Considerable latitude exists in the selection of a strain rate in the CRS test. A strain rate should be selected which generates at least 1 psi $(7 \mathrm{kPa})$ pore pressure but does not generate pore pressures in excess of 30 to 50 percent of the applied stress at any time during the test. Selection of strain rate may be based on the liquid limit of the soil to be tested.

5. Values of coefficient of consolidation, $\mathrm{C}_{\mathrm{V}}$, should be considered valid only above the preconsolidation pressure, $P_{c}$. Rate of consolidation below $P_{c}$ is controlled by compressibility rather than permeability, and the theory used to derive the equations for $\mathrm{C}_{\mathrm{V}}$ does not apply.

6. $P_{c}$ may be determined in the CRS test from plots of pore pressure, $u_{b}$, versus vertical effective stress, $\sigma_{\mathrm{V}}{ }^{\prime}$, and in the CG test from plots of applied stress versus time. 